\title{
COST ACTION CM1407 2nd Training School
}

18 a 20 September | 18 a 20 Setembro

Lisbon U. Lusofona's | Lisboa - Universidade Lusófona

\section{Scientific Commitee /Comissão Científica}

Bruno Botta

Sandra Liekens

Markus Kalesse

Juana Díez

Milica Pešić

Gunter Schneider

Mark Brönstrup

Daniele Passarella

Mattia Mori

Michael S. Christodoulou

Patrícia Rijo

\section{Organizing Commitee /Comissão Organizadora}

Patrícia Rijo, CBIOS - ULHT

Maria M. M. Santos

Maria José U. Ferreira

Carlos M. Monteiro

Marisa Nicolai

Paula Pereira

Filipa Marcelo

Catarina Garcia

Joana Marçalo

Luís Roque

Valentina Barcherini

Margarida Espadinha

Elizabeth Lopes

Joana Pereira

Carolina Oliveira

Ricardo Ferreira

David Cardoso

Svilen Simenov

Ângelo Rocha

Escola de Ciências e Tecnologias da Saúde (ECTS) da U. Lusófona de Humanidades e Tecnologias

ALIES - Associação Lusófona para o Desenvolvimento do Ensino e Investigação das Ciências da Saúde

CBIOS - Centro de Investigação em Biociências e Tecnologias da Saúde

\section{Program /Programa}

18 September | 18 de Setembro

Open Session | Sessão de abertura

L. Monteiro Rodrigues

Patrícia Rijo

Bruno Botta

Free Comunications | Comunicações livres

Flow chemistry synthesis | Síntese de química de fluxo

Chairman | Moderador - Maria M. M. Santos

Speakers | Prelectores

Rafael Antunes

Carlos A. M. Afonso

Rudi Oliveira

19 September | 19 de Setembro

Free Comunications | Comunicações livres

Extraction and isolation of natural products using Buchi equipments | Extração e isolamento de produtos naturais usando equipamentos Buchi

Chairman | Moderador - Peter Naf

Speakers | Prelectores

Daniele Passarella

Markus Kalesse

Mattia Mori

Patrícia Rijo

20 September $\mid 20$ de Setembro

Free Comunications | Comunicações livres

Natural products structural characterization works using the

MestreNova software | Funcionamento da caracterização estrutural de produtos naturais usando o software MestreNova

Chairman | Moderador - Maria José U. Ferreira

Speakers | Prelectores

Antonella Goggiamani

Filipa Marcelo

María Cecilia Carpinella 


\section{Flow chemistry synthesis | Síntese de química de fluxo}

Chairman / Moderador

Maria M. M. Santos

Speaker / Prelector

Continuous Flow as a Tool for Process Development Intensification

\section{Rafael Antunes}

Abstract / Resumo da Comunicação

The topic of Research, Development and Innovation productivity has been one of the main concerns and objectives of both Academy, Industry, Investors and Governments. Hovione builds upon its long experience in batch process chemistry development by incorporating new technologies and tools that are more efficient and provide economic and environmental benefits. The adoption of flow chemistry to support kinetic studies, mechanistic modelling and design of experiments studies in early development phase enable Process Development Intensification. The latter are critical success factors to ensure high confidence in the processes and to achieve reduced development time, cost and straightforward scale-up.

\section{Examples from this Laboratory on Flow Chemistry}

\section{Speaker / Prelector}

\section{Carlos A. M. Afonso}

Abstract / Resumo da Comunicação

This team has been involved on the development of synthetic methodologies based on diverse functional groups transformations under batch conditions. In this line, the presentation will provide an overview of our successful and unsuccessful examples on the application of flow chemistry to some studied transformations under batch conditions such as enzymatic resolution, organocatalyzed dihydroxylation of olefins, synthesis of 5-hydroxymethylfurfural (HMF), dehydration of tertiary alcohols, heterogeneous catalyzed transformation of furfural to trans-4,5-diaminocyclopent-2-enones, oxidation of 5-chloromethylfurfural (CMF) to 2,5-diformylfuran (DFF) and sequential photochemical rearrangement and hydration of $\mathrm{N}$-alkyl pyridinium salts.

\section{Practical Insight on Flow Chemistry for Industrial Applications}

\section{Speaker / Prelector}

\section{Rudi Oliveira}

Abstract / Resumo da Comunicação

Flow chemistry has been around for many decades, but only recently it has been pointed out as an alternative to batch processes in the synthesis of Pharmaceutical products. The potential advantages in efficiency, safety, quality and even costs are well described, but the adaptation of this new technology takes is time. The reasons behind this are related, among other things, to the required investment in equipment in an industry highly focused in batch, but the actual shortage of scientists and technicians with knowledge and critical thinking to operate the technology and achieve good results. This presentation intends to be a starting point to chemists and engineers that are interested in flow chemistry and what it can bring to the production of Pharmaceutical products. It will focus on what to consider when moving to flow, types of equipment and other basic concepts directed to the application of flow chemistry in industry.

\section{Extraction and isolation of natural products using Buchi equipments | Extração e isolamento de produtos naturais usando equipamentos Buchi}

Chairman / Moderador

Peter Naf

Speaker / Prelector

\section{Unearthing Nature's Gifts: Extraction and Purification of Natural Products}

\section{Daniele Passarela}

Abstract / Resumo da Comunicação

The presentation will take into consideration the extraction, isolation and purification of natural products with a specific focus on some of those characterized by a pharmaceutical activity. In particular, the discussion will be centered on general methods and some specific examples connected with the expertise, the research interests and the collaborations of the speaker. Some examples of the use of natural compounds as starting material for the obtainment of relevant Active Pharmaceutical Ingredients will be illustrated.

Some of the recent interesting compounds will be discussed.

References:

[1]. Hervey, A.L. et al Nat Rev Drug Discov 14: 111-129. 


\title{
Structural Prediction and Total Synthesis of Paleosoraphens and Isotedanolide
}

\author{
Speaker / Prelector
}

\section{Markus Kalesse}

\section{Abstract / Resumo da Comunicação}

The lecture will cover the biosynthesis of polyketides and provide an overview of how the configuration of polyketides can be deduced through statistical methods from the amino acid sequence of the underlying keto reductases.1 Based on this method, the unknown configuration of polyketides can be predicted and ultimately verified through total synthesis.2-5

In addition, the analysis of the biosynthetic gene clusters of natural products unravels that natural products are not necessarily built according to their biosynthetic plan. This might be due to an evolutionary change of the structure of polyketides. Being able to predict the structure of natural products by looking at their biosynthetic enzymes, we can start synthesizing natural products as if their fully obey their biosynthetic plan. This approach might shed light on the origin of their mode of action and help to discover new biologically active compounds. This concept will exemplified with the soraphens and tedanolides. Besides looking at the biological activity, the lecture will cover the pivotal transformation leading to these natural products.

\section{References:}

[1]. A. Kitsche, M. Kalesse ChemBioChem. 2013, 14, 851

[2]. a) D. Janssen, D. Albert, R. Jansen, R. Müller, M. Kalesse, Angew. Chem. 2007, 119, 4985. b) T. Brodmann, D. Janssen, M. Kalesse J. Am. Chem. Soc. 2010, 132, 13610 .

[3]. H. Steinmetz, J. Li, C Fu, N. Zaburannyi, B. Kunze, K. Harmrolfs, V. Schmitt, J. Herrmann, H. Reichenbach, G. Höfle, M. Kalesse, R. Müller, Angew. Chem. Int. Ed. 2016, 55, 10113.

[4]. T. Tautz, J. Hoffmann, T. Hoffmann, H. Steinmetz, P. Washausen, B. Kunze, V. Huch, A. Kitsche, H. Reichenbach, G. Höfle, R. Müller, M. Kalesse, Org. Lett. 2016, 18, 2560.

[5]. O. Hartmann, M. Kalesse, Angew. Chem. Int. Ed. 2014, 53, 7335.

[6]. a) H.-H. Lu, A. Raja, R. Franke, D. Landsberg, F. Sasse, M. Kalesse Angew. Chem. 2013, 52, 13549. b) H.-H. Lu, B. Hinkelmann, T. Tautz, J. Li, F. Sasse, R. Franke, M. Kalesse Org. Biomol. Chem. 2015, 13, 8029.

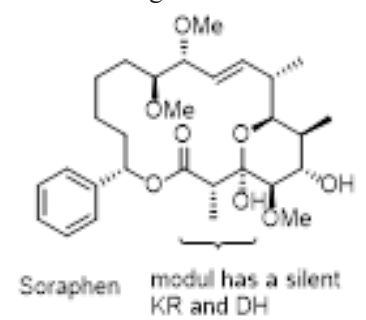

Figure 2. Biosynthesis of the soraphens.

\section{Diels-Alder-type adducts isolated from Morun nigra are potent inhibitors of Mycobacterium tuberculosis protein tyrosine phosphatase $B$}

\author{
Speaker / Prelector
}

\section{Mattia Mori}

\section{Abstract / Resumo da Comunicação}

Mycobacterium tuberculosis (Mtb) protein tyrosine phosphatases A and B (PtpA and PtpB) have been recognized as potential molecular targets for the development of new therapeutic strategies against tuberculosis (TB) [1]. In this context, we have recently reported on the identification, characterization and total synthesis of the naturally occurring Diels-Alder-type adduct Kuwanol $\mathrm{E}$ as inhibitor of $\mathrm{PtpB}(\mathrm{Ki}=1.6 \pm 0.1 \mu \mathrm{M})[2,3]$.

Here, we describe additional compounds isolated from Morus nigra roots bark that inhibit PtpB at sub-micromolar concentrations. The two most potent compounds, namely Kuwanon G and Kuwanon H, are Diels-Alder-type adducts that showed Ki values of $0.39 \pm 0.27$ and $0.20 \pm 0.01 \mu \mathrm{M}$, respectively, and interacted with the active site of the enzyme as suggested by kinetics and mass spectrometry studies. Molecular docking coupled with intrinsic fluorescence analysis and isothermal titration calorimetry (ITC) further characterized the interaction of these promising PtpB inhibitors. Notably, in an Mtb survival assay inside macrophages, Kuwanon G showed inhibition of Mtb growth by $61.3 \%$.

All these results point to the common Diels-Alder-type adduct scaffold, and highlight its relevance for the development of PtpB inhibitors as candidate therapeutics for TB.

References:

[1]. A. Mascarello, L.D. Chiaradia-Delatorre, M. Mori, H. Terenzi, B. Botta, Curr. Pharm. Des., (2016).

[2]. A. Mascarello, M. Mori, L.D. Chiaradia-Delatorre, A.C.O. Menegatti, F.D. Monache, F. Ferrari, R.A. Yunes, R.J. Nunes, H. Terenzi, B. Botta, M. Botta, PLoS ONE, 8 (2013) e77081.

[3]. V. Iovine, I. Benni, R. Sabia, I. D'Acquarica, G. Fabrizi, B. Botta, A. Calcaterra, J. Nat. Prod., 79 (2016) 2495-2503 


\title{
Extraction and isolation of the cytotoxic 6,7-dehydroroyleanone
}

\section{Speaker / Prelector}

\section{Patrícia Rijo}

Abstract / Resumo da Comunicação

In natural products chemistry, extraction is an important step for the successful isolation of pure compounds. Medicinal plants from Plectranthus genus are employed in traditional medicine and the aromatic herb P. madagascariensis (Pers.) Benth. is widely distributed and traditionally used throughout southern and eastern Africa. The main component of its essential oil is the abietane diterpene 6,7-dehydroroyleanone (DHR, Figure 1) obtained as orange-to-reddish crystals1 which holds interesting antitumoral properties 2.

In this work, several methods of extraction were performed in order to optimize the extraction of this diterpene. Its extraction optimization was carried out through high pressure extractions and hydrodistillations in a Clevenger-apparatus. A preliminar toxicity test was carried out resourcing to the Artemia salina $\mathrm{L}$. brine shrimp method. Its proved toxicity allowed further cellular testings. A preliminary study to unveil the possible cellular targets of 6,7-dehydroroyleanone was performed on several tumoral cell lines3. In conclusion, after optimizing its extraction and isolation, we were able to obtain DHR in high amounts. Its promising anticancer properties may serve for future derivatization studies using DHR as a starting material.

References

[1]. L. Ascensão, L et al., International Journal of Plant Sciences, 1998, 159(1): 31-38.

[2]. N. Kusumoto et al., Adv. Biol. Chem, 2014, 4 (2), 109-115.

[3]. C. Garcia et al., 3rd Meeting of COST Action CM1407, Krakow, Poland, 2-3 March 2017.

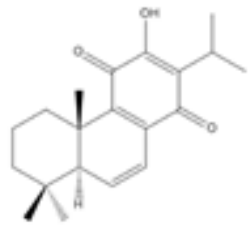

Figure 1.6,7-dehydroroyleanone

\section{Natural products structural characterization works using the MestreNova software | Funcionamento da caracterização estrutural de produtos naturais usando o software MestreNova}

\author{
Chairman / Moderador
}

Maria José U. Ferreira

\section{Recent advances in metal-assisted heterocycles synthesis}

\section{Speaker / Prelector}

\section{Antonella Goggiamani}

Abstract / Resumo da Comunicação

Heterocycles are important structural motifs of a wide range of natural substances, compound of pharmaceutical interest and commodity chemicals. Because of this, a large number of methods have been developed to provide access to almost every type of heterocyclic derivative. Transition metal-catalyzed reactions, particularly palladium and copper-catalyzed reactions, have been widely employed in the synthesis of the heterocyclic rings providing increased functional group tolerance, simplified procedures and improved yields.

In this contest, our research program is focused on the construction of indole system from benzenoid precursors through cyclization reactions and on the functionalization of preformed indole rings. [1] Furthermore, the development of new syntheses of polyfunctionalized organic molecules via palladium and/ or copper-catalyzed C-H bond activation has been widely studied. [2]

In this communication, we will report recent results in this area.

References:

[1] Cacchi S, Fabrizi G, Goggiamani A, "Indoles via Palladium-catalyzed Cyclization"; Organic Reactions (2012) 76, 281-534; Cacchi S, Fabrizi G, Goggiamani A, Org. Biomol. Chem. (2011), 9 (3), 641-652.

[2]. S. Cacchi, G. Fabrizi, A. Goggiamani, "Copper catalysis in arene and heteroarene functionalization through C-H bond activation", (2012) Andersson, Pher G. (Ed.). Innovative Catalysis in Organic Synthesis: Oxidation, Hydrogenation, and C-X Bond Forming Reactions. p. 211-232, Weinheim:Wiley-VCH Verlag GmbH \& Co. KgaA). 


\section{NMR Guide to Unravel Molecular Recognition Events}

Speaker / Prelector

\section{Filipa Marcelo}

Abstract / Resumo da Comunicação

Molecular recognition events are at the heart of Life processes1. The understanding of these events is of paramount importance to achieve a better knowledge of the living systems. Therefore, study of the structure and dynamics of biological active small molecules and their interaction with receptors (proteins, nucleic acids, ...) is crucial for several aspects of life sciences and vitally needed to develop new bio therapeutics. In this context, NMR has become a major tool to disclose the conformational behaviour and the interaction properties of ligand-receptor interactions2. In this communication, different molecular recognition events studied by NMR spectroscopy and assisted by molecular modelling simulations in distinct biological contexts, will be reported3 .

References:

[1] Rebek, J. Proc. Natl. Acad. Sci. USA 2009, 106, 10423-10424.

[2] Fernández-Alonso, M. C.; Díaz, D.; Berbis, M. A.; Marcelo, F.; Jiménez-Barbero J.; Curr. Protein Pept. Sci. 2012, 13, 816-830.

[3] a) Marcelo, F.; Huecas S.; Cañada, F. J.; Ruiz-Avila, L. B.; Perona A.; Poveda A.; Martin-Santamaría, S.; Morreale, A.; Jiménez-Barbero, J.; Andreu, J. M.; J. Am. Chem. Soc. 2013, 135, 16418 - 16428; b) Blázquez-Sánchez M. T., Marcelo F., Fernández-Alonso M. C., Poveda A., Jiménez-Barbero J., Vicent C., Chem. Eur. J. 2014, 20, 17640-17652; c) Marcelo, F.; Garcia-Martin, F.; Matsushita, T.; Sardinha, J.; Coelho, H.; Oude-Vrielink, A.; Koller, C.; André, S.; Cabrita, E. J.; Gabius, H.-J.; Nishimura, S.-I.; Jiménez-Barbero, J.; Cañada, F. J. Chem. Eur. J. 2014, 20, 16147-16155. d) Coelho, H.; Matsushita, T.; Artigas, G.; Hinou, H.; Cañada, F. J.; Lo-Man, R.; Leclerc, C.; Cabrita, E. J.; Jiménez-Barbero, J.; Nishimura, S. I.; Garcia-Martín, F.; Marcelo, F. J. Am. Chem. Soc., 2015, 137, 12438-12441; e) unpublished results.

\section{Strategies for Discovering Drugs from Plants of Argentina. Isolation and Activity of Active Principles}

Speaker / Prelector

\section{Maria Cecília Carpinella}

Abstract / Resumo da Comunicação

The use of plants with medicinal purposes has been a common practice since ancient years. Numerous extracts and compounds obtained from plants are being investigated in order to find new chemical entities for therapeutic use. Although many plant families are under screening for this purpose, the plant world is far from being totally explored, and this also applies to native flora from the central region of Argentina.

We have thus focused our research to find antibacterial and anticancer compounds as well as enzyme inhibitors from 150 plants belonging to different botanical families. Strategies applied to obtain and identify the active principles will be described, together with the study of activity of each promising molecule and of semi-synthetic compounds therefrom. 


\section{Abstract List | Lista de Resumos Submetidos}

P.01 HCK INHIBITORS AS POTENTIAL THERAPEUTIC AGENTS IN LEUKEMIA AND HIV-1 INFECTION. Alessio Molinari,.Francesca Musumeci, Silvia Schenone, Chiara Brullo, Emmanuele Crespan, Giovanni Maga, José A. Esté and Maurizio Botta

P.02 SULFOCOUMARINS SUPPRESS THE ACTIVITY OF P-GLYCOPROTEIN IN MULTIDRUG RESISTANT HUMAN CANCER CELL LINES. Ana Podolski-Renić, Jelena Dinić, Tijana Stanković, Aiga Grandāne, Raivis Žalubovskis and Milica Pešić.

P.03 TOTAL SYNTHESIS OF ( \pm )-KUWANOL E. Andrea Calcaterra, Valentina Iovine, Irene Benni, Rocchina Sabia, Ilaria D’Acquarica, Giancarlo Fabrizi and Bruno Botta.

P.04 MODULATING EFFECTS OF SOME NOVEL BENZOTHIOPENES ON SARCO/ENDOPLASMIC RETICULUM CA-ATPASE (SERCA) ACTIVITY. Barbora Benesova, Silvia Michalikova, Jana Viskupicova, Muheb Algso, Arif Kivrak, Lubica Horakova

P.05 NOVEL 1,2,3-TRIAZOLE FUSED BETULINIC ACID DERIVATIVES WITH POTENT ANTICANCER PROPERTIES. Besir S. Krasniqi, Joice Thomas, Wim Dehaen, Sandra Liekens.

P.06 NOVEL CHEMICAL PROBES FOR THE INVESTIGATION OF NONRIBOSOMAL PEPTIDE ASSAMBLY. Y. T. Candace Ho, Daniel. J. Leng, and Manuela Tosin.

P.07 IMPROVING THE ANTITUMOR POTENTIAL OF A DITERPENOID THROUGH MITSUNOBU REACTIONS. Catarina Garcia, Carlos M. Monteiro, Lucília Saraiva, Cláudia Bessa, Anastasia Borozan, Epole Ntungwe, Catarina Reis, Carlos A.M. Afonso, Patrícia Rijo.

P.08 INHIBITION OF NOTCH SIGNALLING IN T-CELL ACUTE LYMPHOBLASTIC LEUKEMIA: A CHALLENGE POSED BY A NOVEL CHALCONE DERIVATIVE. Elisa De Paolis, Deborah Quaglio, Mattia Mori, Luca Tottone, Cinzia Ingallina, Silvia Corradi, Isabella Screpanti, Bruno Botta, Rocco Palermo, Francesca Ghirga.

P.09 SPIROOX Santos.

P.010 BIOLOGICAL ACTIVITY SCREENING OF SEVEN PLECTRANTHUS SPECIES: ANTICANCER LEAD MOLECULE SEARCH. Epole Ntungwe N., Joana Marçalo, Catarina Garcia, Catarina Reis, Catarina Teodósio, Carolina Oliveira, Cláudia Oliveira, Amílcar Roberto, Patrícia Rijo.

P.011 DIAMINOCARBAZOLIC RECEPTORS FOR CARBOHYDRATES FEATURING SULFONATE SOLUBILIZING GROUPS. Francesco Papi, Oscar Francesconi, Cristina Nativi, and Stefano Roelens.

P.012 NATURAL PRODUCTS DERIVATIZATION TO FORM NANOPARTICLES FOR CANCER TREATMENT. Gaia Fumagalli and Daniele Passarella.

P.013 TROJAN HORSE STRATEGY: AN ACHILES HEEL OF RESISTANT BACTERIA. Kevin Ferreira, Verena Fetz, Hans Prochnow, Mark Brönstrup

P.014 INSECT IMMUNE RESPONSE RELATED PEPTIDES AS A PLATFORM FOR ANTI-INFECTIVE AND ANTI-CANCER DRUG DISCOVERY. Maider Beitia, Marco Ponassi, Camillo Rosano, Sergey Chernysh.

P.015 DISCOVERY OF ENANTIOPURE TYROSINOL-DERIVED BICYCLIC LACTAM THAT ACTS AS NMDA RECEPTOR ANTAGONIST. Margarida Espadinha, Jorge Dourado, Rocio Lajarin-Cuesta, Clara Herrera-Arozamena, Lidia M. D. Gonçalves, María Isabel Rodríguez-Franco, Cristobal de los Rios, Maria M. M. Santos.

P.016 CYTOTOXIC ACTIVITY OF COMPOUNDS ISOLATED FROM DISMEROTEMMA ASPILIOIDES. María Florencia García Manzano, Mariana Belén Joray, Sara María Palacios, Jerónimo Laiolo, María Cecilia Carpinella.

P.017 P53 TUMOR SUPPRESSOR IS REQUIRED FOR EFFICIENT EXECUTION OF THE DEATH PROGRAM FOLLOWING TREATMENT WITH A CYTOTOXIC LIMONOID OBTAINED FROM MELIA AZEDARACH. Mariana Belén Joray, Florencia Villafañez, María Laura González, María Inés Crespo, Jerónimo Laiolo, Sara María Palacios, José Luis Bocco, Gastón Soria María Cecilia Carpinella.

P.018 EXTENDING THE BINDING OF CYCLOHEXANEDIONE DERIVATIVES TOWARDS THE $\alpha \beta$ TUBULIN INTERFACE. Marta Gargantilla, Oskia Bueno, Juan Estevez Gallego, Andrea E. Prota, J. Fernando Díaz, Michel O. Steinmetz, María-José Camarasa, Federico Gago, Sandra Liekens, Eva-María Priego and MaríaJesús Pérez-Pérez.

P.019 SYNTHESIS OF PLANAR CHIRAL FERROCENE SULFONAMIDES BEARING FENCHANE AND MENTHANE MOIETIES. Martin Ravutsov, Georgi Dobrikov, Miroslav Dangalov,Boris Shivachev, Vladimir Dimitrov.

P.020 ENANTIOSELECTIVE TOTAL SYNTHESIS OF (+)-GEPHYROTOXIN 287C. Miriam Piccichè, Alexandre Pinto, Rosa Griera, Joan Bosch and Mercedes Amat.

P.021 CHEMOENZYMATIC TACTICS TOWARDS THE SYNTHESIS OF PHENYLETHANOID APIOGLUCOSIDES. Peter Kis, Mária Mastihubová.

P.022 DISCOVERY OF POTENT ISOFLAVONE (GLABRESCIONE B) AS SELECTIVE INHIBITOR OF HEDGEHOG-DEPENDENT TUMORS. Pietro Eleuteri, Silvia Corradi, Elisa De Paolis, Cinzia Ingallina, Simone Berardozzi, Francesca Ghirga, Deborah Quaglio, Mattia Mori, Lucia Di Marcotullio, Paola Infante, Romina Alfonsi, Bruno Botta.

P.023 ENANTIOPURE SYNTHESIS OF A NEW MORPHOLINO ß-AMINO ACID AND ITS USE FOR THE PREPARATION OF PEPTIDOMIMETICS Raffaella Bucci, Sara Pellegrino, Silvia Locarno, Maria Luisa Gelmi.

P.024 SYNTHESIS OF (-)-SIELBOLDIANIN A USING A SQUARAMIDE CATALYZED ENANTIOSELECTIVE BROMOLACTONIZATION REACTION. Renate Kristianslund, Jørn Eivind Tungen, Marius Aursnes, Carl Henrik Gørbitz and Trond Vidar Hansen.

P.025 IDENTIFICATION OF NOVEL NATURAL PRODUCTS CHEMOTYPES OF HEDGEHOG-DEPENDENT TUMORS INHIBITORS. Silvia Corradi, Francesca Ghirga, Mattia Mori, Cinzia Ingallina, Simone Berardozzi, Elisa De Paolis, Lucia di Marcotullio, Romina Alfonsi, Bruno Botta, Deborah Quaglio.

P.026 TOTAL SYNTHESIS BASED ON THE ORIGINALLY CLAIMED STRUCTURE OF MUCOSIN. Simen G. Antonsen, Harrison C. Gallantree-Smith, Carl H. Görbitz, Trond V. Hansen, Yngve H. Stenstrøm, Jens M. J. Nolsøe.

P.027 OPTIMIZATION OF TRYPTOPHANOL-DERIVED OXAZOLOISOINDOLINONES: CHEMICAL SCAFFOLD WITH INTERESTING ANTICANCER PROPERTIES. Valentina Barcherini, Sara Gomes, Margarida Espadinha, Joana Loureiro, Alexandra M.M. Antunes, Lucília Saraiva, Maria M.M. Santos.

P.028 SYNTHESIS AND BIOLOGY OF JASPAMIDE, SERAGAMIDE AND GEODIAMOLIDE HYBRIDS. Veselin Nasufovic, F. Küllmer, J. Bößneck, S. Pace, L.-M. Semmrau, O. Werz, H.-D. Arndt.

P.029 MARINE ALKALOID OROIDIN ANALOGUES AS NOVEL HUMAN TOPOISOMERASE II INHIBITORS. Žiga Skok, Nace Zidar, Martina Durcik, Janez Ilaš 


\section{P1 - Hck inhibitors as potential therapeutic agents in leukemia and HIV-1 infection}

Alessio Molinari ${ }^{\mathrm{a}}$, .Francesca Musumeci ${ }^{\mathrm{b}}$, Silvia Schenone ${ }^{\mathrm{b}}$, Chiara Brullo ${ }^{\mathrm{b}}$, Emmanuele Crespan ${ }^{\mathrm{c}}$, Giovanni Maga ${ }^{\mathrm{c}}$, José A. Estéd and Maurizio Botta ${ }^{\mathrm{a}, \mathrm{e}}$

${ }^{a}$ Dipartimento Biotecnologie, Chimica e Farmacia, Università degli Studi di Siena, via De Gasperi 2, 53100 Italy

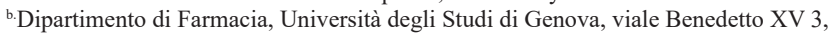
16132 ,

Genova, Italy

'Istituto di Genetica Molecolare IGM-CNR, Via Abbiategrasso 207, 27100 Pavia, Italy

${ }^{\mathrm{d}}$ Irsicaixa, Hospital Germans Trias i Pujol, Universitat Autònoma de Barcelona, 08916 Babalona Spain

${ }^{\mathrm{e}}$ Biotechnology College of Science and Technology Temple University, Biolife

Science Building Suite 333, 1900 North 12th Street, Philadelphia, PA 19122 USA

Hematopoietic cell kinase (Hck) is a member of the Src-family of non-receptor tyrosine kinases, which plays many roles in signalling pathways involved in the regulation of cell processes [1]. Hck is expressed in cells of hematopoietic origin, specifically myelomonocytic cells and B lymphocytes [2]. It participates in phagocytosis, adhesion, migration, regulation of protrusion formation on cell membrane, lysosome exocytosis, podosome formation and actin polymerization. More importantly from a medicinal chemistry point of view, high levels of Hck are involved in chronic myeloid leukemia and other hematologic tumors [3]. Furthermore, Hck activity has been associated with viral infections including HIV-1 [4]. In particular, Hck is activated by the HIV-1 accessory protein Nef, a multifunctional HIV-1 protein that accelerates progression to AIDS and enhances the infectivity of progeny viruses. Nef binding to Hck leads to kinase activation which is important in AIDS pathogenesis.

For these reasons, Hck represents an interesting therapeutic target for the treatment of both specific cancers and HIV infection [5].

On this bases, a new family of compounds was designed and synthesized in order to explore structure-activity relationships. As a result, most of the selected compounds were found active against Hck, with $\mathrm{Ki}$ values ranging from 0.14 to $18.4 \mu \mathrm{M}$, showing an interesting anti hyperproliferative activity. Furthermore hit compound is able to block HIV-1 at micromolar concentration.

References:

[1] G. Manning, D. B. Whyte, R. Martinez, T. Hunter, S. Sudarsanam, Science, 298 (2002) 1912-1934

[2] C. L. Willman, C. C. Steward, T. L. Longacre, D. R. Head, R. Habbersett, S.F. Ziegler, R.M. Perlmutter, Blood, 77 (1991) 726-734.

[3] T. Pene-Dumitrescu, T. E. Smithgall, J. Biol. Chem., 285 (2010) 21446-21457

[4] L. A. Emert-Sed-Lad, P. Narute, S. T. Shu, J. J. Alovarado, J.S. Lazo, J.I. Yeh, P.A Smithgall, Chem. Biol. 20 (2013) 82-91.

[5] F. Musumeci, S. Schenone, C. Brullo, A. Degosus, L. Botta, C. Tintori, Curr. Med. Chem. 22 (2015) 1540-1564

\section{P2 - Sulfocoumarins suppress the activity of P-glycoprotein in multidrug resistant human cancer cell lines}

Ana Podolski-Renića, Jelena Dinića, Tijana Stankovića , Aiga Grandāne ${ }^{\text {, }}$ Raivis Žalubovskis ${ }^{\mathrm{b}}$ and Milica Pešić

anstitute for Biological Research „Siniša Stanković“, University of Belgrade, Despota Stefana142, 11060 Belgrade, Serbia

batvian Institute of Organic Synthesis, Aizkraukles 21, LV-1006 Riga, Latvia

6-Substituted sulfocoumarins incorporating substituted-1,2,3-triazol-4-yl-/5-yl moieties were described as potent inhibitors of the transmembrane human carbonic anhydrase isoforms, CA IX and CA XII involved in cancer progression and invasion [1]. Recent study showed that CA XII is more expressed at the plasma membrane of P-glycoprotein (P-gp) positive cancer cells. Moreover, CA XII activity enables the optimal activity of P-gp which indicates that CA XII inhibitors could be considered as modulators of P-gp activity [2].

The activity of sulfocoumarin AG2-451 was investigated in four different human cancer cell lines (non-small cell lung carcinoma NCI-H460, glioblastoma U87 and their multidrug resistant (MDR) P-gp overexpressing counterparts - NCI-H460/R and U87-TxR) [3]. AG2-451 showed slightly decreased cytotoxicity in MDR when compared to corresponding sensitive cancer cells. The expression of CA IX and CA XII were significantly increased in NCI-H460/R cells compared to sensitive counterparts, while only CA XII expression showed tendency of increase in U87-TxR cells. AG2451 treatment of NCI-H460/R cells caused time-dependent increase in P-gp inhibition assessed by rhodamine 123 accumulation assay. The suppression of P-gp activity was accompanied with increased P-gp expression suggesting a compensatory mechanism of MDR cancer cells. In addition, P-gp inhibition by AG2-451 was not reversible and this compound was able to sensitize MDR cancer cells to doxorubicin treatment. Our results suggest that AG2-451 could be further developed as a promising drug for the treatment of MDR cancers.

Acknowledgements:

This research was supported by the Ministry of Education, Science and Technological Development of the Republic of Serbia (Grant No III41031) and COST Action CM1407.

References:

[1]. Grandane A, Tanc M, Zalubovskis R, Supuran CT (2014). Bioorg Med Chem Lett 24: $1256-1260$

[2]. Kopecka J, Campia I, Jacobs A, Frei AP, Ghigo D, Wollscheid B, Riganti C (2015). Oncotarget 6: 6776-6793.

[3]. Podolski-Renić A, Jadranin M, Stanković T, Banković J, Stojković S, Chiourea M, Aljančić I, Vajs V, Tešević V, Ruždijić S, Gagos S, Tanić N, Pešić M (2013). Cancer ChemotherPharmacol 72: 683-697.

\section{P3 - Total synthesis of ( \pm )-kuwanol E}

\section{Andrea Calcaterra, Valentina Iovine, Irene Benni, Rocchina Sabia, Ilaria D’Acquarica, Giancarlo Fabrizi and Bruno Botta}

Dipartimento di Chimica e Tecnologie del Farmaco, Sapienza Università di Roma, Piazzale Aldo Moro 5, 00185 Rome, Italy

Kuwanol E (1) is a natural compound belonging to the mulberry Diels-Alder adducts isolated from Morus alba1, Morus nigra2 and Sorocea ilicifolia3. We already showed that kuwanol E (1) is the most potent naturally occurring inhibitor of Mycobacterium (Mtb) tuberculosis protein tyrosine phosphatase B reported so far $(\mathrm{Ki}=1.6 \pm 0.1 \mu \mathrm{M})$, a virulence factor secreted into the host cell by Mtb, and necessary for its survival4, therefore compound 1 is a good candidate as lead compound for the development of new antitubercular drugs. The availability of 1 from natural sources is very limited, hence a total synthesis is necessary to provide enough amounts of product for further biological investigations.

Herein we reported the total synthesis of kuwanol E (1) 5 via Diels-Alder reaction, a biomimetic intermolecular [4+2]-cycloaddition between stilbene-derived diene 3 and chalcone-derived dienophile 4 . This key reaction is an extremely useful tool for the construction of a 6-membered monounsaturated ring, moreover modulating the experimental conditions the regio- and stereochemical features of the products can be controlled.

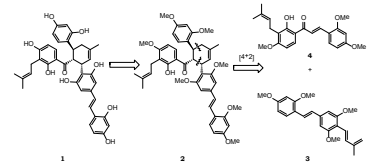

Scheme 1. Retrosynthetic analysis of kuwanol E (1).

The required Diels-Alder partners 3 and 4 have been obtained in five and three steps, in $25 \%$ and $28 \%$ yield respectively. The cycloaddition between 3 and 4 , promoted by Lewis acid catalysis, afforded the desired endo-kuwanol E heptamethyl ether (2), which has been deprotected to obtain kuwanol E (1) in $2 \%$ overall yield.

References:

[1]. Hano Y, Nomura T, Ueda S. (1989). Heterocycles 29: 2035-2041.

[2]. Ferrari F, Monacelli B, Messana I (1999). Planta Med. 65: 85-87.

[3]. Ferrari F, Messana I (1995). Phytochemistry 38, 251-254

[4]. Mascarello A, Mori M, Chiaradia-Delatorre L D, Camila A, Menegatti O, Delle Monache F, Ferrari F, Yunes R A, Nunes R J, Terenzi H, Botta B, Botta M (2013). PLoS One 8: e77081.

[5]. Iovine V, Benni I, Sabia R, D’Acquarica I, Fabrizi G, Botta B, Calcaterra A (2016) J. Nat. Prod. 79(10): 2495-2503.

\section{P4 - Modulating effects of some novel benzothiopenes on sarco/ endoplasmic reticulum Ca-ATPase (SERCA) activity}

\section{Barbora Benesova $^{a}$, Silvia Michalikova ${ }^{a}$, Jana Viskupicova ${ }^{a}$, Muheb Algso ${ }^{b}$, Arif} Kivrak $^{\text {b }}$ Lubica Horakova ${ }^{\text {a }}$

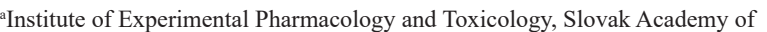
Sciences, Bratislava, Slovakia

${ }^{b}$ Department of Chemistry, Van Yuzuncu Yil University, Van, 65080

Benzothiopenes and their derivatives were found to be candidates for pharmaceutical applications since they show many health benefit properties, mainly antiinflammatory, antibacterial, hypoglycemic and anticancer activities [1]. Some benzothiophene derivatives improved glucose tolerance, protected impaired pancreatic beta-cells, and lowered serum insulin levels in vivo in diabetic mice [2]. We studied possible modulating effects of novel benzothiophene compounds, synthesized in the laboratory of Prof. Arif Kivrak (Turkey), on Ca-ATPase from sarco/endoplasmic reticulum (SERCA). The compounds 3-(4-methoxyphenyl)ethynyl)-2-(thiopen-2-yl)benzo[b] thiophene (MH38F) $(100 \mu \mathrm{M})$ and 2-((2-(methylthio)phenyl)ethyl)-3-(phenylethynyl) thiopene (MH4) $(10 \mu \mathrm{M})$ stimulated SERCA activity, while compound 3-iodo-2 (thiophen-2-yl)benzo[b]thiophene (MH14) $(10-100 \mu \mathrm{M})$ exerted concentration dependent decrease. Decline of SERCA activity as a key enzyme maintaining calcium homeostasis may start apoptosis resulting in anticancer activity. On the other hand, stimulation of SERCA activity may be associated with protection against difficulties associated with some cardiovascular diseases and diabetic complications [3]

References:

[1]. Amakye D, Jagani Z, Dorsch M (2013). Nat Med 19: 1410-1422.

[2]. Shao H, Li D, Yang Y, Guo HF, Liu ZY, Si SY, Yang Z, Li Zr (2010). J Enzyme Inhib Med Chem 25: 282-289.

[3]. Horakova L (2011). Interdisciplinary Toxicol 4: 114-124. 


\section{P5 - Novel 1,2,3-triazole fused betulinic acid derivatives with potent anticancer properties}

Besir S. Krasniqia , Joice Thomas ${ }^{\mathrm{b}}$, Wim Dehaen ${ }^{*}$, Sandra Liekens ${ }^{\star}$

${ }^{a}$ Molecular Design and Synthesis, Department of Chemistry, KU Leuven, Celestijnenlaan 200F, 3001 Leuven, Belgium a

${ }^{\mathrm{b}} \mathrm{R}$ ega Institute for Medical Research, KU Leuven, 3000 Leuven, Belgium

Functionalized 1,2,3-triazoles are a very important pharmacofore in medicinal chemistry, they are found in many drugs functioning as a linker, a bioisostere of an amide or the lead itself [1]. In the previous year has been reported that betulinic acid can induce apoptosis in the some cancer cell with very promising results [2], however there is no report in the literature about 1,2,3-triazole fused triterpenoids, probability due to the lack of synthetic methodologies. In our research group, we were able to synthesize 1,2,3-triazoles via a one pot metal free method, from enolizable ketone, primary amine and 4-nitrophenyl azide [3]. Betulin is commercially available or was extracted from birch bark and then oxidized to betulonic acid as a starting material for triazolation. Based on this we were able to obtain a library of ring A fused 1,2,3-triazole derivatives of betulinic acid which then showed promising activities against several cancer cell lines.

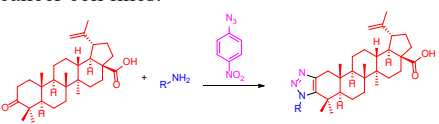

References:

[1]. Idrees Mohammed, Indrasena Reddy Kummetha, Gatikrushna Singh, Natalia Sharova, Gianluigi Lichinchi, Jason Dang, Mario Stevenson, Tariq M. Rana. J. Med. Chem., 2016, 59 (16), pp 7677-7682

[2]. L Potze, F B Mullauer, S Colak, J H Kessler, J P Medema. Nature, Cell Death and Disease (2014) 5, e1169

[3]. Joice Thomas, Sampad Jana, Jubi John, Sandra Liekensb Wim Dehaen. Chem. Commun., 2016,52, 2885-2888.

\section{P6 - SNovel chemical probes for the investigation of nonribosomal peptide assambly}

\section{Y. T. Candace Ho, Daniel. J. Leng, and Manuela Tosin}

Department of Chemistry, University of Warwick, Library Road, Coventry, CV4 7AL, UK

Nonribosomal peptides (NRPs) constitute a broad class of natural products featuring many clinically relevant compounds such as vancomycin and cyclosporine A.1 Nonribosomal peptide biosynthetic intermediates remain covalently bound to nonribosomal peptide synthetases (NRPSs) during product assembly, 2 preventing a full understanding and exploitation of NRP biosynthetic machineries.

Herein we present the synthesis of newly devised chemical probes for nonribosomal peptide intermediate capture in vivo (Figure 1) 3 and their use for the probing of NRPS pathways in vivo.

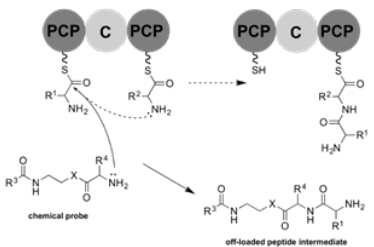

Figure 1 - Mechanism of NRP assembly (in dashed line) and newly devised nonhydrolysable probes $(\mathrm{X}=\mathrm{NH})$ for $\mathrm{NRP}$ intermediate capture

References:

[1] E. A. Felnagle, E. E. Jackson, Y. A. Chan, A. M. Podevels, A. D. Berti, M. D. McMahon and M. G. Thomas, Mol. Pharm., 2008, 5, 191-211.

[2] M. A. Fischbach and C. T. Walsh, Chem. Rev., 2006, 106, 3468-3496.

[3] Y. T. C. Ho, D. J. Leng, F. Ghiringhelli, I. Wilkening, D. P. Bushell, O. Kostner, E. Riva, J. Havemann, D. Passarella and M. Tosin, Chem. Commun., 2017, 53, 7088-709.

\section{P7 - Improving the antitumor potential of a diterpenoid through Mitsunobu Reactions}

Catarina Garcia $^{\text {ab }}$, Carlos M. Monteiro ${ }^{\mathrm{c}}$, Lucília Saraiva ${ }^{\mathrm{d}}$, Cláudia Bessa ${ }^{\mathrm{d}}$, Anastasia Borozan ${ }^{\mathrm{c}}$, Epole Ntungwe ${ }^{\mathrm{a}}$, Catarina Reis ${ }^{\mathrm{c}}$, Carlos A.M. Afonso ${ }^{\mathrm{c}}$, Patrícia Rijo $^{\text {ac }}$

${ }^{a}$ CBIOS - Center for Research in Biosciences \& Health Technologies, Universidade Lusófona de Humanidades e Tecnologias, Campo Grande 376, 1749-024 Lisbon, Portugal

${ }^{b}$ Department of Biomedical Sciences, Faculty of Pharmacy, University of Alcalá, Ctra A2, Km 33.600 - Campus Universitario, 28871 Alcalá de Henares, Spain 'Instituto de Investigação do Medicamento (iMed.ULisboa), Faculdade de Farmácia da Universidade de Lisboa, Av. Prof. Gama Pinto 1649-003 Lisbon, Portugal ${ }^{d}$ UCIBIO/REQUIMTE, Laboratório de Microbiologia, Departamento de Ciências Biológicas, Faculdade de Farmácia,Universidade do Porto, Rua de Jorge Viterbo Ferreira n. ${ }^{\circ} 228,4050-313$ Porto, Portugal

The Plectranthus genus is a known source of bioactive diterpenoids with antitumo potential [1]. Considering this, the optimized extraction from the essential oil of P. madagascariensis was achieved and the isolation of the cytotoxic diterpene 6,7-dehydroroyleanone was performed in high amounts [2]

Its preliminar toxicity was assessed through a lethality test against Artemia salina $\mathrm{L}$. brine shrimp, and its antitumor potential further explored in different cancer cell lines: colon colorectal carcinoma (HCT116), human breast adenocarcinoma (MCF-7) and lung cancer carcinoma (H460)

The promising antitumor profile of 6,7-dehydroroyleanone appeals the creation of a small library of potential anticancer agents. The Mitsunobu reaction relies on the displacement of an alcohol with a pronucleophile $(\mathrm{Nu}-\mathrm{H})$ mediated by phosphine and azocarboxylate reagents, which activate the pronucleophile through deprotonation and convert the alcohol to a reactive alkoxyphosphonium species [3].

Given the special acidity of the C-12 hydroxyl group of this royleanone, the insertion of nucleophiles - such as functionalized primary and secondary alcohols - are expected to change the original 6,7-dehydroroyleanone scaffold. Therefore, new derivatives wer prepared through microwave-assisted Mitsunobu reactions, and its preliminar toxicity evaluated.

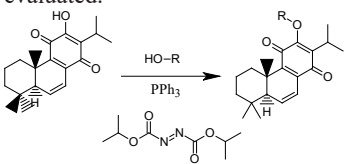

References:

11. Lukhoba C, Simmonds M, Paton A (2006). Journal of Ethnopharmacology 103: 1-24 2]. Ladeiras D, Monteiro C, Pereira F, Reis C, Afonso C, Rijo P. (2016) Curr. Pharm. Des. 22: 12, 1682-1714. [3]. Buonomo J, Aldrich C (2015). Angewandte Chemie International Edition 54: 44, 13041-13044.

P8 - Inhibition of Notch signalling in T-cell acute lymphoblastic leukemia: a challenge posed by a novel chalcone derivative

Elisa De Paolis ${ }^{\text {abb }}$, Deborah Quaglio ${ }^{a}$, Mattia Mori ${ }^{b}$, Luca Tottone ${ }^{c}$, Cinzia Ingallina ${ }^{a}$, Silvia Corradi ${ }^{\mathrm{a}, \mathrm{b}}$, Isabella Screpantic, Bruno Botta ${ }^{\mathrm{a}}$, Rocco Palermo ${ }^{\mathrm{b}}$, Francesca Ghirga ${ }^{b}$

aDepartment of Chemistry and Technology of Drugs, Sapienza University, Rome, Italy ${ }^{b}$ Center for Life Nano Science $@$ Sapienza, Istituto Italiano di Tecnologia, Rome, Italy 'Department of Molecular Medicine, Sapienza University, Rome, Italy

Notch signalling is considered a rationale target in the therapy of several cancers, particularly those harbouring Notch gain of function mutations, including T-cell acute lymphoblastic leukemia (T-ALL).[1] Although currently available Notch-blocking agents are showing anti-tumor activity in preclinical studies, they are not effective in al the patients and often cause severe side-effects, limiting their widespread therapeutic use. Here, by functional and biological analysis of the most representative molecules of an in house library of natural products, the $2^{\prime}, 3,4,4^{\prime}$-tetrahydroxychalcone (butein) was identified as valuable lead compound, thus emphasizing the relevance of the chalcone scaffold in Notch inhibition. Cycles of design-synthesis-bioassay and testing in vitro were established to optimize the potency of initial chalcone compound, and to eliminate or mask the undesirable chemical feature. Notably, the general strategy employed to synthesize chalcones in excellent yield was based on the Claisen-Schmidt condensation: twenty-six chemical derivatives were synthesized and tested in vitro. [2] Structure-activity relationships (SAR) were afforded, and a novel potent Notch inhibitor, namely 8 , was identified.[3] Short term treatments with compound 8 resulted in a dose-dependent decrease of Notch signalling activity, halted cell cycle progression and induced apoptosis, thus affecting leukemia cell growth.

In conclusion, our data indicate that 8 is a novel Notch inhibitor, candidate for further investigation and development as therapeutic option against Notch-dependent cancers. References:

[1]. Weng AP, Ferrando AA, Lee W, Morris JP 4th, Silverman LB, Sanchez-Irizarry C, Blacklow SC, Look AT, Aster JC (2004). Science 306: 269-271.

[2]. Sogawa S, Nihro Y, Ueda H., Miki T, Matsumoto H, Satoh T (1994). Biol Pharm Bull 17: 251-256

[3]. Mattia Mori, Luca Tottone, Deborah Quaglio, Nadezda Zhdanovskaya, Cinzia Ingallina, Marisa Fusto, Francesca Ghirga, Giovanna Peruzzi, Maria Elisa Crestoni, Fabrizio Simeoni, Francesca Giulimondi, Claudio Talora, Bruno Botta, Isabella Screpanti et Rocco Palermo, (2017), Scientific Reports| 7: 2213

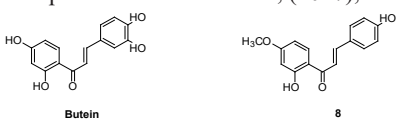




\section{P9 - Spirooxadiazoline oxindoles - a novel family of anticancer agents} Elizabeth Lopes, Damla Uyar, Lídia Gonçalves, Maria M. M. Santos

Research Institute for Medicines (iMed.ULisboa), Faculty of Pharmacy, Universidade de Lisboa, Av. Prof. Gama Pinto, 1649-003 Lisboa, Portugal

Spirooxindole alkaloids are a family of natural products that have a spiro ring fusion at position 3 of the oxindole core. Several natural products that possess this heterocyclic core, such as alstonisine, horsfiline, strychnofoline and spirotryprostatin A, are described to have interesting bioactivities.

In this area of research, we have been working in the development of novel spirooxindole scaffolds that possess interesting in vitro anti-tumor activities in colon cancer cell lines. 1 In this communication, we report the synthesis of a novel library of spirooxadiazoline oxindoles, by 1,3-dipolar cycloaddition of isatin derivatives with different nitrile imines (formed in situ from hydrazonyl chlorides), as well as the results obtained from the screening of this library in breast cancer cell lines: MCF-7 and MDA-MB-231. In this approach the target molecules combine two scaffolds that are known to possess anti-cancer activities (oxadiazoline and indolin-2-one).

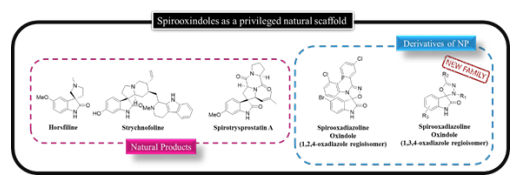

Figure - Spirooxindole natural products and novel spirooxindole derivatives with interesting biological activities.

Acknowledgments:

This work was supported by FCT (Fundação para a Ciência e a Tecnologia) through iMed.ULisboa (UID/DTP/04138/2013), and IF/00732/2013 (M. M. M. Santos).

References:

[1] C. J. A. Ribeiro, J. D. Amaral, C. M. P. Rodrigues, R. Moreira, M. M. M. Santos, "Spirooxadiazoline oxindoles with promising in vitro antitumor activities", Med. Chem. Commun. ("New Talent: Europe" issue) 2016, 7, 420-425;

[2] A. Monteiro, L. Gonçalves, M. M. M. Santos, "Synthesis and antiproliferative activity of spiropyrazoline oxindoles against cancer cell lines", Eur. J. Med. Chem. 2014, 79, 266-272

\section{P10 - Biological activity screening of seven Plectranthus species: anticancer lead molecule search}

Epole Ntungwe N. ${ }^{\mathrm{a}}$, Joana Marçalo ${ }^{\mathrm{a}}$, Catarina Garcia ${ }^{\text {ab }}$, Catarina Reis ${ }^{\mathrm{c}}$, Catarina

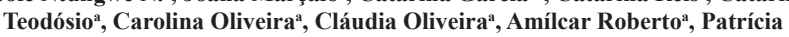
Rijo $^{\text {ac }}$

${ }^{\mathrm{a}} \mathrm{CBIOS}$ - Center for Research in Biosciences \& Health Technologies, Universidade Lusófona de Humanidades e Tecnologias, Campo Grande 376, 1749-024 Lisbon, Portugal

${ }^{b}$ Department of Biomedical Sciences, Faculty of Pharmacy, University of Alcalá, Ctra A2, Km 33.600 - Campus Universitario, 28871 Alcalá de Henares, Spain

'Instituto de Investigação do Medicamento (iMed.ULisboa), Faculdade de Farmácia

da Universidade de Lisboa, Av. Prof. Gama Pinto 1649-003 Lisbon, Portugal

Natural products from Plectranthus spp. plants have a vast ethnopharmacological use, inspiring several scientific investigations [1]. Considering this, a biological activity screening was performed in order to scientifically validate these plants use.

Assays on acetylcholinesterase (AChE) inhibition in vitro [2], antioxidant effect [2], antimicrobial activity [3] and Artemia salina lethality assay [4] of seven Plectranthus spp. acetonic extracts (P. swynnertonii, P. welwischii, P. woodii, P. cylindraceus, P. spicatus, P. ramosior and P. petiolaris) were performed, after its obtainment by sonication $(10 \% \mathrm{w} / \mathrm{v})[5]$

P. ramosior had the highest yield of dry extract $(13.49 \% \mathrm{w} / \mathrm{w})$ among all extracts tested. The antimicrobial activity was screened using the well diffusion method, against yeast, Gram-positive and -negative bacteria. P. ramosior extract showed not only a moderate inhibition zone against $\mathrm{S}$. aureus and $\mathrm{C}$. albicans (15 and $11 \mathrm{~mm}$, respectively), but also the highest scavenging activity (DPPH method, $36.4 \pm 0.04 \%)$. On the lethality test in A. salina, P. swynnertonnii extract was the most toxic $($ LC50 $=0.036 \mathrm{mg} / \mathrm{L})$. On the other hand, only P. cylindraceus extract decreased enzymatic activity $(30.2 \pm 3.78 \%)$.

These preliminary results showed that P. cylindraceus, P. ramosior and P. swynnertonnii are potential bioactive extracts for further isolation, antimicrobial and cytotoxic studies. References:

[1] Lukhoba C, Simmonds M, Paton A (2006). Journal of Ethnopharmacology 103: $1-24$

[2] Rijo P, Rijo P, Matias D, Fernandes AS, Simões MF, Nicolai M, Reis CP (2014). Polymers (Basel), 6 (2):479-90.

[3] Rijo P, Falé PL, Serralheiro ML, Simões MF, Gomes A, Reis C (2014). Measurement, 58:249-55.

[4] Alanís-Garza BA, González-González GM, Salazar-Aranda R, Waksman de Torres N, Rivas-Galindo VM (2007). J Ethnopharmacol, 114(3):468-71,

[5] Rijo P, Batista M, Matos M, Rocha H, Jesus S, Simões MF (2012). Biomed Biopharm Res.; 9 (2):225-35.

\section{P11 - Diaminocarbazolic receptors for carbohydrates featuring} sulfonate solubilizing groups

Francesco Papi, Oscar Francesconi, Cristina Nativi, and Stefano Roelens

\author{
University of Florence
}

Carbohydrates are essential mediators of a wide range of biological processes, including cell-to-cell adhesion, tumor metastasis, immune surveillance and promotion of inflammatory response. 1 All of these phenomena rely on selective recognition of specific saccharides, mainly exerted by several classes of proteins such as lectins. Mimicking lectin function in specific recognition events could affect a wide range of processes and open the way to possible therapeutic applications. 2

Biomimetic synthetic receptors that recognize carbohydrates by the same non covalent interactions used by lectins in nature, may represent powerful tools featuring usefu advantages over their natural counterparts. 2 The search for synthetic receptors is therefore actively pursued, but competition with water for carbohydrate recognition is still a challenge. Indeed, only few examples of effective biomimetic synthetic receptors for carbohydrates in water are reported in literature up to date. 4

In the last decade we have been involved in molecular recognition of carbohydrates, mostly developing synthetic receptors designed for biomimetic recognition and focusing on the selective binding of specific, biologically relevant saccharides. In particular we have developed several families of diaminopyrrolic receptors that show effective recognition properties in competitive organic media towards mono- and disaccharides. 5 Unfortunately, no evidence of binding could be detected in water, mainly because of the insolubility of the prepared structures. To overcome this problem we have recently designed a new architecture in which the diaminopyrrolic moiety has been replaced with a diaminocarbazolic unit featuring two phopshonate groups, in order to increase water solubility. Preliminary studies have shown excellent affinities for biologically relevant monosaccharides in aqueous solvents. Despite the very good results, there are still some issues: i) a $\mathrm{pH}$-dependency due to the protonation of the phosphonate groups that generates microspieces in solution and ii) aggregation phenomena due to hydrophobic intermolecular interactions between the anthracene units. Both these issues complicate the measurements of binding ability towards saccharides. The main goal of this research project was the design and synthesis of a new class of hydrosoluble diaminocarbazolic receptors, based on cyclic and acyclic architectures with known capabilities for carbohydrate recognition, with the aim of overcoming the limitations of the progenitor receptors. This goal was pursued by isostructurally replacing phosphonate with sulfonate groups as alternative water solubilizers. Their smaller size, strong solubilizing capacity, and full deprotonation at physiological $\mathrm{pH}$ should ensure compliance with the essential requirements without affecting their binding ability. The structures investigated in this project are shown in the following chart.

References:

[1]. A. Varki, Glycobiology, 2017, 27, 3-49

2]. Y. Nakagawa; Y. Ito, Adv. Carbohydr. Chem. Biochem., 2012, 68, 1-58.

[3]. S. Jin; Y. Cheng; S. Reid; M. Li; B. Wang, Med. Res. Rev., 2010, 30, 171-257.

[4]. T. S. Carter; T. J. Mooibroek; P. F. N. Stewart; M. P. Crump; M. C. Galan; A. P Davis, Angew. Chem. Int. Ed. Engl., 2016, 55, 9311-9315.

[5]. M. Gentili,; C. Nativi,; O. Francesconi; S. Roelens, Synthetic Receptors for [5]. M. Gentili,; C. Nativi,; O. Francesconi; S. Roelens, Synthetic Receptors for
Molecular Recognition of Carbohydrates, In Carbohydrate Chemistry; A. P. Rauter Ed.; Specialist Periodical Reports (SPR); The Royal Society of Chemistry: Cambridge, U.K., 2016; Vol. 41, 149-186.

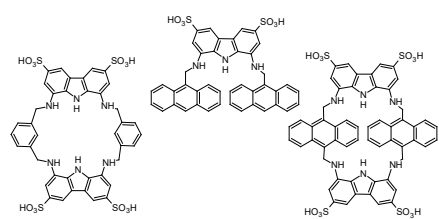

\section{P12 - Natural products derivatization to form nanoparticles for cancer treatment}

Gaia Fumagalli and Daniele Passarella

Dipartimento di Chimica, Università degli Studi di Milano, via Golgi 19, 20133 Milano

Our continuous interest in natural products moved us to study the preparation of a novel class of conjugate compounds using natural products with anticancer properties as building blocks with the aim to target cancer cells. In previous efforts we used squalene tail as self-assembling inducer and a disulphide containing linker to secure the release of the drugs after cell internalization.1 Subsequently we demonstrated the possibility to generate hetero and fluorescent nanoparticles by mixing a paclitaxelsqualene conjugate and fluorescein-squalene conjugate. 2 In the light of facing the high demanding issue of resistance due to cancer stem cells 3 we studied the formation of cyclopamine-paclitaxel containing nanoparticles and we had the way to detect the internalization by confocal microscopy and super-resolution.4 Our efforts are actually focused on: a) new combination of drugs to overcome drug resistance, b) new selfassembling inducers, c) new hetero-nanoparticles and d) new drug-conjugates deriving by modification of active natural products.

References:

[1]. Borrelli S, Silvani A, Dosio F, Passarella Det al (2014). Eur J.Med Chem 85: 179-190.

[2]. Borrelli S, Fumagalli G, Dosio F, Passarella D et al. (2015). ChemPlusChem 80: 47-49.

[3]. Sotiropoulou PA, Passarella D et al. (2014) Drug Discovery Today 19: 1547-1562.

[4]. Fumagalli G, Dosio F, Passarella D et al. (2015). ChemPlusChem 9: 1380-1383. 


\section{P13 - Trojan Horse strategy: an achiles heel of resistant bacteria}

Kevin Ferreira ${ }^{a}$, Verena Fetz ${ }^{b}$, Hans Prochnow ${ }^{a}$, Mark Brönstrupa

${ }^{a}$ Helmholtz Centre for Infection, Braunschweig, Germany

${ }^{\mathrm{b}}$ German Federal Institute for Risk Assessment, Berlin, Germany

The design of novel label/antibiotic-siderophore conjugates with a crucial proof of internalization represents a milestone towards theranostics against bacteria of the ESKAPE panel. Infections caused by multidrug-resistant Gram-negative bacteria result in significant mortality and morbidity worldwide despite the development of new anti-infective drugs [1]. The need for novel antibiotics is currently not met by R\&D efforts, in particular in the area of infections caused by Gram-negative bacteria. A main scientific hurdle is the lack of understanding how to assure a sufficient translocation of bioactive molecules across the Gram-negative cell wall. Another limitation is the lack of reliable and sensitive methods that permit the detection of bacteria at early stages of infections where antibiotic treatments would still be effective [2]. Our efforts to induce an active transport of small molecules into Gram-negative bacteria and methods to quantify such uptake were performed.

We report a series of theranostic agents based on DOTAM derivatives comprising siderophores that actively target bacteria, inhibit bacterial growth and demonstrate efficacy to visualize bacterial infections (Figure 1).

Preliminary studies were achieved to characterize our designed conjugates as $\mathrm{Fe}$ (III) chelating agents. To quantify the intracellular accumulation of such conjugates, we pursue an fluorogen activating protein-based approach (FAP) that allow the determination of the subcellular localization of malachite green dye-coupled small molecules. This system serves to validate the efficiency of vehicles for bacterial penetration [3]. We expect that the use of such active targeting principles attached to the described DOTAM/Metal-platform will be generally useful for the development of new drug conjugates that have different cellular targets and modes of action against Gram-negative bacteria.

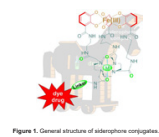

References:

[1]. Ho, J.; Tambyah, P. A.; Paterson, D. L. Curr. Opin. Infect. Dis. 2010, 23, 546 [2]. Ning, X.; Lee, S.; Wang, Z.; Kim, D.; Stubblefield, B.; Gilbert, E.; Murthy, N. Nat Mater., 2011, 10, 602.

[3]. Ferreira, K., Hu, H., Fetz, V., Prochnow, H., Rais, B., Mmüller, P., Brönstrup, M. Angew. Chem. 2017 (Accepted).

\section{P14 - Insect immune response related peptides as a platform for anti- infective and anti-cancer drug discovery}

\section{Maider Beitia ${ }^{\mathrm{a}}$, Marco Ponassi ${ }^{\mathrm{b}}$, Camillo Rosano ${ }^{\mathrm{b}}$, Sergey Chernysh ${ }^{\mathrm{c}}$}

${ }^{a}$ University of Basque Country (UPV/EHU), Leioa, Spain bIRCCS AOU San Martino - IST, Genova, Italy cSaint Petersburg State University, St. Petersburg, Russia

Naturally occurring peptides are one of fastest-growing groups of medicines and drug candidates destined for the treatment of viral infections and cancer. However, nonhuman immune response related peptides are nearly unusable in Medicine. Alloferon-1, antiviral and antitumor peptide from insects [1] [2] registered as antiviral medicine is one of very rare drugs of this type. The presentation discloses two novel drug candidates related to insect immunity: allostatine and FLIP7.

Allostatine is a synthetic oligopeptide combining structures of insect alloferon- 1 and polypeptide binding region of human immunoglobulins [3]. The peptide demonstrates strong antitumor activity in mice as well as antiviral activity in different animal models. Allostatine mode of action includes enhancement of NK and Th cells functionality: NK cell cytotoxicity to cancer cells; number of IFgamma and IL2 producing NK and Th cells; number of the cells expressing CD25 (IL2 receptor) etc. Characterization of $\mathrm{NK}$ and T cell allostatine-binding receptor(s) responsible for the cells activation is in progress now. Moreover, allostatine is known to activate IFalpha production by human mononuclears in presence of herpes virus antigens and to inhibit proliferation of mouse
oncornavirus transformed cancer cells. Thus, allostatine is capable of boosting key elements of antiviral and anticancer immunity. Allopharm Co. developed allostatine topical formulation (hydrogel Allomedin ${ }^{\mathrm{TM}}$ ) and marketed it for dermatocosmetology use since 2007. Clinical observations demonstrated Allomedin potential in the skin protection against cold sores manifestation as well as neoplasms caused by human papilloma virus. Allomedin drug registration is under preparation now.

FLIP7 is a naturally occurring composition containing a battery of antimicrobial peptides belonging to the families of insect defensins, cecropins, diptericins and proline-rich peptides encoded by a single genome [4] [5]. FLIP7 demonstrates therapeutically invaluable properties: broad spectrum of antibacterial activity towards many, although not all, kinds of antibiotic resistant strains; efficacy against antibiotic resistant bacterial biofilms; capacity of preventing drug resistance development in Gram-negative bacteria; delay of resistance development to conventional antibiotics applied in combination with FLIP7. Preclinical and clinical tests proved FLIP7 safety under cutaneous application. It is registered and marketed for dermatocosmetology use although subsequent FLIP7 drug registration seems quite reasonable in a view of recent crisis in the therapy of antibiotic resistant bacteria and bacterial biofilms References:

11]. Chernysh SI, Kim SI, Bekker G, Pleskach VA, Filatova NA, Anikin VB, et al (2002) PNAS. 99: 12628-12632 [2]. Chernysh S, Kozuharova I, Artsibasheva I (2012). Intern Immunopharmacol 12: 312-314

[3]. Chernysh S, Kozuharova I (2013). Intern Immunopharmacol 17: 1090-1093

4]. Chernysh, SI, Gordja, NA (2011). J Evol Biochem Physiol 47: 524-533

[5]. Chernysh S, Gordya N, Suborova T (2015) PLoS ONE 10 (7): e0130788 doi:10.1371/journal.pone.0130788.
P15 - Discovery of enantiopure tyrosinol-derived bicyclic lactam that acts as NMDA receptor antagonist

Margarida Espadinha, ${ }^{a}$ Jorge Dourado, ${ }^{a}$ Rocio Lajarin-Cuesta, ${ }^{\text {b,c }}$ Clara HerreraArozamena ${ }^{\mathrm{d}}$ Lidia M. D. Gonçalves, ${ }^{\mathrm{a}}$ María Isabel Rodríguez-Franco, ${ }^{\mathrm{d}}$ Cristobal de los Rios, ${ }^{\mathrm{b}, \mathrm{c}}$ Maria M. M. Santos ${ }^{\mathrm{a}}$

${ }^{a}$ Research Institute for Medicines (iMed.ULisboa), Faculty of Pharmacy, Universidade de Lisboa, Lisboa, Portugal

b Instituto Teófilo Hernando, Facultad de Medicina, Universidad Autonoma de Madrid, Madrid, Spain

Instituto de Investigacion Sanitaria, Hospital Universitario de la Princesa, Madrid, Spain; d Instituto de Química Médica (IQM-CSIC), Madrid, Spain.

N-Methyl-D-aspartate (NMDA) receptors belong to the family of ionotropic glutamate receptors (iGluRs) and are localized in the cell membrane of neurons.1 These receptors are fundamental for the normal function of the central nervous system (CNS) and play a vital role in the normal development of the nervous system. The over-activation of a vital role in the normal development of the nervous system. The over-activation of
NMDA receptors leads to neuronal loss associated with major neurological disorders and, for this reason, the development of effective NMDA receptor antagonists is a promising therapeutic approach to fight these neurodegenerative diseases. ${ }^{1}$

Here we will present our latest results on the hit optimization of aminoalcoholderived bicyclic lactams as NMDA receptor antagonists. 2 A small library of twentytwo enantiopure target small molecules were designed, synthesized, and evaluated as NMDA receptor antagonists. Their capacity to inhibit NMDA-induced increase of intracellular $\mathrm{Ca} 2+$ levels was measured, using in vitro cultures of embryonary rat of intracellular $\mathrm{Ca} 2+$ levels was measured, using in vitro cultures of embryonary rat cortical neurons and $\mathrm{Ca} 2+-$-sensitive fluorescent dye Fluo-4. Most compounds showed
NMDA receptor antagonism and one (S)-tyrosinol derived bicyclic lactam revealed an IC50 value in the same order of magnitude as that of memantine (NMDA recepto antagonist in clinical use). Finally, we have shown that this small molecule can cross the blood-brain barrier (determined by an in vitro assay) and is non-hepatotoxic. Collectively, our results underline the potential therapeutic use of tyrosinol-derived bicyclic lactams in reducing NMDA receptor activity. ${ }^{2}$

Acknowledgments:

This work was supported by FCT (Fundação para a Ciência e a Tecnologia) through iMed.ULisboa (UID/DTP/04138/2013), and grants PTDC/QUI-QUI/111664/2009 and IF/00732/2013 (M. M. M. Santos), and also by Instituto de Salud Carlos III, Spanish Ministry of Health (PI13/00789), by Spanish Ministry of Economy and Competitiveness (MINECO, grants SAF2012-31035 and SAF2015-64948-C2-1-R), and by Consejo Superior de Investigaciones Científicas (CSIC, grant PIE-201580E109).

References:

[1] a) Stawski P., Janovjak H., Trauner D. Bioorg. Med. Chem. 2010, 18, 7759-7772. b) Morris R. Neuropharmacology, 2013, 74, 32-40.

[2] Espadinha M., Dourado J., Lajarin-Cuesta R., Herrera-Arozamena C., Gonçalves L. Rodríguez-Franco I., de los Ríos C., Santos M. M. M. ChemMedChem. 2017, 12, 537-545.

\section{P16 - Cytotoxic activity of compounds isolated from Dismerotemma aspilioides}

María Florencia García Manzano, Mariana Belén Joray, Sara María Palacios, Jerónimo Laiolo, María Cecilia Carpinella

Research Institute of Natural Resources and Sustainability José Sánchez Labrador S.J. (IRNASUS-CONICET), School of Chemistry, Catholic University of Córdoba, Argentina.

Cancer is one of the major threat to human health. The currently available cancer chemotherapy regimes may result in several critical problems, including lack of effectiveness, serious adverse effects and the development of multidrug resistance (MDR). Thus, more effective cancer therapies that result from the discovery of new (MDR). Thus, more effectiv
drugs are of high priority.

Plants have played a critical role in anticancer drug discovery. Plant or derived agents, including a variety of terpenoids, alkaloids, the epipodophyllotoxin lignanes, the taxanes and the camptothecins, have been among the most widely used cancer chemotherapeutics available. The interest in the chemical diversity of the plant-derived metabolites is increasing with the aim of finding new hits or lead compounds for future chemotherapeutic drugs.

In the search of these entities, ninety three native and naturalized plants collected from central region of Argentina were screened for their anti-proliferative effect over the chronic myelogenous leukemia (CML) cell line K562.

Dimerostemma aspilioides was selected as the plant with the highest potential for processing in search of novel cytotoxicity principles.

The extraction and separation of Dimerostemma aspilioides were carried out by bioguided isolation. The ethanol extract was initially subjected to vacuum liquid chromatography on silica gel eluted with a step gradient of hexane/ethyl acetate/methanol
to yield 15 fractions, which where combined in 6 groups according to their thin layer to yield 15 fractions, which where combined in 6 groups according to their thin layer
chromatography (TLC) profile (F1 to F6). Of these, F4 and F5 demonstrated cytotoxic activity at concentrations $<2 \mu \mathrm{g} / \mathrm{mL}$ and were therefore submitted to additional column to yield 10 groups. Of these, F4,54-F4,55-F4,56 and F4,57 demonstrated cytotoxicity. From fraction F4,55, compound 1 was obtained by spontaneous crystallization. Fraction F4,56 was further processed by flash chromatography, eluted with a step gradient of hexane/ethyl acetate/methanol. The fractions obtained were combined in 8 groups (FI1 to FI8). Compound 2 was obtained fom FI6 by extraction with acetonitrile/ groups (FI1 to FI8). Compound 2 water/diethyl ether $(25: 25: 50)$.

water/diethyl ether $(25: 25: 50)$.
On activity assays, the cytotoxic effect was determined by MTT assay on K562.

The results obtained positioned these structures as possible anticancer agents.

References:

[1]. Newman, D J, Cragg, G M (2016). J. Nat. Prod. 79: 629-661.

[2]. Schmidt B, Ribnicky, D M, Poulev A, Logendra S, Cefalu W T, Raskin I (2008) Metabolism 57: S3-9.

[3]. Kinghorn A D, Carcache-Blanco E J, Chai H-B, Orjala J, Farnsworth N R, Soejarto D D, Oberlies N H, Wani M C, Kroll D J, Pearce C J, Swanson S M, Kramer R A, Rose W C, Fairchild C R, Vite G D, Emanuel S, Jarjoura D, Cope F O (2009). Pure Appl. Chem 81: 1051-1063.
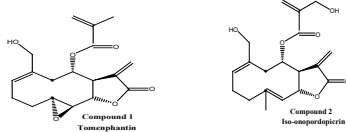
P17 - P53 tumor suppressor is required for efficient execution of the death program following treatment with a cytotoxic limonoid obtained from Melia azedarach

Mariana Belén Joray ${ }^{a}$, Florencia Villafañez ${ }^{\mathrm{b}}$, María Laura González ${ }^{\mathrm{a}}$, María Inés Crespo ${ }^{a}$, Jerónimo Laiolo ${ }^{a}$, Sara María Palacios ${ }^{\mathrm{a}}$, José Luis Boccob ${ }^{\mathrm{b}}$, Gastón Soria $^{\mathrm{b}}$ María Cecilia Carpinella

${ }^{a}$ Fine Chemicals and Natural Products Laboratory, School of Chemistry, Catholic University of Córdoba, Avda Armada Argentina 3555, X5016DHK Córdoba, Argentina.

${ }^{\mathrm{b}}$ CIBICI CONICET and Department of Clinical Biochemistry, Faculty of Chemica Science, National University of Córdoba, Haya de la Torre and Medina Allende, Córdoba, Argentina.

Cancer still remains a major cause of disease and death worldwide and thus new therapeutic options are a high priority for most of researchers. The genus Melia is well-known as a rich and valuable source of bioactive tetranortriterpenoids known as limonoids. In previous research conducted by our group, the fractionation of a kernel extract obtained from Melia azedarach L. led to the isolation of meliartenin (1), an antifeedant limonoid, which exists as a mixture with its tautomeric isomer 12-hydroxyamoorastatin [1].

In this study, the antitumor activity of 1 was evaluated over a panel of human tumorderived cell lines, resulting in a cytotoxic effect that was highly selective to the human colorectal carcinoma cell line HCT116 over the rest of the assayed cell lines. Mechanistic analysis revealed that treatment with 1 induced a time-dependent increase in the number of cells transiting the S-phase of the cell cycle, with a similar activity from $0.4 \mu \mathrm{M}$ to that obtained with the positive control hydroxyurea (HU). Subsequen detection with an anti-BrdU antibody confirmed a sustained anti-proliferative effect on HCT116 cells. In addition to slowing down the cellular progression through S-phase, flow cytometry analysis after SYTOX Red stain showed that 1 induced cell death in a time-dependent manner, reaching percentages of death higher than $53 \%$ from 0.2 $\mu \mathrm{M}$ at $72 \mathrm{~h}$. Furthermore, Annexin V/SYTOX Red double staining demonstrated that this compound was able to induce apoptosis in HCT116 cells with values higher than $70 \%$ at $72 \mathrm{~h}$. It was also found that 1 was not only capable of killing HCT116 but also strongly impaired its clonogenic potential at a concentration as low as $0.04 \mu \mathrm{M}$. In the light of our findings we evaluated whether the biological effects mediated by 1 were related to the induction and activity of $\mathrm{p} 53$ and its downstream target $\mathrm{p} 21$. The increased expression profile of these proteins was similar to that observed with the treatment with HU. It was found that p53-dependent apoptosis was responsible for treatment with HU. It was found that p53-dependent apoptosis was responsible for
the cytotoxicity observed in HCT116. The fact that p53, but not p21, was linked to the cytotoxic effect mediated by this compound strongly suggests that only the proapoptotic functions of p53 are critical for this effect.

Taken together, the results described in this work position compound 1 as a strong antitumoral agent, with great potential for targeting $\mathrm{p} 53+$ tumors.

[1] Carpinella MC, Ferrayoli CG, Valladares GR, Defago MT, Palacios SM (2002) Biosc. Biotechnol. Biochem. 66: 1731-1736.

P18 - Extending the binding of cyclohexanedione derivatives towards the $\alpha \beta$ tubulin interface

Marta Gargantilla, ${ }^{a}$ Oskia Bueno ${ }^{\text {a }}$, Juan Estevez Gallego ${ }^{\text {b }}$, Andrea E. Prota ${ }^{c}$, J. Fernando Díaz ${ }^{\mathrm{b}}$, Michel O. Steinmetz ${ }^{\mathrm{c}}$, María-José Camarasa, Federico Gago, ${ }^{d}$ Sandra Liekens, ${ }^{\mathrm{e}}$ Eva-María Priego and María-Jesús Pérez-Pérez

a Instituto de Química Médica (IQM-CSIC), Juan de la Cierva 3, 28006 Madrid, Spain.

${ }^{\mathrm{b}}$ Centro de Investigaciones Biológicas (CIB-CSIC), Ramiro de Maeztu 9, 28040 Madrid, Spain

${ }^{c}$ Laboratory of Biomolecular Research, Paul Scherrer Institut, 5232 Villigen, Switzerland

d Department of Biomedical Sciences, University of Alcalá, Unidad Asociada CSIC Alcalá de Henares, Madrid, Spain

'Rega Institute for Medical Research, KU Leuven, Herestraat 49, B-3000 Leuven, Belgium

Compounds binding at the colchicine site in tubulin have received renewed interest due to their capacity to act as vascular-disrupting agents (VDAs). The prototype VDA acting at the colchicine site is the natural product combretastatin A4 (CA-4) [1], that has reached clinical trials through its prodrugs. However, an increasing number of compounds belonging to different chemical families are also able to bind at the colchicine site of an $\alpha \beta$-tubulin heterodimer and to exhibit antivascular properties [2]. We have reported on a new family of colchicine-site binders with a cyclohexanedione We have reported on a new family of colchicine-site binders with a cyclohexanedione
skeleton, the prototype of which is TUB075. This compound binds tubulin with an skeleton, the prototype of which is TUB075. This compound binds tubulin with an
affinity constant of $1.3 \times 107 \mathrm{M}-1$ and has shown antiproliferative activity in the ow subu $\mathrm{M}$ range [3]. We have now determined the crystal structure of the tubulinTUB075 complex and the binding site has been explored with the computational too cGRILL [4] to highlight the molecular interaction fields or "affinity maps". Using the hydrophobic probe $(\mathrm{CH} 3)$ to the TUB075-tubulin complex, two new unexplored regions were identified as suitable for binding. To exploit one of these tunnel-shape regions were identified as suitable for binding. To exploit one of these tunnel-shape
regions, which extends from the ethoxy substituent towards the $\alpha \beta$-tubulin heterodimer regions, which extends from the ethoxy substituent towards the $\alpha \beta$-tubulin heterodimer
interface, new derivatives were designed, synthesized and evaluated for their tubulin binding affinity and for their antiproliferative activity.

Acknowledgements:

This project has been financed by the Spanish SAF2015-64629-C2-1-R (MINECOFEDER), BFU2016-75319-R (AEI/FEDER, UE) from MINECO, Comunidad de Madrid (BIPEDD2; ref. P2010/BMD-2457) and the COST Action CM1407 (to M-J P.-P. S.L., M.O.S. and J.-F.D.).

References:

1].Gasparini, R, Prota, AE, Bargsten, K et al (2017) Chem 2: 102-113

2. Pérez-Pérez, MJ, Priego, EM, Bueno, O et al (2016). J Med Chem. 59: 8685-8711.

3. Canela MD, Bueno O, Noppen, S et al (2016) RSC Adv 6:19492-19506

[4].Cortés-Cabrera, A, Gago, F. Available at http://farmamol.uah.es/index.php/en/

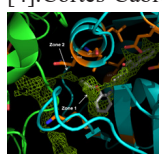

\section{P19 - Synthesis of planar chiral ferrocene sulfonamides} bearing fenchane and menthane moieties

Martin Ravutsov ${ }^{\mathrm{a}}$, Georgi Dobrikova, Miroslav Dangalov ${ }^{\mathrm{a}}$, Boris Shivachev $^{\mathrm{b}}$, Vladimir Dimitrov

${ }^{a}$ Institute of Organic Chemistry with Centre of Phytochemistry,

Bulgarian Academy of Sciences, Acad. G. Bonchev Str. 9, Sofia 1113, Bulgaria

"Institute of Mineralogy and Crystallography "Acad. Ivan Kostov",

Bulgarian Academy of Sciences, Acad. G. Bonchev Str. 107, Sofia 1113, Bulgaria

Ferrocene derived compounds have attracted much attention in a wide range of scientific areas. 1 The stability of the ferrocenyl group in aqueous and aerobic media, and its favorable electrochemical properties, have made ferrocene and its derivative suitable molecules for biological applications. 2 A recent work of our group has revealed promising cytotoxic and cytostatic activities against large set of cancer and normal human cell lines of $(+)$-camphor derivatives bearing ferrocenylmethylidene and sulfonamide moieties. 3 In another study we have shown comparable to ethambutol in vitro activity of fenchane-based sulfonamides against Mycobacterium tuberculosis in vitro actir

H 37 Rv.4
In this regard, herein is reported a diastereoselective ortho-lithiation of chira ferrocenesulfonamides leading to new planar chiral fenchol- and menthol-derivatives with potential biological activity. The configuration of the isolated planar chiral diastereoisomers was determined by NMR experiments and/or X-ray crystallography.

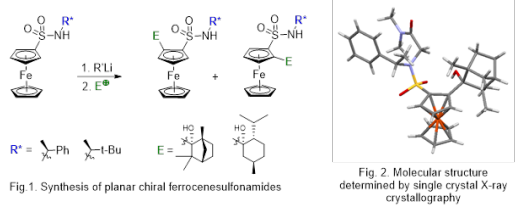

References:

[1]. Adams R. D. (2001). J. Organomet. Chem. 637-639: 1-849.

[2]. Ornelas C. (2011). New J. Chem. 35: 1973-1985 and cited therein.

[3]. Kamenova-Nacheva M., Schröder M., Pasheva E., Slavchev I., Dimitrov V., Momekov G., Nikolova R., Shivachev B., Ugrinova I., Dobrikov G. M. (2017). New J. Chem., in press.

[4] Dobrikov G. M., Valcheva V., Nikolova Y., Ugrinova I., Pasheva E., Dimitrov V. (2014). Eur. J. Med. Chem. 77: 243-247.

\section{P20 - Biological activity screening of seven Plectranthus species:} anticancer lead molecule search

Miriam Piccichè, Alexandre Pinto, Rosa Griera, Joan Bosch and Mercedes Amat*

Laboratory of Organic Chemistry, Faculty of Pharmacy and Food Science, University of Barcelona, 08028-Barcelon

Gephyrotoxin $287 \mathrm{C}$ is a decahydroquinoline (DHQ) alkaloid isolated from the skin extracts of dendrobatid frogs that shows an interesting array of neurological activities Our approach to the synthesis of this alkaloid involves the use of a phenylglycinolderived tricyclic lactam as the starting enantiomeric scaffold, which can be easily converted to enantiopure $\mathrm{C}-5$ substituted 2-oxo-cis-DHQ derivatives bearing a trans $\mathrm{H}-4 \mathrm{a} / \mathrm{H}-5$ relative configuration. 1
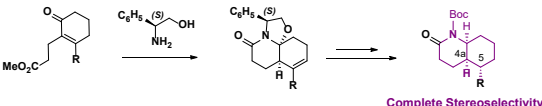

Using this methodology, we prepared cis-DHQ 1, which has the correct configuration at three of the five stereocenters of gephyrotoxin $287 \mathrm{C}$. To complete the synthesis of this target, three main transformations had to be addressed: the elaboration of the appropriate C-2 and C-5 chains and the final closure of the pyrrolidine ring

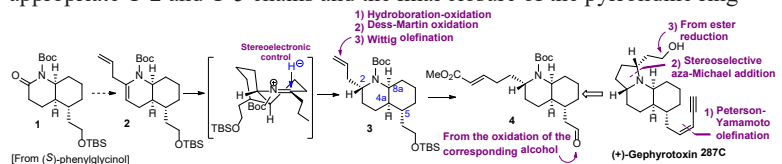

First, a Stille coupling with the vinyl triflate prepared from 1 was used for the introduction of a 3-propenyl chain. The subsequent stereoselective reduction of the enamide moiety of 2 took place under stereoelectronic control to give 3, with a $\mathrm{H}-2 / \mathrm{H}-$ $8 \mathrm{a}$ trans relative configuration. A subsequent hydroboration-oxidation of the terminal double bond, followed by a Dess-Martin oxidation and a Wittig olefination, generated the unsaturated ester function in 4

The elongation of the $\mathrm{C}-5$ lateral chain to introduce the cis-enyne moiety was carried out with total stereoselectivity by a Peterson-Yamamoto reaction from the corresponding aldehyde. Finally, an intramolecular aza-Michael addition of the secondary amine on the unsaturated ester, followed by reduction of the ester group, provided the tricyclic alkaloid (+)-gephyrotoxin 287C

Acknowledgements:

Financial support from the MINECO/FEDER (CTQ2015-65384-R) and the Generalitat the Catalunya (2014-SGR-155) and the networking contribution from the COST Action CM1407. References:

[1]. Amat, M.; Griera, R.; Fabregat, R.; Molins, E.; Bosch, J. Angew. Chem. Int. Ed. 2008, 47, 3348

[2]. Amat, M.; Fabregat, R.; Griera, R.; Bosch, J. J. Org. Chem. 2009, 74, 1794. [3]. Amat, M.; Fabregat, R.; Griera, R.; Florindo, P.; Molins, E.; Bosch, J. J. Org. Chem. $2010,75,3797$

[4]. Amat, M.; Ghirardi, E.; Navio, L.; Griera, R.; Llor, N.; Molins, E.; Bosch. J. Chem. Eur. J. 2013, 19, 16044 


\section{P21 - Chemoenzymatic tactics towards the synthesis of phenylethanoid apioglucosides}

Peter Kis, Mária Mastihubová

Institute of Chemistry, Slovak Academy of Sciences, Dúbravská cesta 9 , SK-845 38 Bratislava, Slovakia

Naturally occurring glycosides containing $\beta$-D-apiofuranose, from among saponins, flavonoids, or phenylethanoid glycosides play crucial roles in the biochemistry of plants [1]. Most of the isolated compounds from the last mentioned structural group possess interesting biological activities such as antimicrobial, hepatoprotective, antitumor, antiviral, etc. [2]. Synthesis of phenylethanoid apioglucosides is therefore an important step in elucidating the relationship between the structures and biological activities of these natural products.

This work deals with the chemoenzymatic synthesis of four phenylethanoid apioglucosides - Darendoside A (1) isolated from Scutelluria orientalis [3] Osmanthuside H (2) isolated from Osmanthus asiaticus [4], Cuneataside (3) isolated from Sargentodoxa cuneata [5] and the non-natural apioglucoside 4. The key acceptor intermediates 7-10 were apiosylated with trichloroacetimidate donor 6 prepared from 5 in two steps involving enzymatic deprotection of anomeric hydroxyl of 5 . The use of regioselective enzymatic protecting technics in the synthesis of the apiosyl donor as well as the suitable glucosyl acceptors 7 and 8 will be discussed.

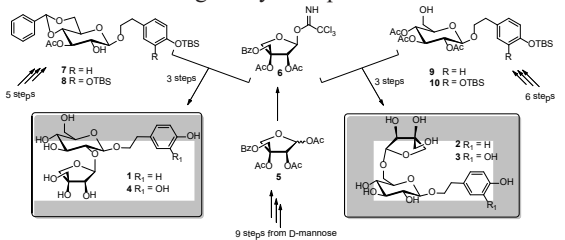

References:

1]. Pičmanová M, Møller BL (2016). Glycobiology 26: 430-442

[2]. Fu G, Pang H, Wong YH (2008). Curr Med Chem 15: 2592-2613.

[3]. Başaran AA, Çaliş I, Saracoğlu I, Sticher, O (1993). Phytochemistry 32: 16211623

[4]. Sugiyama M, Kikuchi M (1993). Phytochemistry 32: 1553-1555.

[5]. Case R, Chang J (2005). Phytochemistry 66: 2752-2758.

P22 - Discovery of potent isoflavone (Glabrescione B) as selective inhibitor of Hedgehog-dependent tumors

Pietro Eleuteri ${ }^{\mathrm{a}}$, Silvia Corradi ${ }^{\mathrm{a}, \mathrm{b}}$, Elisa De Paolis ${ }^{\mathrm{a}, \mathrm{b}}$, Cinzia Ingallina ${ }^{\mathrm{a}}$, Simone Berardozzi $^{\mathrm{a}, \mathrm{b}}$, Francesca Ghirga ${ }^{\mathrm{b}}$, Deborah Quaglio ${ }^{\mathrm{a}}$, Mattia Morib ${ }^{\mathrm{b}}$, Lucia Di Marcotullio $^{\mathrm{c}}$, Paola Infante ${ }^{\mathrm{b}}$, Romina Alfonsic, Bruno Botta ${ }^{\mathrm{a}}$

aDipartimento di Chimica e Tecnologie del Farmaco, Sapienza, Roma ${ }^{b}$ Center for Life Nano Science@Sapienza, Istituto Italiano di Tecnologia, Roma 'Dipartimento di Medicina Molecolare, Sapienza, Roma

Hedgehog $(\mathrm{Hh})$ signaling has emerged in recent years as a druggable target for anticancer therapy. Its aberrant activation, occurring either by ligand-dependent or -independent mechanisms, has been observed in many tumors. Recently, particular interest has been highlighted by the identification of molecules able to hit gliomainterest has been highlighted by the identification of molecules able to hit glioma-
associated oncogene (GLI) factors, the final effectors of the Hh pathway, which provide associated oncogene (GLI) factors, the final effectors of the Hh pathway, which provide of the crystallographic structure of the zinc finger domain of Gli1 (Gli1ZF) in complex with DNA, together with NMR studies as well as computational and experimental mutagenesis, we clarified the structural requirements of Gli1/DNA interaction [1]. We identified Glabrescione B (GlaB), an isoflavone naturally found in the seeds of Derris glabrescens (Leguminosae) [2], as a novel small molecule that proved to be able to bind Gli1ZF and interfere with its interaction with DNA. This small molecule turned out to be an efficient inhibitor of the growth of $\mathrm{Hh} / \mathrm{Gli}$-dependent tumors and cancer stem cells in vitro and in vivo. Moreover, since extraction methods developed allow to get very limited amounts of pure isoflavone, we provided the total synthesis of GlaB which foresees just three steps route with a overall yield $15 \%$. This synthetic strategy allowed us the preparation of five derivatives with the aim to elucidate the structureactivity relationships and to clarify the molecular mechanism behind the Hh signaling modulation

1]. Amakye D, Jagani Z, Dorsch M (2013) Nat Med 19, 1410-1422.

[2]. Delle Monache F., Cairo Valeira G., Sialer de Zapata D., et al., (1977) Gazz Chim

Ital, 107, 403-407.

[3]. Infante, P. et al., (2015) EMBO J. 34, 200.
P23 - Enantiopure synthesis of a new morpholino $\beta$-amino acid and its use for the preparation of peptidomimetics

Raffaella Bucci, Sara Pellegrino, Silvia Locarno, Maria Luisa Gelmi

DISFARM, Università degli Studi di Milano, Milan, Italy

Natural peptides, characterized by well defined secondary structures, were used as drugs for their biological activities and selectivity. Nevertheless, the main draw-back in their use is due to their instability towards proteases. As a result, the preparation of hybrid peptides containing natural amino acids and non-natural molecular architecture, mimicking secondary structure element of the natural one, is of great interest in biology and nanomedicine1. Furthermore, peptide mimics are attractive tools for the synthesis and development of drugs or peptides capable of withstanding the peptidase degradation.

The preparation of molecular scaffolds able to induce specific secondary structures is the main research field of our group2.

Few example of $\alpha / \beta$-peptides are reported in the literature and most of them containing cyclic amino acids.

The aim of this work is the synthesis of a new cyclic chiral $\beta$-amino acid, i.e. the morpholino $\beta$-amino acid named $\beta$-Morph, which could be of great interest for the preparation of peptidomimetics.

$\beta$-Morph is an analogous of nipecotic acid, deeply studied by Gellman as $\beta$-turn inducer, but differs for the presence of the oxygen atom at position one of the morpholino ring. This could give rise a specific orientation to the carbonyl group at $\mathrm{C}-2$, due to a possible repulsive effect between the oxygen atoms. As a result, $\beta$-Morph could drive the secondary peptide conformation when it is inserted in a sequence.

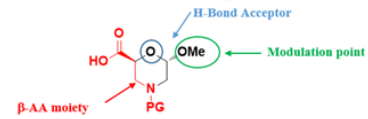

Figure 1 - $\beta$-MorphAA.

The presence of the acetal function could be of general interest in case of a possible functionalization of C-6 with a proper nucleophile such as nucleobases, fluorescent probes and chimeric AAs. Furthermore, this moiety could be of relevance in a peptide sequence considering its ability as H-bond acceptor. As a result, it represents a very interesting tool for the preparation of peptides targeted to the biological field.

In this work, the $\beta$-Morph was used for the preparation of peptide models that were studied by molecular modeling and NMR.

References:

[1]. (a) Yao W, Yan Y, Xue L., Zhang C, Li G, Zheng Q, Zhao Y.S, Jiang H., Yao J., (2013), Angewante Chemie 125: 8875-8879; (b) Torabi S. F., Lu Y., (2014), Current Opinion in Biotechnology 28: 88-95.

[2]. (a) Bonetti A., Pellegrino S., Das P., Yuran S., Bucci R., Ferri N., Meneghetti F. Castellano C., Reches M., Gelmi M. L., (2016), Organic Letters 17: 4468-4471; (b) Bucci R., Bonetti A., Clerici F., Nava D., Pellegrino S. Tessaro D., Gelmi M. L., (2017) Chemistry- A European Journal, DOI: 10.1002/chem.201701045

\section{P24 - ISynthesis of (-)-sielboldianin A using a squaramide catalyzed enantioselective bromolactonization reaction}

\section{Renate Kristianslund, a Jørn Eivind Tungen, ${ }^{\text {a }}$ Marius Aursnes, ${ }^{a}$ Carl Henrik} Grrbitz $^{\mathrm{b}}$ and Trond Vidar Hansen

aSchool of Pharmacy, Department of Pharmaceutical Chemistry, Oslo, Norway. ${ }^{b}$ Department of Chemistry, University of Oslo, Norway.

The bisabol derived sesquiterpene sielboldianin A (1) was isolated from the stem bark of Fraxinus sielboldiana in 2011.1 The relative configuration was determined by a NOE difference experiment, while the absolute configuration was proposed on the basis of biogenetic consideration. This is the first report of a sesquiterpene in the Fraxinus genus. Fraxinus sielboldiana Blume (Oleaceae) is a folk medicine with diuretic, antifebrile, analgesic and anti-rheumatic activities

One of the key steps in our synthesis towards 1 is the organocatalyzed enantioselective bromolactonization of the unsaturated carboxylic acid 3 using squaramide catalyst 5.2 This method produced bromolactone 4 with the new stereogenic center installed in $90 \%$ enantiomeric excess and $91 \%$ yield. Our synthesis of the suggested structure of 1 is presented, that enabled the establishment of the absolute configuration of naturally occuring 1 to be $(+)$-sielboldianin $\mathrm{A}$.

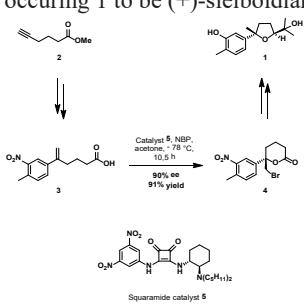

References:

[1]. Lin S, Zhang Y.-L, Liu M.-T, Zi J.-C, Gan M.-L, Song W.-X, Fan X.-N, Wang S.-J

Yang Y.-C, Shi J.-G (2011). Acta Pharm. Sin. B. 2: 89.

[2]. Aursnes M, Tungen J. E, Hansen T. V (2016). J. Org. Chem.: 81, 8287. 


\section{P25 - Identification of novel natural products chemotypes} of Hedgehog-dependent tumors inhibitors

Silvia Corradi a,b, Francesca Ghirga ${ }^{a}$, Mattia Moria ${ }^{\mathrm{a}}$, Cinzia Ingallina ${ }^{\mathrm{b}}$, Simone Berardozzi $^{\mathrm{a}, \mathrm{b}}$, Elisa De Paolis ${ }^{\mathrm{a}, \mathrm{b}}$, Lucia di Marcotullio ${ }^{\mathrm{c}}$, Romina Alfonsi ${ }^{\mathrm{b}}$, Bruno Botta ${ }^{\mathrm{b}}$ Deborah Quaglio ${ }^{\mathrm{b}}$

${ }^{a}$ Center for Life Nano Science@Sapienza, Istituto Italiano di Tecnologia, Rome, Italy ${ }^{b}$ Department of Chemistry and Technology of Drugs, Sapienza University, Rome, Italy ${ }^{\text {'Department }}$ of Molecular Medicine, Sapienza University, Rome, Italy

Hedgehog $(\mathrm{Hh})$ signalling is a morphogenetic pathway that has a crucial role during embryonic development and tissues homeostasis. Aberrant activation of the $\mathrm{Hh}$ pathway occurring either by ligand-dependent or -independent mechanisms is deeply involved in tumorigenesis. In vertebrates, one of the main upstream transducers of the Hh signalling is the transmembrane receptor Smoothened (Smo). For this reason, this receptor is a validated target for the development of anticancer compounds, as underlined by the FDA-approved Smo antagonist Vismodegib (GDC-0449/Erivedge for the treatment of basal cell carcinoma.[1] However, despite an initial clinical response, a number of drug-resistant Smo mutations have emerged during treatmen with Vismodegib. For this reason, the development of new effective Hh inhibitors represents a major challenge for cancer therapy.

Here, starting from an in house library of natural and synthetic or semi-synthetic compounds, we discovered novel chemotypes of Hh inhibitors (Smo antagonists) by mean of virtual screening against the crystallographic structure of Smo. We identified seventeen potential Smo antagonists, which show a noticeable range of chemical diversity and sources. Hh functional based assay identified the chalcone derivative 12 as the most effective $\mathrm{Hh}$ inhibitor within the test set. The synthetic compound 12 is endowed with a natural scaffold, namely chalcone, and has been synthesized by Claisen-Schmidt reaction[2]. The chalcone 12 binds the Smo receptor and promotes the displacement of Bodipy-Cyclopamine in both Smo WT and drug-resistant Smo mutant. Our molecule stands as a promising Smo antagonist, able to specifically impai the growth of Hh-dependent tumor cells in vitro and in vivo and potentially overcome the associated drug resistance.[3]

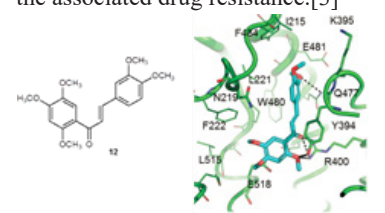

References:

[1]. Sekulic A, Migden MR, Oro AE, Dirix L, Lewis KD, Hainsworth JD, Solomon JA, Yoo S, Arron ST, Friedlander PA, Marmur E, Rudin CM, Chang AL, Low JA Mackey HM, Yauch RL, Graham RA, Reddy JC, Hauschild A (2012). N Engl J Med 366: $2171-2179$

[2]. Sogawa S, Nihro Y, Ueda H., Miki T, Matsumoto H, Satoh T (1994). Biol Pharm Bull 17: 251-256.

[3]. Infante P, Alfonsi R, Ingallina C, Quaglio D, Ghirga F, D'Acquarica I, Di Magno L, Canettieri G, Screpanti I, Gulino A, Botta B, Mori M, Di Marcotullio L (2016). Cell Death \& Disease 7: e2376.

P26 - Total synthesis based on the originally claimed structure of mucosin

Simen G. Antonsen a , Harrison C. Gallantree-Smitha, Carl H. Görbitz ${ }^{\text {b }}$, Trond V. Hansen $^{\text {a,c }}$, Yngve H. Stenstrøma ${ }^{\text {, Jens M. J. Nolsøe }}{ }^{\text {a }}$

${ }^{\mathrm{a} F a c u l t y}$ of Chemistry, Biotechnology and Food Science, NMBU, P.O. Box 5003, NO-1430 ̊̊s, Norway

${ }^{b}$ Department of Chemistry, University of Oslo, PO box 1033, 0315 Oslo, Norway

'Department of Pharmaceutical Chemistry, University of Oslo, PO box 1068, 0316 Oslo, Norway

We describe the first total synthesis aimed at the naturally occurring eicosanoid bicycle mucosin (Figure 1). By devising a practical route, we have explored issues relating to the previous assignment of stereochemistry. In particular, X-ray crystallography on a late stage intermediate allowed us to delve into the topological relationship claimed to be displayed by the featured bicyclo[4.3.0]non-3-ene scaffold.

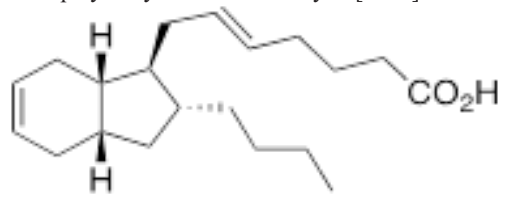

Figure 1. Claimed structure of the marine natural product mucosin References:

[1]. Casapullo, A.; Scognamiglio, G.; Cimino, G. Tetrahedron Lett. 1997, 38, 3643

[2]. Gallantree-Smith, H. C.; Antonsen, S. G.; Görbitz, C. H.; Hansen, T. V.; Nolsøe, J.

M. J.; Stenstrøm, Y. H. Org. Biomol. Chem. 2016, 14, 8433.
P27 - Optimization of tryptophanol-derived oxazoloisoindolinones: chemical scaffold with interesting anticancer properties

Valentina Barcherinia, Sara Gomes ${ }^{\mathrm{b}}$, Margarida Espadinha ${ }^{\mathrm{a}}$, Joana Loureiro ${ }^{\mathrm{b}}$, Alexandra M.M. Antunes ${ }^{\mathrm{c}}$, Lucília Saraiva ${ }^{\mathrm{b}}$, Maria M.M. Santos ${ }^{\mathrm{a}}$

aiMed.Ulisboa, Faculty of Pharmacy, Universidade de Lisboa, Lisboa, Portugal bUCIBIO/REQUIMTE, Faculdade de Farmácia, Universidade do Porto, Portugal ${ }^{\circ} \mathrm{CQE}$, Instituto Superior Técnico, Universidade de Lisboa, Portugal

The synthesis of enantiopure drugs is of high importance in the field of pharmaceutical industry as well as, in organic synthesis. One methodology to access enantiomerically pure compounds involves the use of an enantiopure starting material, such as an amin acid/ alcohol, an alkaloid or a carbohydrate, that acts as chiral inductor. Starting from the enantiopure aminoalcohol tryptophanol, we have recently developed severa biologically active small molecules.1 Here, we will present our most recent result on the development of (S) and (R)-tryptophanol-bicyclic lactams with anticancer properties. Specifically, the chemical library was obtained through a highly efficient atom economic cyclocondensation reaction of enantiopure tryptophanol with different commercially available $\gamma$-ketoacids. The target compounds were screened as p53 activators using a yeast model, followed by validation of the molecular mechanism of action in human tumor cell lines and in human xenograft mice models.2 The stability profile of this chemical family was also assessed in human liver microsomes and plasma.

Acknowledgments:

This work was supported by FCT (Fundação para a Ciência e a Tecnologia) through iMed.Ulisboa (UID/DTP/04138/2013), fellowship SFRH/BD/96189/2013 (S. Gomes), grant IF/00732/2013 (M.M.M. Santos), and also by the European Union and National Funds under the project PTDC/DTP-FTO/1981/2014-POCI-01-0145-FEDER-016581. References:

[1]. a) Espadinha M, Dourado J, Lajarin-Cuesta R, Herrera-Arozamena C, Gonçalves 537-545; b) Pranco MI, de los Rios C, Santos MMM (2017) ChemMedChem 12 : Molecules 21: 1027-1039.

[2]. Soares J, Raimundo L, Pereira NAL, Monteiro A, Gomes S, Bessa C, Pereira C, Queiroz G, Bisio A, Fernandes J, Gomes C, Reis F, Gonçalves J, Inga A, Santos MMM (2016) Oncotarget 7: 4326-4343; b) Saraiva L, Santos MMM, Pereira NAL, Pereira C, Moreira S, Leão M, Monteiro A, Soares J (2014) PCT/IB2014/062617, WO2014/207688 A1; c) Soares J, Espadinha M, Raimundo L, Ramos H, Gomes AS Gomes S, Loureiro JB, Inga A, Reis F, Gomes C, Santos MMM, Saraiva L (2017) Molecular Oncology 11: 612-627.

P28 - Synthesis and Biology of Jaspamide, Seragamide and Geodiamolide Hybrids

Veselin Nasufovic ${ }^{a}$, F. Küllmera, J. Bößneck ${ }^{a}$, S. Paceb, L.-M. Semmrau ${ }^{\text {, }}$ O. Werz $^{\text {b }}$ H.-D. Arndt ${ }^{\mathrm{a}}$

${ }^{a}$ Friedrich Schiller Universität, Institut für Organische Chemie und Makromolekulare Chemie, Humboldtstr. 10, D-07743 Jena 'Friedrich Schiller Universität,

Institut für Pharmazie, Philosophenweg 14, D-07743 Jena

The family of actin binding cyclodepsipeptides consists of more than 50 natura products.[1] Jaspamides, seragamides, chondramides and geodiamolides feature high structural similarities, like methylated and halogenated amino acids, stereochemistry, and high affinity for binding to the actin.[2] We noticed that not all combinations of features are present in the natural products. Hybrid molecules with alternative combinations could provide useful SAR information in design of actin inhibitors and offer advantages compared to the potentially labile natural scaffolds. Fine tuning of activity, permeability and stability could possibly lead to molecules selective for some certain actin isoforms or cancer cell line.
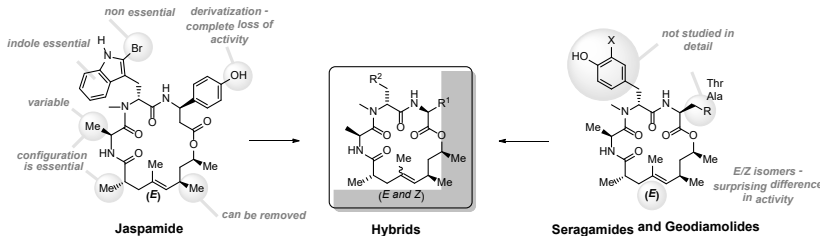

Starting from our previous total synthesis, $[2,3]$ we established synthetic methodology for the synthesis of hybrids and analogs. [4] A focused library of more than 50 compounds was synthesized. Beyond cyclodepsi $\neg$ peptides the corresponding lactan isosters were investigated. Biological profiling showed that some hybrid molecules have significantly lower activity compared to the parent natural products, indicating evolutionary pressure operating during convergent evolution. Systematic structural variations led to highly potent analogs and - importantly - improve our previous SAR models.[2]

References:

[1] J. R. Stehn, N. K. Haass, T. Bonello, M. Desouza, G. Kottyan, H. Treutlein, J. Zeng, P. R. B. B. Nascimento, et al., Cancer Res. 2013, 73, 5169-5182

[2] R. Tannert, L. G. Milroy, B. Ellinger, T. S. Hu, H. D. Arndt, H. Waldmann, J. Am. Chem. Soc. 2010, 132, 3063-3077;

[3] H.-D. Arndt, S. Rizzo, C. Nöcker, V. N. Wakchaure, L.-G. Milroy, V. Bieker, A. Calderon et al., Chem. - A Eur. J. 2015, 21, 5311-5316.

[4] V. Nasufovic, F. Küllmer, J. Bößneck, L.-M. Semmrau, O. Werz, H.-D. Arndt, manuscript in preparation. 


\section{P29 - Marine alkaloid oroidin analogues as novel human Topoisomerase II inhibitors}

\section{Žiga Skok, Nace Zidar, Martina Durcik, Janez Ilaš}

Department of Pharmaceutical Chemistry, Faculty of Pharmacy, University of Ljubljana, Aškerčeva 7, SI-1000 Ljubljana, Slovenia

DNA topoisomerases comprise an important family of enzymes that catalyze the induction of topological changes in the DNA molecule which makes them play vital roles in processes like replication, transcription, chromosome separation and segregation, and thus represent an important collection of design targets for novel anticancer drugs. 1 Because of the similarity of ATPase domain with DNA Gyrase, Hsp90, histidine kinase and MutL proteins, human DNA topoisomerase II belongs to the GHKL protein superfamily.2 Based on that fact we predicted that known ATP-competitive DNA-gyrase inhibitors could be used as a starting point in design of new human DNA topoisomerase II inhibitors. Faculty of Pharmacy in Ljubljana possesses a library of about 800 ATP-competitive DNA-gyrase based on the structure of marine alkaloid oroidin, isolated from Agelas sponges, which shows antibacterial activity. 3 We selected 132 compounds from that library and screened them for their human DNA topoisomerase II inhibitory activity using Inspiralis human DNA topoisomerase relaxation assay. We identified 13 hits in micromolar affinity range and predicted their binding poses using molecular docking (Maestro by Schrödinger). One of the hit compounds also shows antiproliferative activity on MCF-7 breast cancer cell line. The goal of future research is to optimize the structure of hit compounds into a promising lead compound. Our optimization strategy includes synthesis of lower molecular mass analogues of our original hits in order to find new inhibitors with a better ligand efficiency which would potentially provide us with more optimizable leads. would potential
References:

[1]. Pogorelčnik B, Perdih A, Šolmajer T (2013). Curr Med Chem 20: 694-709.

[2]. Dutta, R.; Inouye, M. (2000). Trends Biochem Sci 25: 24-28.

[3]. Tomašič T, Katsamakas S,2, Hodnik Ž, Ilaš J, Brvar M, Solmajer T, Montalvão S, Tammela P, Banjanac M, Ergović G, Anderluh M, Peterlin Mašič L, Kikelj D (2015). J Med Chem 58: 5501-5521. 


\section{COST ACTION CM1407 4th Meeting}

21 e 22 September | 21 a 22 Setembro

Lisbon U. Lusofona's | Lisboa - Universidade Lusófona

\section{Scientific Commitee /Comissão Científica}

Bruno Botta

Sandra Liekens

Markus Kalesse

Juana Díez

Milica Pešić

Gunter Schneider

Mark Brönstrup

Daniele Passarella

Mattia Mori

Michael S. Christodoulou

Patrícia Rijo

\section{Organizing Commitee /Comissão Organizadora}

Patrícia Rijo, CBIOS - ULHT

Maria M. M. Santos

Maria José U. Ferreira

Carlos M. Monteiro

Marisa Nicolai

Paula Pereira

Filipa Marcelo

Catarina Garcia

Joana Marçalo

Luís Roque

Valentina Barcherini

Margarida Espadinha

Elizabeth Lopes

Joana Pereira

Carolina Oliveira

Ricardo Ferreira

David Cardoso

Svilen Simenov

Ângelo Rocha

Escola de Ciências e Tecnologias da Saúde (ECTS) da U. Lusófona de Humanidades e Tecnologias

ALIES - Associação Lusófona para o Desenvolvimento do Ensino e Investigação das Ciências da Saúde

CBIOS - Centro de Investigação em Biociências e Tecnologias da Saúde

\section{Program /Programa}

21 September | 21 de Setembro

Open Session | Sessão de abertura

L. Monteiro Rodrigues

Patrícia Rijo

Bruno Botta

1st Session |Sessão 1

Charmain | Moderador - Maurizio Botta

Speakers | Prelectores

Carlos A. M. Afonso

Javier Sánchez-Céspedes

Milica Pešić

2st Session |Sessão 2

Charmain | Moderador - Daniele Passarella

Speakers | Prelectores

Jose Prieto

Maurizio Botta

Christoph Wiesner

Ricardo J. Ferreira

3st Session |Sessão 3

Charmain | Moderador - Milica Pešić

Speakers | Prelectores

Peter Näf

María Cecilia Carpinella

Stephen J. Fey

Yves Mély

22 September | 22 de Setembro

4st Session |Sessão 4

Charmain | Moderador - Maria M. M. Santos

Speakers | Prelectores

Rafael Antunes

Maria Cristina de Rosa

Máté Vágvölgyi

Vittorio Pace

5st Session |Sessão 5

Charmain | Moderador - Markus Kalesse

Speakers | Prelectores

Al-Jamal Khuloud

Yngve H. Stenstrøm

Vasile I. Parvulescu

Sanja Glisic

6st Session |Sessão 6

Charmain | Moderador - Sandra Liekens

Speakers | Prelectores

Nuno Candeias

Wolfgang Link

Daniel Lucena-Agell

Yusuf Tutar

Elisa De Paolis 


\title{
1st Session |Sessão 1
}

\section{Synthetic Valorization of Bio renewable Resources}

\author{
Speaker / Prelector
}

\section{Carlos A. M. Afonso}

Abstract / Resumo da Comunicação

Due to the reduction of fossil resources for energy consumption and platform chemicals for different purposes, several building blocks derived from renewable resources such as ethanol, glycerol, lactic acid, furfural, succinic acid, levulinic acid, are already in use or considered with potential importance in the near future. Among them, 5-hydroxymethyl-furfural (HMF) has been considered a very promising intermediate building block due to its potential rich chemistry that allows different transformations such as to biofuels, polymer monomers, levulinic acid, adipic acid, caprolactam and caprolactone and many other more specific molecules. In line with our interest in the valorization of natural resources, will be described recent achievements from this laboratory on the production of HMF, transformation of HMF and furfural to several building blocks and the synthetic modification of other isolated natural products.

\section{Anti-HAdV drug discovery and development}

\section{Speaker / Prelector}

\section{J Sánchez-Céspedes}

Abstract / Resumo da Comunicação

Background: Despite its clinical impact, currently there are no approved drugs to treat HAdV infections. Our strategy for the identification of hit compounds, as the first step in the development of new anti-HAdV drugs, can be divided in four lines of work: i) high-throughput screening of synthetic small molecule libraries to identify compounds that restrict HAdV infection [1,2]; ii) Screening of libraries of extracts and characterized marine natural products; iii) repurposing drugs approved for other indications; and iv) proteomics of HAdV isolated chromatin segments (PvICh) to identify potential targets for the design of a new family of host-directed antiviral drugs [3].

Material and Methods: Inhibition of HAdV infection by any of the compounds assayed was evaluated by plaque assay and qPCR. Following different approaches, hit compounds were further evaluated to gain some mechanistic understanding for inhibition. Purification of the HAdV chromatin-associated protein complexes (PvICh) was based on nucleic acid probe hybridization to the DNA moieties present in formaldehyde-crosslinked chromatin and on the use of HAdV specific locked nucleic acids (LNA) containing oligos.

Results: i) Until now, 16 piperazine derivatives showing significant inhibition of HAdV infection at low micromolar concentration and targeting DNA transcription, replication and later steps in HAdV replication cycle have been identified; ii) Among the 50 marine extracts evaluated, nine of them showed significant anti-HAdV activity with IC50 ranging from 0.06 to $0.16 \mathrm{mg} / \mathrm{ml}$ and no cytotoxicity; iii) The salicylanilide anthelmintic drugs niclosamide, oxylozanide and rafoxanide showed potent anti-HAdV activities at low micromolar concentrations, exhibiting no cytotoxicity at those concentrations and presenting different mechanism of action; iii) Forty-eight proteins have found to be associated with the promoter of the HAdV E1A gene. Among them, we found HAdV-associated proteins (DBP, E1B, E2A), proteins involved in the host chromatin organization (H2A, H2B, H3.1, H4, SETD2), host replication and transcriptional-associated proteins (DNA helicase B, polyubiquitin-C, TAFII68, EF-1A/2), or proteins involved in the immune response (HNP1, proteins S100-A7/A8).

Conclusions: i) The piperazine derivatives have proven to be significant and broad-spectrum inhibitors of DNA replication. They could represent hit candidates for the development of a new class of antiviral compounds; ii) The marine extracts might represent a potential source of new classes of antiviral drugs. Next step in their development will be the identification of the specific molecules involved in this antiviral activity; iii) Niclosamide, oxyclozanide and rafoxanide represent strong candidates to be further evaluated in an animal model of HAdV infection to prove their efficacy and safety; iv) PICh could be a useful approach to unravel the complex events involved in viral DNA replication, as well as a promising tool for the identification of host targets to design a new generation of antiviral drugs.

References:

[1] Sanchez-Cespedes J, Moyer CL, Whitby LR, Boger DL, Nemerow GR. Inhibition of adenovirus replication by a trisubstituted piperazin-2-one derivative. Antiviral Res. 2014, 108:65-73.

[2] Sánchez-Céspedes J, Martínez-Aguado P, Vega-Holm M, Serna-Gallego A, Candela JI, Marrugal-Lorenzo JA, Pachón J, Iglesias-Guerra F and Vega-Pérez JM. New 4-acyl-1-phenylaminocarbonyl-2-phenylpiperazine derivatives as potential inhibitors of adenovirus infection. Synthesis, biological evaluation and structure-activity relationships. J Med Chem. 2016, 59:5432-5448.

[3] Déjardin J and Kingston RE. Purification of Proteins Associated with Specific Genomic Loci. Cell. 2009, 136:175-186.

\section{Dual inhibitors in cancer treatment}

\section{Speaker / Prelector}

\section{Milica Pešić}

Abstract / Resumo da Comunicação

Typically, new drug design is based on the knowledge of a biological target. The commonly utilized standard in pharmaceutical industry is "one target - one drug - one disease". The main idea behind this approach is that modulation of a single biomarker will achieve a therapeutic benefit. Selective drugs used in cancer research eradicate tumors more specifically, reducing side effects in normal cells. However, the inhibition of a single target often shows transient efficacy due to the development of drug resistance. Knowing that cancers are heterogeneous entities, the simultaneous intervention on multiple targets is necessary to obtain the optimal effect.

One way to achieve the simultaneous blockage of two or multiple targets is combination chemotherapy. However, two or more drugs likely exhibit different pharmacokinetic profiles and metabolic stabilities. In addition, combination chemotherapy may produce adverse drug-drug interactions. An alternative strategy to overcome these problems is to suppress two or multiple targets with a single drug. In cancer research, several targeted drugs were approved for clinical application such as imatinib, gefitinib and trastuzumab. Although developed as single target drugs, they possess diverse mechanisms of action that include inhibition of several molecules involved in signaling transduction. This could be the reason for their success in clinical application.

Herein, we present our current studies on small molecule inhibitors that possess specific targets (c-Src kinase, Carbonic Anhydrase IX and XII, $\beta$-tubulin) but at the same time inhibit P-glycoprotein activity in multidrug resistant cancer cells. In addition, we discuss the challenges and the potential of dual inhibitors in cancer treatment. 


\title{
2st Session |Sessão 2
}

\section{Artificial Intelligence and Statistic tools to predict, find and interpret the bioactivities of complex natural products}

\author{
Speaker / Prelector
}

\section{Jose Maria Prieto}

\section{Abstract / Resumo da Comunicação}

Complex Chemical Entities (CCE) include natural products such as Herbal crude extracts, herbal semi purified fractions and Essential oils (EOs). These are vastly used as active principles (APIs) of medicinal products in both Clinical and Complementary/Alternative Medicine. In the food industry, they add 'functionality' to many nutraceuticals. However, the intrinsic variability of their composition and synergisms and antagonisms between major and minor components makes difficult to ensure consistent effects through different batches.

The use of Artificial Neural Networks (ANNs) for the modelling and/or prediction of the bioactivity of CCE as a substitute of laboratory tests has been actively explored during the last two decades. Similarly, advanced statistical methods are also gaining a preponderant role in extracting information from complex numerical matrices (Multiple regression and cluster analysis) [1].

Prediction of antioxidant and antimicrobial properties of natural products have been a common target for researchers. We successfully achieved this by modelling the chemistry of CCE in ANNs [2,3]. The accuracy of the predictions seems to be limited only by the inherent errors of the modelled tests and the lack of international agreements in terms of experimental protocols. However, with sufficient accumulation of suitable information, ANNs can become reliable, fast and cheap tools for the prediction of anti-inflammatory, antioxidant, antimicrobial and anti-inflammatory activities, thus improving their use in medicine and nutrition [1].

Finding active principles in CCE is a similarly big challenge. Multiple regression analysis could reveal 6 active compounds from 22 EOs with Acetylcholinesterase inhibitory activity [4].

Interpretation of the mode of use of CCE by other Medical Systems may lead to new medicines underpinned by molecular pharmacology. By applying cluster analysis, we could understand patterns between their Traditional Chinese Attributes and their differential inhibition of lipid peroxidation and / or eicosanoids release [5].

References:

[1] Jose M. Prieto. Artificial intelligence for the modelling and prediction of the bioactivities of complex natural products. In Artificial Intelligence: Advances in Research and Applications. Ed. Luiz Rabelo. 2017. Nova Science Publishers, Inc. NY.

[2] Mathieu Daynac, Alvaro Cortes-Cabrera, Jose M. Prieto. 2015. Application of Artificial Intelligence to the Prediction of the Antimicrobial Activity of Essential Oils. Evidence-Based Complementary and Alternative Medicine, Article ID 561024, 9 pages.

[3] Alvaro Cortes Cabrera, Jose M. Prieto. 2010. Application of artificial neural networks to the prediction of the antioxidant activity of food additives: the case of essential oils. Food Chemistry 118(1): 141-146.

[4] Tugba Ucar. 2016. Essential Oils for the Inhibition of Acetylcholinesterase: A Critical Appraisal Applying Multiple Regression Analysis and Artificial Intelligence Tools. MSc dissertation, University College London.

[5] Jose M Prieto, Guillermo R. Schinella. 2017. Multivariate analysis reveals a link between traditional characters of Chinese herbal medicinal drugs and their molecular anti-lipoperoxidative properties. Oxidative Medicine and Cellular Longevity (submitted).

\section{Novel fungal chitinase inhibitors and their possible use in Drug Discovery}

\section{Speaker / Prelector}

\section{Maurizio Botta}

Abstract / Resumo da Comunicação

In the last ten years, we identified and developed a new therapeutic class of antifungal agents, the macrocyclic amidinoureas.1-7 These compounds are active against several Candida species, including clinical isolates resistant to currently available antifungal drugs. We identified the Chitinase enzyme as target for these compounds thanks to an in-silico target fishing procedure, and biological evaluation highlights a strong inhibition of this enzyme. The significant activity they show against azole-resistant strains makes these compounds play a key role in the fight against antifungal resistance.

References:

[1]. Maccari G, Deodato D, Fiorucci D, Orofino F, Truglio G I, Pasero C, Martini R, De Luca F, Docquier J D, Botta M (2017). Bioorg Med Chem Lett 27 (15): 3332-3336.

[2]. Deodato D, Maccari G, De Luca F, Sanfilippo S, Casian A, Martini R, D'Arezzo S, Bonchi C, Bugli F, Posteraro B, Vandeputte P, Sanglard D, Docquier J. D, Sanguinetti M, Visca P, Botta M (2016). J Med Chem 59 (8): 3854-3866.

[3]. Sanfilippo S, Posteraro B, Sanguinetti M, Botta M, Maccari G, De Luca F, Docquier J. D, Deodato D (2014). WO2014/202697.

[4]. Sanguinetti M, Sanfilippo S, Castagnolo D, Sanglard D, Posteraro B, Donzellini G, Botta M (2013). ACS Med Chem Lett 4 (9): $852-857$.

[5]. Manetti F, Castagnolo D, Raffi F, Zizzari A. T, Rajamaki S, D'Arezzo S, Visca P, Cona A, Fracasso M. E, Doria D, Posteraro B, Sanguinetti M, Fadda G, Botta M (2009). J Med Chem 52 (23): 7376-7379.

[6]. Botta M, Raffi F, Visca P (2009). WO2009/113033

[7]. Dreassi E, Zizzari A. T, D'Arezzo S, Visca P, Botta M (2007). J Pharm Biomed Anal 43 (4): 1499-1506. 


\title{
2st Session |Sessão 2
}

\section{Innovative cancer models for pre-clinical drug discovery}

\author{
Speaker / Prelector
}

\section{Christoph Wiesnera}

Abstract / Resumo da Comunicação

With approximately 8.8 million deaths in 2015 cancer represents the second leading cause of mortality worldwidel. One defining feature of cancer is the development of tumors from single cells that begin to proliferate abnormally and to grow beyond their usual boundaries, invade adjoining parts of the body and spread to other organs (metastasis)2. Disruption of tightly regulated processes such as cell cycle, cell adhesion, cell differentiation, migration and cell death are predominant in cancer development.

Although the pharmaceutical industry spent millions of Euros on the research for new, more effective drugs, the attrition rates in clinical development are still very high. This clinical failure can be, at least partially, attributed to a lack of clinical efficacy, indicating a strong need for highly predictive test systems for the screening of new therapeutic drugs3.

Our research at the IMC Krems focuses on the establishment of innovative test systems for the rapid identification and optimization of novel synthetic or biological drug candidates and the discovery of drug targets and biomarkers. We are developing high-content in vitro disease models for hit identification and hit to lead optimization. At present, our portfolio consists of cell- and tissue based models for cancer, immune disorders, leaky gut syndrome and skin diseases4- 7.

For cancer screening, two-dimensional cell culture models (2D) on plastic, filter inserts or gold film electrodes (impedance measurement) are established to provide basic information on cytotoxicity, cell proliferation, (de)differentiation, cell migration and penetration in high throughput assays. For a better physiological screening, three-dimensional (3D) tissue models, including homo- and heterotypic spheroids, that mimic in vivo conditions and the functions of living tissue more accurately, are developed. To discriminate between the different cells types in heterotypic tumors, stroma cells such as endothelial cells, fibroblasts and/or diverse immune cells were stable transfected with different reporter constructs GFP) and heterotypic spheroids were developed. The novel test system has been successfully established to study tumor cell proliferation, invasion, response to toxicants (induction of cellular apoptosis), and can be used for various other applications8-11. These methods are compatible with automated high-throughput screening or bio-imaging and high-content phenotype-based drug discovery. To facilitate the identification of promising druggable targets, we are currently establishing a large panel of pathway-specific reporter cell lines allowing the evaluation of specific signaling pathways in tumor spheroids.

In summary, these sensitive and reproducible test systems permit an imaged based screening of morphological changes (e.g. cellular differentiation, migration, gene expression), predict in vitro toxicity, and suggest pathways or molecular targets (pathway profiling) of novel compounds and are therefore a useful tool to elucidate the mode of action of new lead compounds.

References:

[1]. Ferlay J, Soerjomataram I, Ervik M, Dikshit R, Eser S, Mathers C et al. (2012). IARC CancerBase No. 11.

[2]. A. Eger, W. Mikulits (2005). Drug Discov. Today 2: 57-63

[3]. Riedl A, Schlederer M, Pudelko K, Stadler M, Walter S, Unterleuthner D, et al. (2017). J Cell Sci.:1;130(1):203-218.

[4]. Hundsberger H, Koppensteiner A, Hofmann E, Ripper D, Pflüger M, Stadlmann V, et al. (2017). SLAS Discov. 1:2472555217697435.

[5]. Pretsch A, Nagl M, Schwendinger K, Kreiseder B, Wiederstein M, Pretsch D et al. (2014). PLoS One. ;9(6): e97929.

[6]. Pflüger M, Kapuscik A, Lucas R, Koppensteiner A, Katzlinger M, Jokela J et al. (2013). J Biomol Screen. 2013 Jan;18(1):67-74.

[7]. Wiesner C, Pflüger M, Kopecky J, Stys D, Entler B, Lucas R. et al. (2008). GMS Krankenhhyg Interdiszip. 11;3 (1).

[8]. Kreiseder B, Holper-Schichl YM, Muellauer B, Jacobi N, Pretsch A, Schmid JA, et al. (2015) PLoS One. 20;10(3):e0119402.

[9]. Genov M, Kreiseder B, Nagl M, Drucker E, Wiederstein M, Muellauer B, et al. (2016). J Cancer. 12;7(5):555-68.

[10]. Kreiseder B, Orel L, Bujnow C, Buschek S, Pflueger M, Schuett W, et al. (2013). Int J Cancer 1;132(3):521-30.

[11]. Amatschek S, Lucas R, Eger A, Pflueger M, Hundsberger H, Knoll C, et al. (2011). Br J Cancer. 1;104(3):469-79.

\section{Flavonoids as efflux modulators for $\mathrm{ABC}$ transporters: useful building blocks towards the development of novel multidrug resistance reversal agents}

\section{Speaker / Prelector}

\section{Ricardo J. Ferreira}

\section{Abstract / Resumo da Comunicação}

IMultidrug resistance (MDR) to anticancer drugs, due to the over-expression of efflux pumps of the ABC transporters superfamily as P-glycoprotein (P-gp), multidrug-resistance protein 1 (MRP1) and breast cancer resistance protein (BCRP), is considered one of the most reported mechanisms by which cancers cells can decrease the success rates of current chemotherapeutics regimens. Together with the development of novel selective efflux modulators for P-gp, MRP1 and BCRP, the development of small molecules able to simultaneously modulate more than one efflux pump is also an attractive strategy.

Aiming at developing novel modulators towards the most prominent efflux pumps in MDR, a flavanone was used as building block to obtain novel derivatives in which nitrogen atoms and aromatic rings were added as an attempt to improve its MDR reversal properties. While propanolamine derivatives were found to be active as P-gp modulators, hydrazones, azines, hydrazides or thiosemicarbazones also allowed the development of efflux modulators active in P-gp but also in MRP1 and BCRP. In addition, our results showed that while selective efflux modulation could be achieved for each pump, some compounds additionally modulated drug efflux in more than one $\mathrm{ABC}$ transporter.

New structure-activity relationships from ligand- and structure-based approaches allowed the identification of which structural features were intimately related with the selective inhibition of each efflux pump. At the end, this work provides a proof of concept that the flavanone core can be used as a suitable scaffold for developing new MDR modulators against the most important members related with overexpression of ABC transporters in cancer cells. Acknowledgements

We thank the Fundação para a Ciência e Tecnologia (FCT) for financial support through projects PTDC/QEQ-MED/0905/2012 and UID/DTP/04138/2013. Ricardo Ferreira acknowledges FCT for the PhD grant SFRH/BD/84285/2012. 


\title{
3st Session |Sessão 3
}

\section{Active Natural Substances and Materials: Isolation and Purification Workflow}

\author{
Speaker / Prelector
}

\section{Peter Näf}

\section{Abstract / Resumo da Comunicação}

The presentation will cover the topic of a typical workflow for the isolation and purification of interesting natural compounds. A main focus is dedicated to the process for the isolation of individual cannabinoids for medical and recreational use. Moreover the three main production steps are covered. These steps are the extraction, the evaporation and the separation of the compounds. Additionally theory and interesting, natural compound related applications can be highlighted.

\section{Bioprospecting Argentinian plants as source of potential drug candidates}

Speaker / Prelector

\section{María Cecilia Carpinella}

Abstract / Resumo da Comunicação

For thousands of years plants have played a key role in the treatment of a wide range of diseases being an excellent reservoir of biologically active compounds with a significant contribution to chemotherapy. The exceptional structural diversity of plant-derived metabolites offers a great range of possibilities for finding novel pharmacologically active compounds with high effectiveness and selectivity.

Even when many compounds with medicinal properties have been obtained from the flora from Argentina, this resource is far from being completely explored. As part of our continuing search for drug candidates, a panel of extracts and bioactive metabolites obtained from native and naturalized plants from central Argentina were screened in order to determine their cytotoxic effect, the multidrug-resistance reversing potential in sensitive and P-gp-overexpressed cell lines and the tyrosinase inhibitory activity. The inhibition on growth of sensitive and resistant pathogenic bacteria was also investigated. The most effective principles were further studied in view of determining their modes of action. In addition, derivatives of these compounds were obtained with some of them showing improved activity in relation to the lead molecules.

\section{Tissue-mimetic 3D cultures can determine the commercial potential of natural products and their derivatives}

Speaker / Prelector

\section{Stephen J. Fey}

\section{Abstract / Resumo da Comunicação}

The commercial potential of natural products is mainly determined by two reciprocally independent factors: their efficacy to treat ailments and their toxicity [1]. Because cells grown in active 3D spheroid cultures have physiological performance that mimics that seen in human tissues (radically better than 2D cultures), they are ideally positioned to select which derivatives should be developed and which should not [2-6].

Currently, the 3D culture field is highly diverse and expanding rapidly [2]. No single technology can claim supremacy: all have drawbacks and limitations. It is therefore necessary to select which model is used with caution. Each model needs to be carefully validated before it is used to select natural compounds as drug candidates. Not only has the emergence of induced pluripotent stem cells (iPSCs) revealed a surprising level of plasticity in cells, but it is becoming clear that all cells (whether primary, stem or immortal) show this plasticity when exposed to the extracellular matrix, other cell types or even simply the growth media that they are grown in.

In view of this plasticity, two features stand out when selecting a 3D culture system: the system should be stable over 'long' periods (weeks) and it should 'bounce back' when the natural product is removed. Spheroid cultures offer both features [2-6].

References:

[1] J.E. Kristiansen \& S.J. Fey (2017) The Accepted "Clinical Interaction Model" - a special case of reality. Journal of Bioequivalence \& Bioavailability 9(3) 418-423 DOI: $10.4172 /$ jbb. 1000335

[2] K. Wrzesinski \& S.J. Fey (2015). From 2D to 3D - a new dimension for modelling the effect of natural products on human tissue. Current Pharmaceutical Designs. 21(38): 5605-5616.

DOI: $10.2174 / 1381612821666151002114227$.

[3] S.J. Fey \& K. Wrzesinski. Determination of drug toxicity using 3D spheroids constructed from immortalized human hepatocytes (2012) Toxicological Sciences 127(2) 403-411; DOI: 10.1093/toxsci/kfs122

[4] K. Wrzesinski \& S.J. Fey (2013) After trypsinisation, 3D spheroids of C3A hepatocytes need 18 days to re-establish similar levels of key physiological functions to those seen in the liver. Toxicology Research 2(2) 123-135; DOI: 10.1039/C2TX20060K

[5] K. Wrzesinski, et al (2013) Human liver spheroids exhibit stable physiological functionality for at least 24 days after recovering from trypsinisation. Toxicology Research 2(3) 163-172; DOI: 10.1039/C3TX20086H

[6] K. Wojdyla, et al. (2016) Acetaminophen-induced S-nitrosylation and S-sulfenylation signalling in 3D cultured hepatocarcinoma cell spheroids. Toxicology Research 5(2) 905-920, DOI: 10.1039/C5TX00469A 


\title{
3st Session |Sessão 3
}

\section{Calixarenes as potent inhibitors of the nucleic acid chaperone activity of the HIV-1 nucleocapsid protein with a new mechanism of action}

Speaker / Prelector

\section{Yves Mélya}

\section{Abstract / Resumo da Comunicação}

The nucleocapsid protein (NC) is a highly conserved protein that plays key roles in HIV-1 replication through its nucleic acid chaperone properties mediated by its two zinc fingers and basic residues. $\mathrm{NC}$ is a promising target for antiviral therapy, particularly to control viral strains resistant to currently available drugs. Since calixarenes with antiviral properties have been described, we explored the ability of calixarene hydroxymethylphosphonic or sulfonic acids to inhibit NC chaperone properties and exhibit antiviral activity. By using fluorescence- and cell-based assays, we selected four low toxic calixarenes inhibiting NC chaperone activity and HIV-1 infectivity with sub-micromolar IC50 values. These compounds with high therapeutic index were further shown by mass spectrometry, isothermal titration calorimetry and fluorescence anisotropy to bind to NC with no zinc ejection, and to compete with nucleic acids for the binding to NC. Mechanisms of action studies confirmed that NC is their primary target in infected cells. Molecular dynamic simulations further indicated that these compounds interact via their phosphonate or sulfonate groups with the basic surface of NC, but not with the hydrophobic plateau at the top of the folded fingers. Calixarenes form thus a class of non-covalent NC inhibitors, endowed with a new mechanism.

References:

[1]. Amakye D, Jagani Z, Dorsch M (2013). Nat Med 19: 1410-1422.

[2]. Reference two Reference two Reference two Reference two Reference two Reference two Reference two.

[3]. Reference three Reference three Reference three Reference three Reference three Reference three Reference three Reference three Reference three Reference three Reference three Reference three.

\section{4st Session |Sessão 4}

\section{Scientific Management from Drug Discovery to Market}

\section{Speaker / Prelector}

\section{Rafael Antunes}

Abstract / Resumo da Comunicação

The discovery of a new drug is an exciting event, but needs proper management to successfully reach its patients. Fundamental research may identify drug candidates with interesting biological activity but one needs to ask the right questions and take proper action to protect the intellectual property before stepping into the long, expensive and risky stage of applied research and development. What problems are we trying to solve? What other drugs are addressing the same problems? How strong is our IP? What are the steps to market? How much money do we need? When do we need a partner? When do we cut the umbilical cord and license out? These are just a few questions that this lecture will try to address.

\section{An in silico approach to discovering novel inhibitors useful for the treatment of autoimmune diseases}

\author{
Speaker / Prelector
}

\section{Maria Cristina De Rosa}

Abstract / Resumo da Comunicação

Autoimmune diseases are characterized by the dysfunction of T-cells which erroneously react against the body's own tissues, leading to their damage. The interaction of the T-cell receptors (TCRs), located on the surface of T-cells and MHC-peptide complexes on the targeted tissues, lead to these unwanted immune responses. Current therapies for autoimmune disorders are non-selective and are associated with limited clinical efficacy and significant side effects [1]. The protein-protein interactions (PPIs) between TCR and autoantigen in complex with MHC can serve as targets for the development of new drugs against autoimmune diseases that may selectively block only the immune response to the self antigen, while leaving the rest of the immune system response intact and efficient. With this aim, we worked out a novel strategy based on the development of a structural model of the TCR/MHCII-peptide interface and on in silico virtual screening. The feasibility of our method was demonstrated by its application to rheumatoid arthritis which led to the patenting of new and potent small molecules that are able to interfere with the TCR/collagenII-HLA-DR4 interaction, representing the first compounds to show activity against these specific PPIs [2]. These inhibitors open new possibilities in the treatment of rheumatoid arthritis and preclinical studies are being pursued. References:

[1]. Balagué C, Kunkel SL, Godessart N (2009). Drug Discov Today 14: 926- 934.

[2]. De Rosa MC, Ria F, Giardina B, Ferraccioli G, Pirolli D, Nicolò C Patent US2017204059 


\title{
4st Session |Sessão 4
}

\section{Flow chemical synthesis of a new antitumor ecdysteroid lactam through Beckmann rearrangement}

\author{
Speaker / Prelector
}

\section{Máté Vágvölgyi}

Abstract / Resumo da Comunicação

The discovery of a new drug is an exciting event, but needs proper management to successfully reach its patients. Fundamental research may identify drug candidates with interesting biological activity but one needs to ask the right questions and take proper action to protect the intellectual property before stepping into the long, expensive and risky stage of applied research and development. What problems are we trying to solve? What other drugs are addressing the same problems? How strong is our IP? What are the steps to market? How much money do we need? When do we need a partner? When do we cut the umbilical cord and license out? These are just a few questions that this lecture will try to address.

\section{An in silico approach to discovering novel inhibitors useful for the treatment of autoimmune diseases} Speaker / Prelector

\section{Maria Cristina De Rosa}

Abstract / Resumo da Comunicação

Ecdysteroids are well known for their complex biological functions in Nature, including their various mild, non-hormonal beneficial bioactivites in mammals. [1] Potent chemo-sensitizing activity of less polar ecdysteroid derivatives towards various cancer cell lines was discovered by our research group, and has been studied since.[2-4]

Our recent results indicated a remarkably strong MDR selective chemo-sensitizing potential for a new lactam derivative (2) that does not interfere with the efflux function of P-gp. This compound can be obtained via Beckmann-rearrangement from the corresponding (6E)-oxime (1), but the batch preparation gives only a very poor (ca. $8 \%$ ) yield.
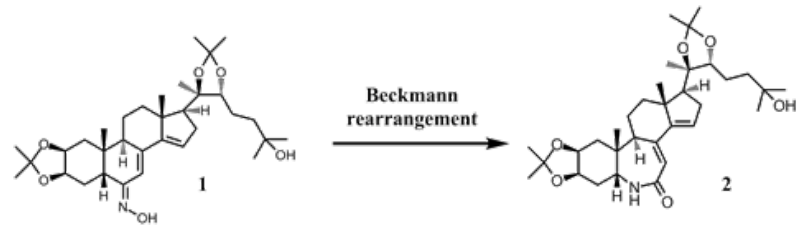

Easy optimization and scale-up, as well as safe reaction conditions are all among the advantages of flow chemical synthesis, making it a highly useful technique for the preparation of novel drug candidates. Thus, a COST STSM was carried out to study the possibilities of performing the above Beckmannrearrangement through flow chemical solutions. During our work, we step-by-step investigated a large scale of parameters including the role of the solvent, reagent, pressure, temperature, residence time and concentration, in order to identify the experimental conditions with the highest conversion and selectivity towards compound 2 .

To the best of our knowledge, this work was the first attempt to carry out flow chemistry utilized modification on the ecdysteroid B ring. As a result of our efforts, a great improvement was achieved in the yield of compound 2 (ca. $>90 \%$ ) with a total conversion of the substrate. The utilized method is simple, fast, and requires no acid catalyst in contrast with most Beckmann-reactions. Additionally, foundations of a new international cooperation were established with the support of COST.

\section{Acknowledgements:}

M.V. was supported by a Short-Term Scientific Mission (STSM) Grant from COST Action CM1407 “Challenging organic syntheses inspired by nature - from natural products chemistry to drug discovery”. This work was supported by the NKFIH, Hungary (K119770). A.H. acknowledges the János Bolyai fellowship of the Hungarian Academy of Sciences and the Kálmán Szász Prize.

References:

[1] Lafont R \& Dinan L. J Insect Sci 2003; 3:7.

[2] Martins A et al. J Med Chem 2012; 55: 5034-5043.

[3] Martins A et al. Biomed Res Int 2015; ID 895360.

[4] Hunyadi A et al. Molecules 2017; 22, 199. 


\title{
4st Session |Sessão 4
}

\section{Building-up molecular complexity with carbenoids: new vistas in homologation chemistry}

\author{
Speaker / Prelector
}

\section{Vittorio Pace}

\section{Abstract / Resumo da Comunicação}

Homologation chemistry with carbenoid reagents represents nowadays an established tool for synthetic chemists with focus on medicinal applications. ${ }^{1}$ As documented in recent work by our group, these reagents enable the construction of a new functionalized C-CH2X bond through a single synthetic operation thus, making rapid the installation of a reactive fragment. ${ }^{2}$

New reactivity concepts for the straightforward construction of complex building blocks through a single synthetic operation will be presented. 1) A flash access to $\alpha$-quaternary aldehydes; ${ }^{3}$ 2) The one-pot synthesis of halomethyl aziridines from haloimidates; 3 ) The employment of fluoromethyllithium as nucleophile.

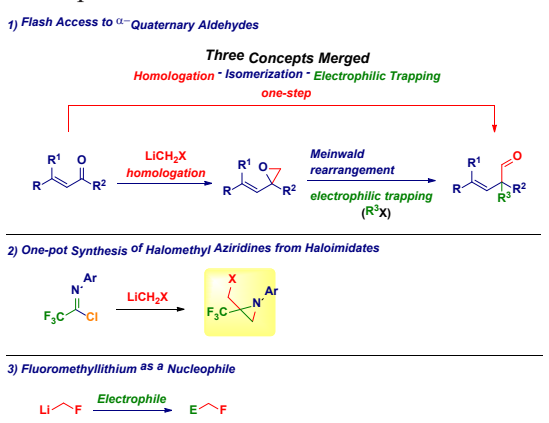

References

[1] (a) Pace, V.; Holzer, W.; De Kimpe, N. Chem. Rec. 2016, 16, 2061-2076. (b) Pace, V.; Castoldi, L.; Monticelli, S.; Rui, M.; Collina, S. Synlett 2017, 28, 879-888.

[2] (a) Pace, V.; Pelosi, A.; Antermite, D.; Rosati, O.; Curini, M.; Holzer, W. Chem. Commun. 2016, 52, 2639-2642. (b) Pace, V.; Murgia, I.; Westermayer, S.; Langer, T.; Holzer, W. Chem. Commun. 2016, 52, 7584-7587. (c) Pace, V.; de la Vega-Hernández, K.; Urban, E.; Langer, T. Org. Lett. 2016, 18, $2750-2753$. (d) Pace, V.; Castoldi, L.; Mamuye, A. D.; Langer, T.; Holzer, W. Adv. Synth. Catal. 2016, 358, 172-177. (e) Pace, V.; Castoldi, L.; Holzer, W. Adv. Synth. Catal. 2014, 356, 1761-1766. (f) Pace, V.; Holzer, W.; Verniest, G.; Alcántara, A. R.; De Kimpe, N. Adv. Synth. Catal. 2013, 355, 919-926. (g) Pace, V.; Castoldi, L.; Holzer, W. Chem. Commun. 2013, 49, 8383-8385. (h) Pace, V.; Castoldi, L.; Holzer, W. J. Org. Chem. 2013, 78, 7764-7770.

[3] Pace, V.; Castoldi, L.; Mazzeo, E.; Rui, M.; Langer, T.; Holzer, W. Angew. Chem. Int. Ed. 2017, DOI: 10.1002/anie.201706236.

\section{5st Session |Sessão 5}

\section{Polymeric nanocapsules for loading and delivery of naturally occurring agents for tumor therapy in vitro and in vivo}

\section{Speaker / Prelector}

\section{Al-Jamal Khuloud}

Abstract / Resumo da Comunicação

Clinical applications of naturally occurring substances such as curcumin, quercetin and glabrescione B for the treatment of cancer and other chronic diseases have been hindered by their short biological half-lives and/or poor water solubility. Nanotechnology-based drug delivery systems have the potential to enhance the efficacy of poorly soluble drugs for systemic delivery. Our recent work has focused on the use of poly(lactic-co-glycolic acid) (PLGA)-based polymeric oil-cored nanocapsules (NCs) for high loading and delivery of such agents to different types of cancer e.g. ovarian, colon and brain cancer in mice after systemic injection, with promising results obtained so far.

Formulations of different oil compositions were prepared and characterised for their drug loading, physico-chemical properties, and shelf-life stability. The results indicated that castor oil-cored PLGA-based NC achieved high drug loading efficiency $(\approx 18 \% \mathrm{w}(\mathrm{drug}) / \mathrm{w}($ polymer$) \%)$ compared to other oil-cored NCs. Curcumin-loaded NCs, for example, internalised more efficiently in CT26 cells than the free drug, and exert therapeutic activity in vitro, leading to apoptosis and blocking the cell cycle. In addition, the formulated $\mathrm{NC}$ exhibited an extended blood circulation profile compared to the non-PEGylated NC, and accumulated in the subcutaneous CT26-tumors in mice, after systemic administration.

Thanks to live imaging techniques, optical and single photon emission computed tomography/computed tomography (SPECT/CT), which also confirmed tumour accumulation of these carriers. In vivo growth delay studies were performed, and significantly smaller tumour volumes were achieved compared to empty NC injected animals, in case of curcumin. Such studies showed the potential of polymeric NC for delivery and solving some physico-chemical problems encountered in the field of natural drugs.

References

[1] Ingallina C, Costa PM, Ghirga F, Klippstein R, Wang JT, Berardozzi S, Hodgins N, Infante P, Pollard SM, Botta B, Al-Jamal KT. Polymeric glabrescione B nanocapsules for passive targeting of Hedgehog-dependent tumor therapy in vitro. Nanomedicine (Lond). 2017 Apr;12(7):711-728.

[2] Klippstein R, Bansal S, Al-Jamal KT. (2016) Doxorubicin Enhances Curcumin's Cytotoxicity in Human Prostate Cancer Cells In Vitro by Enhancing Its Cellular Uptake. International Journal of Pharmaceutics. 514(1):169-175.

[3] Klippstein R, Wang JT, El-Gogary RI, Bai J, Mustafa F, Rubio N, Bansal S, Al-Jamal WT, Al-Jamal KT. (2015) Passively Targeted Curcumin-Loaded PEGylated PLGA Nanocapsules for Colon Cancer Therapy In Vivo. Small. 11(36):4704-22.

[4] El-Gogary R, Rubio N, Wang J T-W, Al-Jamal WT, Bourgognon M, Kafa H, Naeem M, Klippstein R, Abbate V, Leroux F, Bals S, Van Tendeloo G, Kamel AO, Awad GAS, Mortada ND, and Al-Jamal KT. (2014) Polyethylene Glycol Conjugated Polymeric Nanocapsules for Targeted Delivery of Quercetin to Folate-Expressing Cancer Cells In Vitro and In Vivo. ACS Nano. 8(2):1384-401. 


\title{
5st Session |Sessão 5
}

\section{Stereopermutation on the Proposed Structure of Mucosin - A Novel Marine Compound}

\author{
Speaker / Prelector
}

\section{Yngve H. Stenstrøm}

\section{Abstract / Resumo da Comunicação}

Marine organisms continue to be a rich source of novel natural products.1 In particular, compounds originating from polyunsaturated fatty acid metabolites, such as the eicosanoids and docosanoids. A compound that we found particularly interesting was the prostaglandin like eicosanoid, mucosin (1), with a unique bicyclic motif. The isolation and structure elucidation was reported by Caspullo et al.2 some years ago. Based mainly on NMR spectroscopic data they depicted the structure to be 1. A synthesis of its antipode reported in 20123 seemed to support this notion. Both due to the challenging structure and the possible biological activities, we set forth a project synthesizing the proposed natural product. However, a synthesis of 1 published by us 4 revealed severe discrepancies between the reported $1 \mathrm{H}$ and 13C NMR data and the ones reported for the natural product. To ensure the structure we reported was correct, one of the intermediates with all stereogenic centers fixed was elucidated by X-ray crystallography. Based on this we expanded the project to set up syntheses of all possible stereoisomers of 1 . Our efforts along these lines will be presented showing that synthesis still can play a key role in structure elucidation of natural products.

References:
[1]. J. W. Blunt, B. C. Copp, R. A. Keyzers, M. H. G. Munro and M. R. Prinsep (2014) Nat. Prod. Rep., 2014, 31, 160.
Amakye D, Jagani Z, Dorsch M (2013). Nat Med 19: 1410-1422.
[2]. Caspullo, A.; Scognamiglio, G.; Cimino, G., (1997) Tetrahedron Lett. 38: 3643-3646
O4]. Genderson, A. R.; Stec, J., Owen, D. R.; Whitby, R. J. (2012), Chem. Commun. 48: 3409-3411.
Org. Biol. Chem.Smith, H. C.; Antonsen, S. G.; Görbitz, C. H.; Hansen, T. V.; Nolsøe, J. M. J.; Stenstrøm, Y. H. (2016)

\section{Prostaglandins synthesis using a free metal catalyst: an example of a green catalyst for the production of drugs Speaker / Prelector}

\section{Vasile I. Parvulescu}

\section{Abstract / Resumo da Comunicação}

The unprecedented development of pharmaceutical and medicinal industries, mostly based on multi-step organic syntheses generates huge amounts of harmful wastes and pollutants with high environmental impact due to their biological activity. Most of these associate catalytic reactions using precious metals as active components. However, due to their limited abundance and low reserves, the dependence on the use of noble metal catalysts become a bottleneck for the pharmaceutical industry. With the aim to reduce this disadvantage herein we report on the performance of a graphene oxide (GO) in the hydrogen transfer reduction of the lactonic enone intermediate 1 ([3a $\alpha, 4 \alpha(\mathrm{E}), 5 \beta, 6 \mathrm{a} \alpha]-( \pm)-4$-[4-(3-chlorophenoxy)-3-oxo-1-butenyl]-hexahydro-5-hydroxy$2 \mathrm{H}$-cyclopenta[b]furan-2-one) (Scheme 1) used in the synthesis of the commercial drug Cloprostenol..
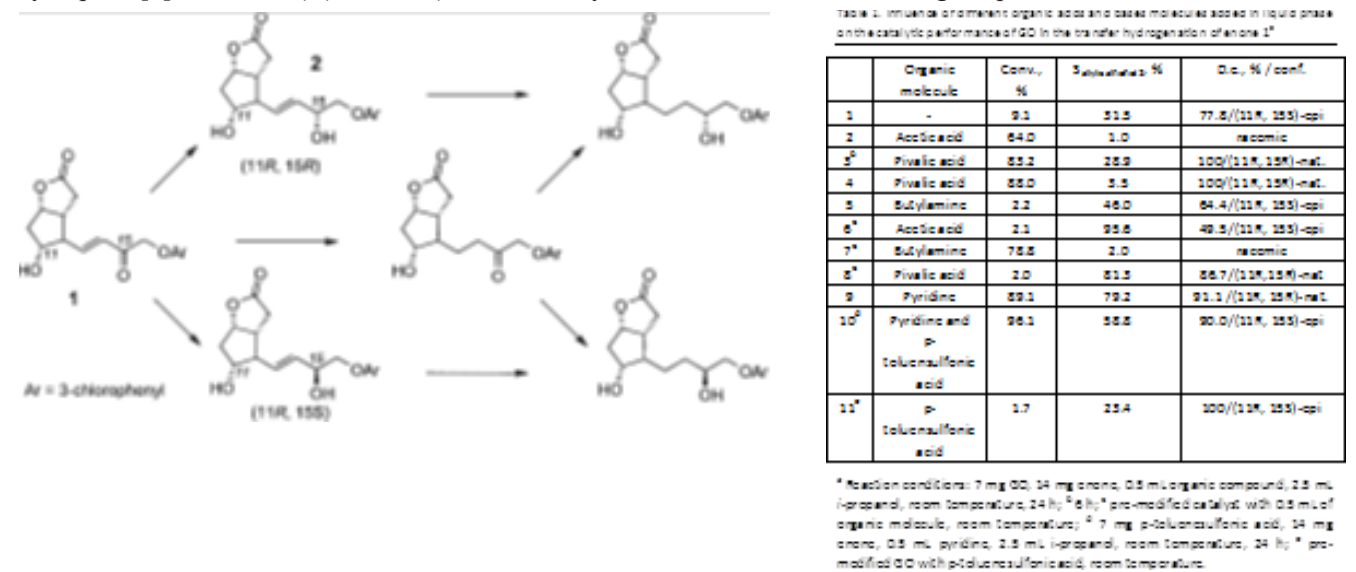

The present study has shown that GO is indeed able for the hydrogen transfer from i-propanol affording the corresponding allylic alcohols with prostaglandin structure (Table 1). The modification of GO by organic molecules changes the electronic properties of the graphene tuning the catalytic activity, affecting the selectivity to allyl alcohol and the diastereoselectivity. Pyridine produced remarkable positive effects in this reaction providing high activity, selectivity to allylic alcohols and diastereoselectivity of an important prostaglandin product. Also, pivalic acid swap the diastereoselectivity the natural diastereoisomer with a total d.e.

References:

[1]. V.I. Parvulescu, S.M. Coman, I. Podolean, M. Tudorache, B. Cojocaru, H. Garcia, submitted. 


\section{5st Session |Sessão 5}

\section{In silico screening of spices with possible anti-HIV ingredients}

\section{Speaker / Prelector}

\section{Sanja Glisic}

Abstract / Resumo da Comunicação

Previously, the criterion for in silico selection of compounds with anti-HIV activity was established.1,2 This criterion, which is based on molecular descriptors the average quasi valence number (AQVN) and the electron-ion interaction potential (EIIP), was used for selection of flavonoid compounds with ant-HIV activity. Here, using this AQVN/EIIP criterion, ingredients of 56 spices were analyzed. This analysis revealed 13 spices which contain natural compounds with putative anti-HIV activity. Possible mode of action of these molecules will be discussed.

References:

[1]. Veljkovic N, Glisic S, Prljic J, Perovic V, Veljkovic V (2013). Curr Pharm Biotechnol 14:561-9.

[2]. Veljkovic V, Mouscadet JF, Veljkovic N, Glisic S, Debyser Z (2017). Bioorg Med Chem Lett. 17:1226-32.

\section{6st Session |Sessão 6}

\section{Antibacterial and antitumor properties of alkylaminophenols derived from Petasis borono-Mannich multicomponent reaction}

\section{Speaker / Prelector}

\section{Nuno Candeias}

Abstract / Resumo da Comunicação

The Petasis borono-Mannich (PBM) reaction, a multicomponent reaction of boronic acids, aldehydes/ketones, and amines, is a remarkable tool for the preparation of complex molecules in a single step from readily available starting materials. The reaction has been used in the preparation of very different classes of compounds spanning from $\alpha$-amino acids, to imininocyclitols or 2,5-dihydrofurans as well as natural products.[1] A small library of alkylaminophenols obtained from salicylaldehyde as the PBM reaction aldehyde component was prepared.

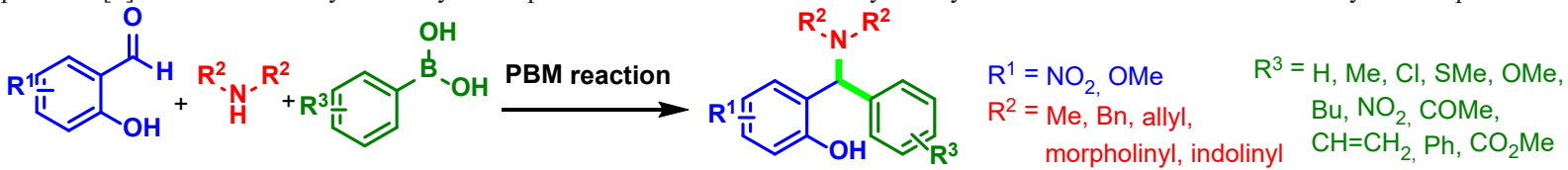

Indoline derived alkylaminophenols containing a nitro group at the para-phenol position showed considerable activity against several bacteria tested, with minimal inhibitory concentrations (MIC) as low as $1.36 \mu \mathrm{M}$ against Staphyloccocus aureus and Mycobacterium smegmatis.[2] The citotoxicity of the same family of compounds was tested against osteosarcoma (U2OS) and human embryonic kidney cells. A citotoxic effect towards U2OS cell line as potent as IC $50=37 \mu \mathrm{M}$ was determined. Further experiments revealed that the most promising compounds induce cell death by apoptosis and also acted as a migration inhibitors. Analysis of the mitochondrial calcium following treatment with the citotoxic agents on U2OS cells showed a significant reduction in the level of mitochondrial calcium concentration suggesting a mitochondrial calcium-independent mechanism in triggering apoptosis.[3]

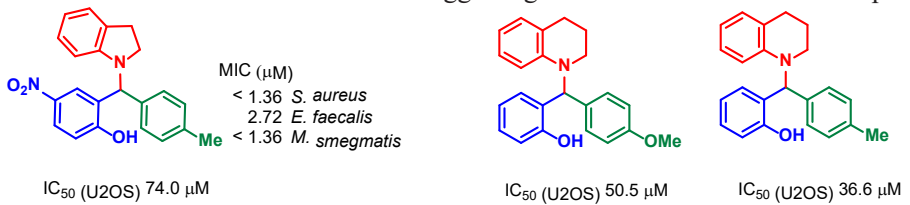

Acknowledgements:

Academy of Finland is thanked for financial support

References:

[1]. a) Candeias NR, Montalbano F, Cal PMSD, Gois PMP (2010) Chem Rev 110: 6169; b) Guerrera CA, Ryder TR, in Boron Reagents in Synthesis, American Chemical Society (2016) vol. 1236, ch. 9, pp. 275.

[2]. Neto I, Andrade J, Fernandes AS, Reis CP, Salunke JK, Priimagi A, Candeias NR, Rijo P (2016) ChemMedChem 11: 2015;

[3]. a) Doan P, Karjalainen A, Chandraseelan J G, Sandberg O, Yli-Harja O, Rosholm T, Franzen R, Candeias NR, Kandhavelu M (2016) Eur J Med Chem, 120: 296. b) Karjalainen A, Doan P, Chandraseelan J G, Sandberg O, Yli-Harja O, Candeias NR, Kandhavelu M, (2017) Anticancer Agents Med Chem, 17: E-pub ahead of print, DOI: 10.2174/1871520617666170327142027; c) Doan P, Nguyen T, Yli-Harjaa O, Candeias NR, Kandhavelu M (2017) Eur J Pharm Sci, 107: 208. 


\title{
6st Session |Sessão 6
}

\section{Targeting the subcellular localization of proteins for targeted therapy in precicion oncology}

\author{
Speaker / Prelector
}

\section{Wolfgang Link}

\section{Abstract / Resumo da Comunicação}

The eukaryotic cell is organized into membrane-covered compartments, each characterized by its specific sets of proteins and biochemically distinct cellular processes. The appropriate subcellular localization of proteins is crucially important to provide the physiological context for their cell function. Aberrant localization of proteins has been shown to contribute to the pathogenesis of many human diseases including cancer and serves as valuable diagnostic or prognostic marker [1]. Disease-related subcellular mislocalization of proteins may provide attractive means for therapeutic intervention. There is a significant number of emerging technologies attempting to deal with the complexity of intact cells [2] allowing for the unbiased identification of small molecule compounds or molecular targets that might be exploited pharmaceutically to restore or interfere with normal protein localization and function. We report here the identification of targets and small molecule compounds to interfere with the nuclear export of tumour suppressor proteins and restore their functions in cancer cells $[3,4]$

References:

[1]. Hung MC and Link W, "Protein localization in disease and therapy", Journal Cell Science (2011) 124:3381-3392.

[2]. Zanella F, Lorens JB and Link W, High Content Screening - Seeing is Believing", Trends Biotechnol. (2010) 28:2

[3]. Cautien B., Castillo F, Musso L, de Pedro N, Rodriguez Quesada L, Vicente Pérez F, Dallavalle S and Link W. (2016) Discovery of a novel, specific isothiazolonaphthoquinone-based small molecule activator of FOXO nuclear-cytoplasmic shuttling. PLoS One 11(12):e0167491

[4]. Cautien B., de Pedro N. Muñoz de Escalona M., González Menéndez V., Tormo J.R., Martin J., El Aouad N., Reyes F., Asensio F., Genilloud O., Vicente Pérez F. and Link W. (2014) High-content screening of natural products reveals novel nuclear export inhibitors. Journal of Biomolecular Screening 19, 57-65.

\section{Using BIOSEA: from virtual screening to discover novel function of old compounds against tubulin assembly}

\section{Speaker / Prelector}

\section{Daniel Lucena-Agell}

\section{Abstract / Resumo da Comunicação}

Microtubules are desirable targets in cancer chemotherapy due to its crucial role during mitotic division [1]. BIOSEA is a statistical classifier able to identify molecules that are capable of reproducing a desired cellular phenotype by scanning a large compound collection based on biological similarity. Thus it could be used to identify novel compounds able to affect cellular division. By virtually screening a library with 365,000 compounds approximately, this algorithm proposed 21 drug-like compounds with reference natural products that inhibit cell division. A preliminary evaluation based on typical cell-arrest phenotype allowed us to distinguish 5 compounds with a clear effect on cell division. These 5 compounds were further studied showing inhibition of microtubule cell dynamics. Furthermore, IC50 assays showed a nanomolar range of action in A549 cells for most of these agents. Having confirmed the cytoskeletal perturbing activity we wanted to confirm the biochemical target as tubulin. To do so, we monitored the effect of the compounds in the time course of assembly of $25 \mathrm{mM}$ tubulin, confirming the inhibitory effect upon microtubule dynamics previously observed in cells. Finally, the binding site for each compound was determined using different competition assays against the most common tubulin depolymerizing binding sites described in the literature. Three of these compounds assayed were confirmed to bind to the colchicine binding site, whereas one of them competed with eribulin and the last one could not be assessed. The results presented confirm BIOSEA as a useful statistical classifier to predict novel active targets from previous screening data [2]. References:

[1]. Mukhtar, E., Adhami, V. M., and Mukhtar, H. Targeting microtubules by natural agents for cancer therapy. Molecular cancer therapeutics. 2014, 13, 275-284.

[2]. Cortes Cabrera, A., Lucena-Agell, D., Redondo-Horcajo, M., Barasoain, I., Díaz, JF., Fasching, B., Petrone, PM. Aggregated Compound Biological Signatures Facilitate Phenotypic Drug Discovery and Target Elucidation. ACS Chem Biol. 2016 Nov 18;11(11):3024-3034.

\section{Benzodiazepine Inhibitors as Anticancer Agents Against Human Breast Cancer}

\section{Speaker / Prelector}

\section{Yusuf Tutar}

\section{Abstract / Resumo da Comunicação}

Invasive ductal breast carcinoma causes high morbidity rates and innovative therapeutic approaches have been conducted for clinical trials. For this purpose, a series of benzodiazepine compounds were designed and synthesized in our laboratory. The compounds screened by array technology along with biochemical experiments. A benzodiazepine derivative D5 binds Hsp90 which folds key substrate proteins with Kd value of 3,93 $\mu \mathrm{M}$ and with estimated free energy of binding -7.99 (kcal/mol). The compound decreases Hsp90 ATPase function and inhibit Hsp90 client protein folding activity. The compound inhibits expression of both Hsp90 isoforms and key proteins (cell cycle receptors; PLK2 and TERT, kinases; PI3KC3 and PRKCE, and growth factors; IGF1, IGF2, KDR, and PDGFRA) on oncogenic pathways. This drug template inhibits growth of MCF-7 cell line efficiently and experiments on endothelial cells to investigate metastasis effect show promising results in the presence of this inhibitor.

Our current effort focuses on preventing HER2 positive breast cancer cells resistance to trastuzumab by treating the cells with D5-Hsp90 and/or KBR1307Hsp70 inhibitors.
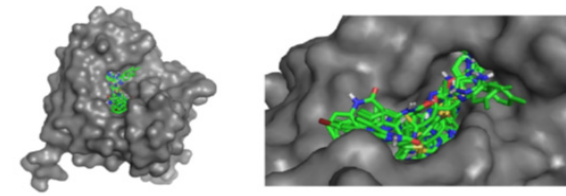

Acknowledgements:

The authors gratefully acknowledge the financial support received from the Scientific and Technological Research Council of Turkey, TÜBİTAK (Grant \# $114 Z 365$ ) and a seed grant from Bozok University. 


\section{6st Session |Sessão 6}

\section{Inhibition of Notch signalling in T-cell acute lymphoblastic leukemia: a challenge posed by a novel chalcone derivative}

\section{Speaker / Prelector}

\section{Elisa De Paolis}

Abstract / Resumo da Comunicação

Notch signalling is considered a rationale target in the therapy of several cancers, particularly those harbouring Notch gain of function mutations, including T-cell acute lymphoblastic leukemia (T-ALL).[1] Although currently available Notch-blocking agents are showing anti-tumor activity in preclinical studies, they are not effective in all the patients and often cause severe side-effects, limiting their widespread therapeutic use.

Here, by functional and biological analysis of the most representative molecules of an in house library of natural products, the $2^{\prime}, 3,4,4^{\prime}$-tetrahydroxychalcone (butein) was identified as valuable lead compound, thus emphasizing the relevance of the chalcone scaffold in Notch inhibition. Cycles of design-synthesisbioassay and testing in vitro were established to optimize the potency of initial chalcone compound, and to eliminate or mask the undesirable chemical feature. Notably, the general strategy employed to synthesize chalcones in excellent yield was based on the Claisen-Schmidt condensation: twenty-six chemical derivatives were synthesized and tested in vitro.[2] Structure-activity relationships (SAR) were afforded, and a novel potent Notch inhibitor, namely 8, was identified.[3] Short term treatments with compound 8 resulted in a dose-dependent decrease of Notch signalling activity, halted cell cycle progression and induced apoptosis, thus affecting leukemia cell growth.

In conclusion, our data indicate that 8 is a novel Notch inhibitor, candidate for further investigation and development as therapeutic option against Notchdependent cancers.<smiles>O=C(Cc1ccc(O)c(O)c1)C(=O)c1ccc(O)cc1O</smiles>

Butein

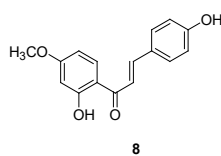

References:

[1]. Weng AP, Ferrando AA, Lee W, Morris JP 4th, Silverman LB, Sanchez-Irizarry C, Blacklow SC, Look AT, Aster JC (2004). Science 306: $269-271$.

[2]. Sogawa S, Nihro Y, Ueda H., Miki T, Matsumoto H, Satoh T (1994). Biol Pharm Bull 17: 251-256.

[3]. Mattia Mori, Luca Tottone, Deborah Quaglio, Nadezda Zhdanovskaya, Cinzia Ingallina, Marisa Fusto, Francesca Ghirga, Giovanna Peruzzi, Maria Elisa Crestoni, Fabrizio Simeoni, Francesca Giulimondi, Claudio Talora, Bruno Botta, Isabella Screpanti et Rocco Palermo, (2017), Scientific Reports| 7: 2213. 
Abstract List | Lista de Resumos Submetidos

P.01 GRAPHENE OXIDE AND GRAPHENE DERIVATIVES AS NEW VECTORS IN NANOMEDICINE. Andrea Calcaterra, F. Valentini, M. Talamo

P.02 NOVEL 1,2,3-TRIAZOLE FUSED BETULINIC ACID DERIVATIVES WITH POTENT ANTICANCER PROPERTIES. Besir S. Krasniqi, Joice Thomas, Wim Dehaen, Sandra Liekens.

P.03 IMPROVING THE ANTITUMOR POTENTIAL OF A DITERPENOID THROUGH MITSUNOBU REACTIONS. Catarina Garcia Carlos M. Monteiro, Lucília Saraiva, Cláudia Bessa, Anastasia Borozan, Epole Ntungwe, Catarina Reis, Carlos A.M. Afonso, Patrícia Rijo.

P.04 SPIROOXAdiAZOLINE OXINDOLES - A NOVEL FAMILY OF ANTICANCER AGENTS. Elizabeth Lopes, Damla Uyar, Lídia Gonçalves, Maria M. M. Santos

P.05 BIOLOGICAL ACTIVITY SCREENING OF SEVEN PLECTRANTHUS SPECIES: ANTICANCER LEAD MOLECULE SEARCH. Epole Ntungwe N., Joana Marçalo, Catarina Garcia, Catarina Reis, Catarina Teodósio, Carolina Oliveira, Cláudia Oliveira, Amílcar Roberto, Patrícia Rijo.

P.06 SYNTHESIS OF FERROCENYLMETHYLIDENE AND ARYLIDENE SUBSTITUTED CAMPHANE-BASED COMPOUNDS AS POTENTIAL ANTICANCER AGENTS. Georgi M. Dobrikov, Mariana Kamenova-Nacheva, Yana Nikolovaa, Iva Ugrinova, Ivan Stoykov, Evdokia Pasheva, Ivaylo Slavchev, Vladimir Dimitrov, George Momekov.

P.07 PREPARATION OF SIDE-CHAIN CLEAVED PHYTOECDYSTEROID METABOLITES ACTIVATING PROTEIN KINASE B. Halima Meriem Issaadi, József Csábi, Zoltán Kele, Tusty-Jiuan Hsieh, Gábor Tóth, Attila Hunyadi

P.08 ANALOGUES OF THE LIGNAN PINORESINOL AND THEIR REVERSAL ACTIVITIES ON CELL MULTIDRUG RESISTANCE MEDIATED BY P-GLYCOPROTEIN (P-GP). Jerónimo Laiolo, Tihomir Tomašič, Domingo Mariano Vera, María Laura González, Priscila A. Lanza, Danijel Kikelj, María Cecilia Carpinella.

P.09 TROJAN HORSE STRATEGY: AN ACHILES HEEL OF RESISTANT BACTERIA. Kevin Ferreira, Verena Fetz, Hans Prochnow, Mark Brönstrup.

P.010 SARCO/ENDOPLASMIC CA2+-ATPASE (SERCA) AND PANCREATIC BETA CELLS MODIFIED BY PRENYLATED PHENOLIC COMPOUNDS FROM MORUS NIGRA. Vladimir Heger, Jana Viskupicova, Zoofishan Zoofishan, Attila Hunyadi Lubica Horakova.

P.011 ANTIBACTERIAL COMPOUNDS ISOLATED FROM LEPECHINIA MEYENII AND SYNTHESIS OF ANALOGUES WITH IMPROVED ACTIVITY. Macarena Funes Chaban, Antonia I. Antoniou, Mariana B. Joray, Catherine A. Karagianni, Claudia Sola, José L. Bocco, María I. Crespo, Sara M. Palacios, Constantinos Athanassopoulos, María C. Carpinella.

P.012 DISCOVERY OF ENANTIOPURE TYROSINOL-DERIVED BICYCLIC LACTAM THAT ACTS AS NMDA RECEPTOR ANTAGONIST. Margarida Espadinha, Jorge Dourado, Rocio Lajarin-Cuesta, Clara Herrera-Arozamena, Lidia M. D. Gonçalves, María Isabel Rodríguez-Franco, Cristobal de los Rios, Maria M. M. Santos.

P.013 EXTENDING THE BINDING OF CYCLOHEXANEDIONE DERIVATIVES TOWARDS THE $\alpha \beta$ TUBULIN INTERFACE. Marta Gargantilla, Oskia Bueno, Juan Estevez Gallego , Andrea E. Prota, J. Fernando Díaz, Michel O. Steinmetz, María-José Camarasa, Federico Gago, Sandra Liekens, Eva-María Priego and María-Jesús Pérez-Pérez.

P.014 SYNTHESIS OF PLANAR CHIRAL FERROCENE SULFONAMIDES BEARING FENCHANE AND MENTHANE MOIETIES. Martin Ravutsov, Georgi Dobrikov, Miroslav Dangalov,Boris Shivachev, Vladimir Dimitrov.

P.015 DOSAGE AND TIME RELATED EFFICACY ASSESSMENT OF GROWTH INHIBITORY ACTIVITY OF ANKAFERD HEMOSTAT ON PRIMARY MELANOMA CELLS AND CELL LINES. Mehdi Ghasemi, Seyhan Turk, Umit Malkan, Duygu Mutlu, Helin Hocaoglu, Ali Gure, Ibrahim C. Haznedaroglu.

P.016 SUbGROUPS OF ACUTE LEUKEMIA BASED ON RAS GENE FAMILY EXPRESSION. Seyhan Turk, Mehdi Ghasemi, Umit Malkan, Nilgun Sayinalp, Mufide Okay, Ibrahim C. Haznedaroglu, Ali Gure.

P.017 FERROCENE QUINIDINE - EPIMERS SENSITIZE HUMAN CANCER CELL LINES TO PACLITAXEL EXERTING PRO-OXIDANT ACTIVITY. Ana Podolski-Renić, Szilvia Bősze, Jelena Dinić, László Kocsis, Ferenc Hudecz, Antal Csámpai and Milica Pešić.

P.018 ENANTIOSELECTIVE TOTAL SYNTHESIS OF (+)-GEPHYROTOXIN 287C. Miriam Piccichè, Alexandre Pinto, Rosa Griera, Joan Bosch and Mercedes Amat

P.019 CHEMOENZYMATIC TACTICS TOWARDS THE SYNTHESIS OF PHENYLETHANOID APIOGLUCOSIDES. Peter Kis, Mária Mastihubová.

P.020 SYNTHESIS OF (-)-SIELBOLDIANIN A USING A SQUARAMIDE CATALYZED ENANTIOSELECTIVE BROMOLACTONIZATION REACTION . Renate Kristianslund, Jørn Eivind Tungen, Marius Aursnes, Carl Henrik Gørbitz and Trond Vidar Hansen.

P.021 IDENTIFICATION OF NOVEL NATURAL PRODUCTS CHEMOTYPES OF HEDGEHOG-DEPENDENT TUMORS INHIBITORS. Silvia Corradi, Francesca Ghirga, Mattia Mori, Cinzia Ingallina, Simone Berardozzi, Elisa De Paolis, Lucia di Marcotullio, Romina Alfonsi, Bruno Botta, Deborah Quaglio.

P.022 SYNTHESIS AND BIOLOGICAL ACTIVITY OF OXIDIZED CHALCONE DERIVATIVES. Tímea Gonda, Gabriella Spengler, Annamária Kincses, Attila Csorba, Norbert Kúsz, Attila Hunyadi.

P.023 OPTIMIZATION OF TRYPTOPHANOL-DERIVED OXAZOLOISOINDOLINONES: CHEMICAL SCAFFOLD WITH INTERESTING ANTICANCER PROPERTIES. Valentina Barcherini, Sara Gomes, Margarida Espadinha, Joana Loureiro, Alexandra M.M. Antunes, Lucília Saraiva, Maria M.M. Santos.

P.024 SYNTHESIS AND BIOLOGY OF JASPAMIDE, SERAGAMIDE AND GEODIAMOLIDE HYBRIDS. Veselin Nasufovic, F. Küllmer, J. Bößneck, S. Pace, L.-M. Semmrau, O. Werz, H.-D. Arndt.

P.025 MARINE ALKALOID OROIDIN ANALOGUES AS NOVEL HUMAN TOPOISOMERASE II INHIBITORS. Žiga Skok, Nace Zidar, Martina Durcik,Janez Ilaš. 


\section{P1 - Graphene Oxide and Graphene derivatives as new vectors in Nanomedicine}

\section{Andrea Calcaterra ${ }^{\mathrm{a}}$, F. Valentini ${ }^{\mathrm{a}, \mathrm{b}, \mathrm{c}}$, M. Talamo}

${ }^{a}$ Inuit, Università degli Studi di Roma Tor Vergata, via dell'Archiginnasio snc, 00133 Roma (Italy)

${ }^{b}$ Parco Scientifico Romano, Via della Ricerca Scientifica 1, 00133 Roma (Italy)

${ }^{\mathrm{C}}$ Dipartimento di Scienze e Tecnologie Chimiche, Università degli Studi di Roma Tor Vergata, Via della Ricerca Scientifica 1, 00133 Roma (Italy)

Graphene Oxide (GO) and Graphene derivatives (Gds) represent a new challenge in biomedical and pharmaceutical field applications, especially for the chemico-physical properties exhibited by these new carbon based nanomaterials. The highest surface nominal area (about two orders larger than that exhibited by the conventional materials), the high biocompatibility (this latter related to the metal free nature of graphene and its particular sheet shape), the electronic/electrochemical properties (very important for the delivery role [1]), the magnetic features (for an oriented and aligned movement, induced by applying an external magnetic field, as in the case of nanowires [2]) and the auto-fluorescence effects (due to the unique optical properties, completely different from that exhibited by the traditional/conventional micrometric graphite) make GOs and Gds extremely useful for the assembly of the drug delivery tools.

In particular, the tested biocompatibility of GOs and Gds [3], also combined with their antibacterial/antimicrobial features, provides new nano-platform suitable for the loading of pharmacological active natural compounds. For this purpose, works are in progress to optimize the best conditions for the oriented and aligned conjugation of the active natural compounds with the graphene nano-platforms.

Acknowledgment:

This work is partially supported by Smart Campus Project. References:

[1]. (a): Valentini F, Roscioli D, Carbone M, Conte V, Floris B, Palleschi G, Flammini R, Bauer E M, Nasillo G, Caponetti E (2012). Anal. Chem. 84(13): 5823-5831; (b): Valentini F, Romanazzo D, Carbone M, Palleschi, G. (2012). Electroanalysis, 24(4): $872-881$

[2]. Wang J, Scampicchio M, Laocharoensuk R, Valentini F, González-García O, Burdickc J (2006). J. Am. Chem. Soc., 128(14): 4562-4563.

[3]. Mari E, Mardente S, Morgante E, Tafani M, Lcoco E, Fico F, Valentini F, Zicari A. (2016). Int. J. Mol. Sci, 17(12): 1999-2008.

\section{P2 - Novel 1,2,3-triazole fused betulinic acid derivatives with potent anticancer properties}

Besir S. Krasniqii, Joice Thomas ${ }^{\mathrm{b},}$ Wim Dehaen*, Sandra Liekens

${ }^{a}$ Molecular Design and Synthesis, Department of Chemistry, KU Leuven, Celestijnenlaan 200F, 3001 Leuven, Belgium

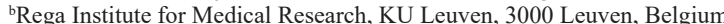

Functionalized 1,2,3-triazoles are a very important pharmacofore in medicinal chemistry, they are found in many drugs functioning as a linker, a bioisostere of an amide or the lead itself [1]. In the previous year has been reported that betulinic acid can induce apoptosis in the some cancer cell with very promising results [2], however there is no report in the literature about 1,2,3-triazole fused triterpenoids, probability due to the lack of synthetic methodologies. In our research group, we were able to synthesize 1,2,3-triazoles via a one pot metal free method, from enolizable ketone, primary amine and 4-nitrophenyl azide [3]. Betulin is commercially available or was extracted from birch bark and then oxidized to betulonic acid as a starting material for triazolation. Based on this we were able to obtain a library of ring A fused 1,2,3-triazole derivatives of betulinic acid which then showed promising activities against several cancer cell lines.

References:

[1]. Idrees Mohammed, Indrasena Reddy Kummetha, Gatikrushna Singh, Natalia Sharova, Gianluigi Lichinchi, Jason Dang, Mario Stevenson, Tariq M. Rana. J. Med. Chem., 2016, 59 (16), pp 7677-7682

[2]. L Potze, F B Mullauer, S Colak, J H Kessler, J P Medema. Nature, Cell Death and Disease (2014) 5, e1169

[3]. Joice Thomas, Sampad Jana, Jubi John, Sandra Liekensb Wim Dehaen. Chem. Commun., 2016,52, 2885-2888
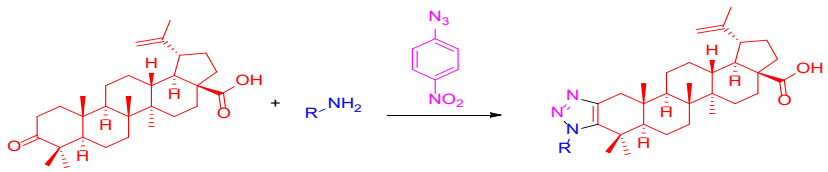

\section{P3 - Improving the antitumor potential of a diterpenoid through} Mitsunobu Reactions

Catarina Garcia ${ }^{\mathrm{a}, \mathrm{b}}$, Carlos M. Monteiro ${ }^{\mathrm{c}}$, Lucília Saraiva ${ }^{\mathrm{d}}$, Cláudia Bessa ${ }^{\mathrm{d}}$, Anastasia Borozan ${ }^{c}$, Epole Ntungwe ${ }^{a}$, Catarina Reis ${ }^{c}$, Carlos A.M. Afonso ${ }^{c}$, Patrícia Rijo ${ }^{\mathrm{a}, \mathrm{c}}$

${ }^{\mathrm{a}} \mathrm{CBIOS}$ - Center for Research in Biosciences \& Health Technologies, Universidade Lusófona de Humanidades e Tecnologias, Campo Grande 376, 1749-024 Lisbon, Portugal

'Department of Biomedical Sciences, Faculty of Pharmacy, University of Alcalá, Ctra A2, Km 33.600 - Campus Universitario, 28871 Alcalá de Henares, Spain 'Instituto de Investigação do Medicamento (iMed.ULisboa), Faculdade de Farmácia da Universidade de Lisboa, Av. Prof. Gama Pinto 1649-003 Lisbon, Portugal ${ }^{\mathrm{U} U C I B I O / R E Q U I M T E}$, Laboratório de Microbiologia, Departamento de Ciências Biológicas, Faculdade de Farmácia,Universidade do Porto, Rua de Jorge Viterbo Ferreira n. ${ }^{\circ} 228,4050-313$ Porto, Portugal

The Plectranthus genus is a known source of bioactive diterpenoids with antitumor potential [1]. Considering this, the optimized extraction from the essential oil of P. madagascariensis was achieved and the isolation of the cytotoxic diterpene 6,7-dehydroroyleanone was performed in high amounts [2]

Its preliminar toxicity was assessed through a lethality test against Artemia salina L. brine shrimp, and its antitumor potential further explored in different cancer cell lines: colon colorectal carcinoma (HCT116), human breast adenocarcinoma (MCF-7) and lung cancer carcinoma $(\mathrm{H} 460)$

The promising antitumor profile of 6,7-dehydroroyleanone appeals the creation of a small library of potential anticancer agents. The Mitsunobu reaction relies on the displacement of an alcohol with a pronucleophile $(\mathrm{Nu}-\mathrm{H})$ mediated by phosphine and azocarboxylate reagents, which activate the pronucleophile through deprotonation and convert the alcohol to a reactive alkoxyphosphonium species [3].

Given the special acidity of the C-12 hydroxyl group of this royleanone, the insertion of nucleophiles - such as functionalized primary and secondary alcohols - are expected to change the original 6,7-dehydroroyleanone scaffold. Therefore, new derivatives were prepared through microwave-assisted Mitsunobu reactions, and its preliminar toxicity evaluated. References:

[1]. Lukhoba C, Simmonds M, Paton A (2006). Journal of Ethnopharmacology 103: 1-24 [2]. Ladeiras D, Monteiro C, Pereira F, Reis C, Afonso C, Rijo P. (2016) Curr. Pharm. Des. 22: 12, 1682-1714. [3]. Buonomo J, Aldrich C (2015). Angewandte Chemie International Edition 54: 44, 13041-13044.

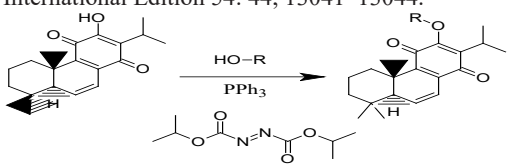

\section{P4 - Spirooxadiazoline oxindoles - a novel family of anticancer agents}

\section{Elizabeth Lopes, Damla Uyar, Lídia Gonçalves, Maria M. M. Santos}

Research Institute for Medicines (iMed.ULisboa), Faculty of Pharmacy, Universidade de Lisboa, Av. Prof. Gama Pinto, 1649-003 Lisboa, Portugal

Spirooxindole alkaloids are a family of natural products that have a spiro ring fusion a position 3 of the oxindole core. Several natural products that possess this heterocyclic core, such as alstonisine, horsfiline, strychnofoline and spirotryprostatin A, are described to have interesting bioactivities.

In this area of research, we have been working in the development of novel spirooxindole scaffolds that possess interesting in vitro anti-tumor activities in colon cancer cell lines.1 In this communication, we report the synthesis of a novel library of spirooxadiazoline oxindoles, by 1,3-dipolar cycloaddition of isatin derivatives with different nitrile imines (formed in situ from hydrazonyl chlorides), as well as the results obtained from the screening of this library in breast cancer cell lines: MCF-7 and MDA-MB-231. In this approach the target molecules combine two scaffolds that are known to possess anti-cancer activities (oxadiazoline and indolin-2-one).

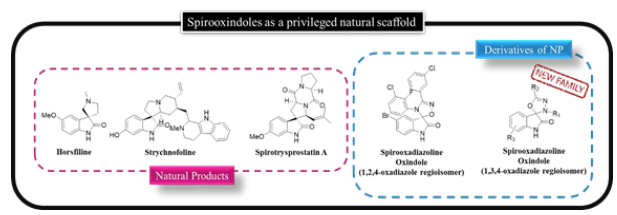

Figure - Spirooxindole natural products and novel spirooxindole derivatives with interesting biological activities.

Acknowledgments: This work was supported by FCT (Fundacão para a Ciência e a Tecnologia)
through iMed.ULisboa (UID/DTP/04138/2013), and IF/00732/2013 (M.M. M. Santos)

References: M. Santios, "Spirooxadiazoline oxindoles with promising in vitro antitumor 420-425; [2]. A. Monteiro, L. Gonçalves, M. M. M. Santos, "Synthesis and lines”, Eur. J. Med. Chem. 2014, 79, 266-272. 
P5 - Biological activity screening of seven Plectranthus species: anticancer lead molecule search

Epole Ntungwe N. ${ }^{a}$, Joana Marçalo ${ }^{\mathrm{a}}$, Catarina Garciaa, ${ }^{\mathrm{b}}$, Catarina Reis ${ }^{\mathrm{c}}$, Catarina Teodósio ${ }^{a}$, Carolina Oliveira ${ }^{\mathrm{a}}$, Cláudia Oliveira ${ }^{\mathrm{a}}$, Amílcar Roberto ${ }^{\mathrm{a}}$, Patrícia Rijo ${ }^{\mathrm{a}, \mathrm{c}}$

${ }^{a}$ CBIOS - Center for Research in Biosciences \& Health Technologies, Universidade Lusófona de Humanidades e Tecnologias, Campo Grande 376, 1749-024 Lisbon, Portugal

${ }^{b}$ Department of Biomedical Sciences, Faculty of Pharmacy, University of Alcalá, Ctra A2, Km 33.600 - Campus Universitario, 28871 Alcalá de Henares, Spain 'Instituto de Investigação do Medicamento (iMed.ULisboa), Faculdade de Farmácia da Universidade de Lisboa, Av. Prof. Gama Pinto 1649-003 Lisbon, Portugal

Natural products from Plectranthus spp. plants have a vast ethnopharmacological use inspiring several scientific investigations [1]. Considering this, a biological activity screening was performed in order to scientifically validate these plants use.

Assays on acetylcholinesterase (AChE) inhibition in vitro [2], antioxidant effect [2], antimicrobial activity [3] and Artemia salina lethality assay [4] of seven Plectranthus spp. acetonic extracts (P. swynnertonii, P. welwischii, P. woodii, P. cylindraceus, P. spicatus, P. ramosior and P. petiolaris) were performed, after its obtainment by sonication $(10 \% \mathrm{w} / \mathrm{v})[5]$.

P. ramosior had the highest yield of dry extract $(13.49 \% \mathrm{w} / \mathrm{w})$ among all extracts tested. The antimicrobial activity was screened using the well diffusion method, against yeast, Gram-positive and -negative bacteria. P. ramosior extract showed not only a moderate inhibition zone against $\mathrm{S}$. aureus and $\mathrm{C}$. albicans (15 and $11 \mathrm{~mm}$, respectively), but also the highest scavenging activity (DPPH method, $36.4 \pm 0.04 \%$ ). On the lethality test in A. salina, P. swynnertonnii extract was the most toxic $(\mathrm{LC} 50=0.036 \mathrm{mg} / \mathrm{L})$. On the other hand, only P. cylindraceus extract decreased enzymatic activity $(30.2 \pm 3.78 \%)$.

These preliminary results showed that P. cylindraceus, P. ramosior and P. swynnertonni are potential bioactive extracts for further isolation, antimicrobial and cytotoxic studies. References:

[1] Lukhoba C, Simmonds M, Paton A (2006). Journal of Ethnopharmacology 103: $1-24$

[2] Rijo P, Rijo P, Matias D, Fernandes AS, Simões MF, Nicolai M, Reis CP (2014). Polymers (Basel), 6 (2):479-90.

[3] Rijo P, Falé PL, Serralheiro ML, Simões MF, Gomes A, Reis C (2014). Measurement, 58:249-55.

[4] Alanís-Garza BA, González-González GM, Salazar-Aranda R, Waksman de Torres N, Rivas-Galindo VM (2007). J Ethnopharmacol, 114(3):468-71,

[5] Rijo P, Batista M, Matos M, Rocha H, Jesus S, Simões MF (2012). Biomed Biopharm Res.; 9 (2):225-35

\section{P6 - Synthesis of ferrocenylmethylidene and arylidene substituted} camphane-based compounds as potential anticancer agents

\section{Georgi M. Dobrikova, Mariana Kamenova-Nachevaa, Yana Nikolovaa, Iva Ugrinova $^{\text {b }}$, Ivan Stoykov ${ }^{b}$, Evdokia Pasheva ${ }^{\text {b }}$, Ivaylo Slavchev ${ }^{a}$, Vladimir Dimitrov $^{a}$, George Momekov}

anstitute of Organic Chemistry with Centre of Phytochemistry, Bulgarian Academy of Sciences

'Institute of Molecular Biology "Roumen Tsanev", Bulgarian Academy of Sciences cFaculty of Pharmacy, Medical University of Sofia

Compounds possessing bicyclic skeleton have shown promising biological activities as antioxidant, anti-inflammatory, anticancer or anti-infective agents [1]. Herein we present a small library of $(+)$-camphor-derived compounds realizing structural diversity through variation of substituents (i.e. sulfonamide groups, ferrocenyl-methylidene and arylidene moieties and heterocyclic substituents). These compounds were synthesized by using organometallic strategies. The obtained derivatives were tested against seven human cancer cells lines and two normal human cell lines in order to determine their activity against malignant cells. Some of them exhibit IC50 values below $10 \mu \mathrm{M}$ in at least one of the cancer cell lines.

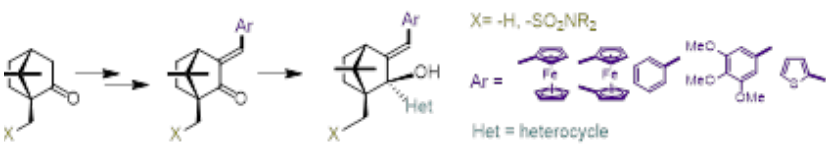

There is a clear trend showing that the presence of conjugated ferrocenylmethylidene group is essential for the cytotoxicity, however different substituents within the sulfonamide groups can further influence the activity.

References:

[1]. Reddy NL, Hill J, Ye L, Fernandes PB, Stout DM (2004). Bioorg Med Chem Lett 14: 5645-5649.

\section{P7 - Preparation of side-chain cleaved phytoecdysteroid metabolites activating protein kinase $B$}

Halima Meriem Issaadia , József Csábi ${ }^{a}$, Zoltán Kele ${ }^{\mathrm{b}}$, Tusty-Jiuan Hsieh ${ }^{\mathrm{c}}$, Gábor Tóth $^{\mathrm{d}}$, Attila Hunyadia,

${ }^{a}$ Institute of Pharmacognosy, University of Szeged, 6720 Szeged, Hungary

${ }^{b}$ Department of Medical Chemistry, University of Szeged, 6720 Szeged, Hungary

Graduate Institute of Medicine, Kaohsiung Medical University, Kaohsiung 807 Taiwan, R.O.C

${ }^{\mathrm{d}}$ NMR Group, Department of Inorganic and Analytical Chemistry, Budapest

University of Technology and Economics, H-1111 Budapest, Hungary

e Interdisciplinary Center for Natural Products, University of Szeged, 6720 Szeged, Hungary

Phytoecdysteroids are analogues of arthropod steroid hormones found in plants. Due to their various health benefits accompanied by a negligible acute toxicity in mammals including humans [0], phytoecdysteroids attracted a great scientific attention in the past 60 years. The mechanism of action of these compounds in mammals is known to involve the activation of protein kinase B (Akt) [2]

The aims of the current study were to prepare a series of new side-chain cleaved ecdysteroid derivatives including autoxidized derivatives of poststerone, and to evaluate their activity on the protein kinase $B$ activation in murine skeletal muscle cells The side-chain cleavage between the 20,22-diol of 20-hydroxyecdysone (20E), 2-deoxy-20E, ajugasterone $\mathrm{C}$, polypodine $\mathrm{B}$, dacryhainansterone and calonysterone was performed by using the hypervalent reagent [bis(trifluoroacetoxy)iodo]benzene or phenyliodine(III) diacetate. The combined use of various chromatographic techniques, including rotation planar chromatography, flash chromatography, centrifugal partition chromatography (CPC) and preparative HPLC, allowed us to obtain the side-chain cleaved analogues of the above ecdysteroids. The base-catalyzed autoxidation of poststerone was completed in a mixture of $\mathrm{MeOH}: \mathrm{H} 2 \mathrm{O}(1: 9, \mathrm{v} / \mathrm{v})$ in the presence of $\mathrm{NaOH}$, and the purification of the resulting oxidized derivatives was performed by $\mathrm{CPC}$ and preparative HPLC.

Altogether 12 ecdysteroid metabolites including 8 new compounds were obtained and characterized by mass spectrometry and comprehensive 1 and 2D NMR spectroscopy. The compounds were tested for their capacity to increase the activation of protein kinase B in murine skeletal muscle cells, and 9 of them were found to exert significant activity.

Acknowledgments

This work was supported by the NKFIH, Hungary (K119770), the EU-funded Hungarian grant EFOP-3.6.1-16-2016-00008, and GINOP-2.3.2-15-2016-00012. A.H. acknowledges the János Bolyai fellowship of the Hungarian Academy of Sciences and the Kálmán Szász Prize.

References:

[1]. Dinan L (2009). Insect Biochem Physiol 72: 126 - 141.

[2]. Gorelick-Feldman J, Cohick W, Raskin I (2010). Steroids 75: 632 - 637.

P8 - Analogues of the lignan pinoresinol and their reversal activities on cell multidrug resistance mediated by $\mathbf{P}$-glycoprotein $(\mathrm{P}-\mathrm{gp})$

Jerónimo Laiolo ${ }^{a}$, Tihomir Tomašičc, Domingo Mariano Vera ${ }^{\mathrm{b}}$, María Laura González $^{\mathrm{a}}$, Priscila A. Lanza ${ }^{\mathrm{b}}$, Danijel Kikelj ${ }^{\mathrm{c}}$, María Cecilia Carpinella ${ }^{\mathrm{a}}$

${ }^{a}$ Research Institute of Natural Resources and Sustainability José Sánchez Labrador S.J. (IRNASUS-CONICET), School of Chemistry, Catholic University of Córdoba, Argentina ${ }^{b}$ Department of Chemistry, School of Exact and Natural Sciences, National University of Mar del Plata, Mar del Plata, Argentina

${ }^{c}$ Faculty of Pharmacy, University of Ljubljana, Republic of Slovenia

P-glycoprotein (P-gp) is a multi-specific efflux transporter belonging to ATP-binding cassette $(A B C)$ family, which significantly impacts on the resistance to anticance drugs. Previous results demonstrated that the lignan pinoresinol was able to reverse resistance to doxorubicin in P-gp overexpressed leukemia cells. This compound also increased the accumulation of drugs inside the cells, showed a low activation of ATP hydrolysis and antagonized verapamil-stimulated ATPase activity. On the other hand, pinoresinol decreased the presence of P-gp in the cell surface [1].

With the aim of finding derivatives with improved activity, pinoresinol was used as reference compound for a similarity search using ROCS (OpenEye Scientific Software) in the small library of PXR ligands [2,3] and ZINC DrugsNow subset of commercially available compounds. Twenty three compounds were identified as potential candidates to be submitted to molecular docking studies on P-gp. The modelling showed low estimated free energies of binding ranging from -7.07 to $-10.89 \mathrm{Kcal} / \mathrm{mol}$ for a panel of compounds, with similar values to those obtained with the potent inhibitors used as reference. From the results obtained, seven compounds were obtained and submitted to in vitro screening. The compounds KDS-26 and ZINC44917327 successfully restored sensitivity to doxorubicin and increased the intracellular doxorubicin accumulation in $\mathrm{nM}$ range. A detailed description of the results will be presented.

The results obtained positioned these compounds as potential leads for effective agents to overcome P-gp-mediated MDR, leading to better outcomes for chemotherapy.

References:

[1] González ML, Vera DMA., Laiolo J, Joray MB, Maccioni M, Palacios SM, Molina G, Lanza PA, Gancedo S, Rumjanek V, Carpinella MC (2017). Front. Pharmacol. 8. $1-19$

[2] Hodnik Ž, Tomašič T, Smodiš D, D'Amore C, Peterlin Mašič L, Fiorucci S, Kikel D (2015). Eur. J. Med. Chem. 103: 551-562.

[3] Hodnik Ž, Peterlin Mašič L, Tomašić T, Smodiš D, D'Amore C, Fiorucci S, Kikelj D (2014). J. Med. Chem. 57: 4819-4833. 


\section{P9 - Trojan Horse strategy: an achiles heel of resistant bacteria}

\section{Kevin Ferreira a, Verena Fetz ${ }^{\mathrm{b}}$, Hans Prochnowa, Mark Brönstrup ${ }^{\mathrm{a}}$}

${ }^{a}$ Helmholtz Centre for Infection, Braunschweig, Germany

${ }^{\mathrm{b}}$ German Federal Institute for Risk Assessment, Berlin, Germany

The design of novel label/antibiotic-siderophore conjugates with a crucial proof of internalization represents a milestone towards theranostics against bacteria of the ESKAPE panel. Infections caused by multidrug-resistant Gram-negative bacteria result in significant mortality and morbidity worldwide despite the development of new anti-infective drugs [1]. The need for novel antibiotics is currently not met by R\&D efforts, in particular in the area of infections caused by Gram-negative bacteria. A main scientific hurdle is the lack of understanding how to assure a sufficient translocation of bioactive molecules across the Gram-negative cell wall. Another limitation is the lack of reliable and sensitive methods that permit the detection of bacteria at early stages of infections where antibiotic treatments would still be effective [2]. Our efforts to induce an active transport of small molecules into Gram-negative bacteria and methods to quantify such uptake were performed.

We report a series of theranostic agents based on DOTAM derivatives comprising siderophores that actively target bacteria, inhibit bacterial growth and demonstrate efficacy to visualize bacterial infections (Figure 1).

Preliminary studies were achieved to characterize our designed conjugates as $\mathrm{Fe}(\mathrm{III})$ chelating agents. To quantify the intracellular accumulation of such conjugates, we pursue an fluorogen activating protein-based approach (FAP) that allow the determination of the subcellular localization of malachite green dye-coupled small molecules. This system serves to validate the efficiency of vehicles for bacterial penetration [3]. We expect that the use of such active targeting principles attached to the described DOTAM/Metal-platform will be generally useful for the development of new drug conjugates that have different cellular targets and modes of action against Gram-negative bacteria.

References:

[1]. Ho, J.; Tambyah, P. A.; Paterson, D. L. Curr. Opin. Infect. Dis. 2010, 23, 546. [2]. Ning, X.; Lee, S.; Wang, Z.; Kim, D.; Stubblefield, B.; Gilbert, E.; Murthy, N. Nat. Mater., 2011, 10, 602.

[3]. Ferreira, K., Hu, H., Fetz, V., Prochnow, H., Rais, B., Mmüller, P., Brönstrup, M., Angew. Chem. 2017 (Accepted).

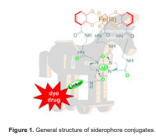

P10 - Sarco/endoplasmic Ca2+-ATPase (SERCA) and pancreatic beta cells modified by prenylated phenolic compounds from Morus nigra

\section{Vladimir Heger ${ }^{\text {a }}$, Jana Viskupicova ${ }^{\text {a }}$, Zoofishan Zoofishan ${ }^{\text {b }}$, Attila Hunyadi ${ }^{\text {b }}$ Lubica Horakova}

anstitute of Experimental Pharmacology and Toxicology, Slovak Academy of Sciences, Bratislava Slovakia bInstitute of Pharmacognosy, University of Szeged

The leaves and root bark of Morus nigra are rich sources of phenolic compounds used for the prevention and treatment of a wide variety of chronical diseases, including diabetes and hypertension. From the root bark, seven prenylated phenolic compounds were isolated in pure form, identified by HRMS and 1 and 2D NMR techniques: morusin, kuwanon E, kuwanon U, albanol A, albanol B, moracin P and moracin R. $\mathrm{Ca} 2+-$ ATPase is an enzyme which belongs to the main calcium regulatory proteins. Dysfunction of $\mathrm{Ca} 2+-\mathrm{ATPase}$ is associated with oxidative-stress-related diseases and aging [1]. Modulation of $\mathrm{Ca} 2+-\mathrm{ATP}$ ase by phenolic compounds may be a therapeutic tool for improvement of complications associated with human diseases. We found a correlation between reduction of SERCA activity in non-cellular system and decrease of cell viability as well as initiation of apoptosis in pancreatic beta cells induced by prenylated phenolic compounds (morusin, Kuwanon E and U, albanol A and B). These properties may be useful in cancer treatment. On the other hand, some of the isolated compounds (moracin P and R) increased cell viability and did not induce apoptosis, suggesting that they might have a potential use against cardiovascular diseases and/ or diabetes.

Acknowledgments:

This work was performed in collaboration within COST Action CM1407. Support from the Slovak National grants VEGA 2/0111/16 and APVV-15-0455, and from the National Research, Development and Innovation Office, Hungary (NKFIH; K119770) is acknowledged. AH acknowledges the János Bolyai fellowship of the Hungarian Academy of Sciences, and the Kálmán Szász Prize.

References:

[1] Tong X, Evangelista A, Cohen RA (2010). Curr Opin Pharmacol 10: 133-138.
P11 - Antibacterial compounds isolated from Lepechinia meyenii and synthesis of analogues with improved activity

Macarena Funes Chaban a, Antonia I. Antoniouc, Mariana B. Joray ${ }^{\mathrm{a}}$, Catherine A. Karagiannic, Claudia Sola ${ }^{\mathrm{b}}$, José L. Bocco ${ }^{\mathrm{b}}$, María I. Crespo a, Sara M. Palacios ${ }^{\mathrm{a}}$, Constantinos Athanassopoulos ${ }^{\mathrm{c}}$, María C. Carpinella ${ }^{\mathrm{a}}$

${ }^{a}$ Research Institute of Natural Resources and Sustainability José Sánchez Labrador S.J. (IRNASUS-CONICET), School of Chemistry, Catholic University of Córdoba, Argentina ${ }^{b}$ CIBICI-CONICET and Department of Clinical Biochemistry, Faculty of Chemical Sciences, National University of Córdoba, Argentina

c Synthetic Organic Chemistry Laboratory, Department of Chemistry, University of Patras, Greece

Bacterial infections are dramatically increasing every day for diverse reasons, mainly due to the development of resistance to conventional antibiotics. Staphylococcus aureus resistant to methicillin and gentamicin (MRSA) is one of the major pathogen being responsible for $60-89 \%$ of nosocomial infections.

The urgent need to develop new antibiotics to deal with ever more resistant bacteria is therefore of great interest to researchers and pharmaceutical industries.

Plants have played a dominant role in the development of sophisticated traditional medicine systems. The chemodiversity in nature offers a valuable source of new drugs, new drug leads, and new chemical entities (NCEs). Although many plant families have been investigated, the plant world is far from being totally explored and this also applies to the native flora from Argentina.

In our ongoing effort to identify antibacterial agents of plant origin, sixty nine native In our ongoing effort to identify antibacterial agents of plant origin, sixty nine native
plants from central Argentina were screened against Enterococcus faecalis, methicillinsusceptible S. aureus (MSSA), MRSA, CA-MRSA, HA-MRSA and LA-MRSA Extract from Lepechinia meyenii (Walp.) Epling showed itself the most effective with MIC values ranging from 32 to $125 \mu \mathrm{g} / \mathrm{ml}$, showing an outstanding selectivity agains all MRSA strains. Bioguided fractionation led to the isolation of carnosol and rosmanol as its active principles with MIC values ranging from 9 to 62 and 15 to $125 \mu \mathrm{g} / \mathrm{ml}$, respectively.

Analogues of the isolated diterpenes with improved activity were obtained synthetically from abietic acid. Among them, two promising compounds showed MIC values ranging from 7 to $125 \mu \mathrm{g} / \mathrm{ml}$ against the bacteria tested. A structure-activity relationship will be described in detail.

The results obtained positioned these compounds as potential candidates for effective agents to tackle infections caused by pathogenic bacteria; especially by resistant phenotypes.
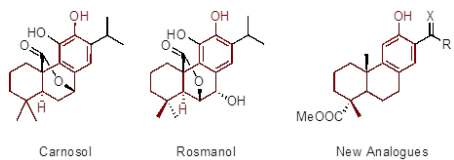

P12 - Discovery of enantiopure tyrosinol-derived bicyclic lactam that acts as NMDA receptor antagonist

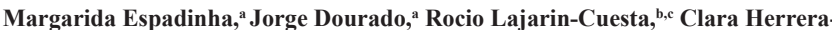
Arozamena,${ }^{\mathrm{d}}$ Lidia M. D. Gonçalves, ${ }^{\mathrm{a}}$ María Isabel Rodríguez-Franco, ${ }^{\mathrm{d}}$ Cristobal de los Rios, ${ }^{\mathrm{b}, \mathrm{c}}$ Maria M. M. Santos ${ }^{\mathrm{a}}$

${ }^{\text {a }}$ Research Institute for Medicines (iMed.ULisboa), Faculty of Pharmacy, Universidade de Lisboa, Lisboa, Portugal

b Instituto Teófilo Hernando, Facultad de Medicina, Universidad Autonoma de Madrid, Madrid, Spain

${ }^{\mathrm{c}}$ Instituto de Investigacion Sanitaria, Hospital Universitario de la Princesa, Madrid, Spain d Instituto de Química Médica (IQM-CSIC), Madrid, Spain

N-Methyl-D-aspartate (NMDA) receptors belong to the family of ionotropic glutamate receptors (iGluRs) and are localized in the cell membrane of neurons.1 These receptors are fundamental for the normal function of the central nervous system (CNS) and play a vital role in the normal development of the nervous system. The over-activation of NMDA receptors leads to neuronal loss associated with major neurological disorders and, for this reason, the development of effective NMDA receptor antagonists is and, for this reason, the development of effective NMDA receptor antag
promising therapeutic approach to fight these neurodegenerative diseases.1

Here we will present our latest results on the hit optimization of aminoalcohol derived bicyclic lactams as NMDA receptor antagonists. 2 A small library of twentytwo enantiopure target small molecules were designed, synthesized, and evaluated as NMDA receptor antagonists. Their capacity to inhibit NMDA-induced increase of intracellular Ca2+ levels was measured, using in vitro cultures of embryonary rat cortical neurons and $\mathrm{Ca} 2+$-sensitive fluorescent dye Fluo-4. Most compounds showed NMDA receptor antagonism and one (S)-tyrosinol derived bicyclic lactam revealed an IC50 value in the same order of magnitude as that of memantine (NMDA recepto antagonist in clinical use). Finally, we have shown that this small molecule can cross the blood-brain barrier (determined by an in vitro assay) and is non-hepatotoxic. Collectively, our results underline the potential therapeutic use of tyrosinol-derived bicyclic lactams in reducing NMDA receptor activity.2

Acknowledgments:

This work was supported by FCT (Fundação para a Ciência e a Tecnologia) through iMed.ULisboa (UID/DTP/04138/2013), and grants PTDC/QUI-QUI/111664/2009 an IF/00732/2013 (M. M. M. Santos), and also by Instituto de Salud Carlos III, Spanish Ministry of Health (PI13/00789), by Spanish Ministry of Economy and Competitiveness (MINECO, grants SAF2012-31035 and SAF2015-64948-C2-1-R), and by Consejo Superior de Investigaciones Científicas (CSIC, grant PIE-201580E109).

References:

[1] a) Stawski P., Janovjak H., Trauner D. Bioorg. Med. Chem. 2010, 18, 7759-7772. b) Morris R. Neuropharmacology, 2013, 74, 32-40.

[2] Espadinha M., Dourado J., Lajarin-Cuesta R., Herrera-Arozamena C., Gonçalves L., Rodríguez-Franco I., de los Ríos C., Santos M. M. M. ChemMedChem. 2017, 12 537-545. 
P13 - Extending the binding of cyclohexanedione derivatives towards the $\alpha \beta$ tubulin interface

Marta Gargantilla, ${ }^{a}$ Oskia Bueno ${ }^{\mathrm{a}}$, Juan Estevez Gallego ${ }^{\mathrm{b}}$, Andrea E. Prota c, J. Fernando Díaz ${ }^{\mathrm{b}}$, Michel O. Steinmetz ${ }^{\mathrm{c}}$, María-José Camaras ${ }^{\mathrm{a}}$, Federico Gago, ${ }^{\mathrm{d}}$ Sandra Liekens, ${ }^{\mathrm{e}}$ Eva-María Priego and María-Jesús Pérez-Pérez

a Instituto de Química Médica (IQM-CSIC), Juan de la Cierva 3, 28006 Madrid, Spain.

${ }^{b}$ Centro de Investigaciones Biológicas (CIB-CSIC), Ramiro de Maeztu 9, 28040 Madrid, Spain

${ }^{c}$ Laboratory of Biomolecular Research, Paul Scherrer Institut, 5232 Villigen, Switzerland

${ }^{d}$ Department of Biomedical Sciences, University of Alcalá, Unidad Asociada CSIC, Alcalá de Henares, Madrid, Spain

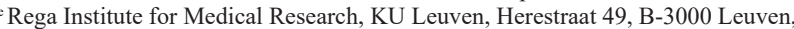
Belgium

Compounds binding at the colchicine site in tubulin have received renewed interest Compounds binding at the colchicine site in tubulin have received renewed interest
due to their capacity to act as vascular-disrupting agents (VDAs). The prototype
VDA acting at the colchicine site is the natural product combretastatin A4 (CA-4) [1], VDA acting at the colchicine site is the natural product combretastatin A4 (CA-4) [1],
that has reached clinical trials through its prodrugs. However, an increasing number of compounds belonging to different chemical families are also able to bind at the colchicine site of an $\alpha \beta$-tubulin heterodimer and to exhibit antivascular properties [2]. We have reported on a new family of colchicine-site binders with a cyclohexanedione skeleton, the prototype of which is TUB075. This compound binds tubulin with an skefton, the prototype of which is TUB low sub $\mu \mathrm{M}$ range [3]. We have now determined the crystal structure of the tubulinlow sub $\mu \mathrm{M}$ range [3]. We have now determined the crystal structure of the tubulin-
TUB075 complex and the binding site has been explored with the computational tool cGRILL [4] to highlight the molecular interaction fields or "affinity maps". Using the hydrophobic probe $(\mathrm{CH} 3)$ to the TUB075-tubulin complex, two new unexplored regions were identified as suitable for binding. To exploit one of these tunnel-shape regions, which extends from the ethoxy substituent towards the $\alpha \beta$-tubulin heterodimer interface, new derivatives were designed, synthesized and evaluated for their tubulin binding affinity and for their antiproliferative activity.

Acknowledgements:

Acknowledgements:

This project has been financed by the Spanish SAF2015-64629-C2-1-R (MINECOFEDER), BFU2016-75319-R (AEI/FEDER, UE) from MINECO, Comunidad de Madrid (BIPEDD2; ref. P2010/BMD-2457) and the COST Action CM1407 (to M-J. P.-P. S.L., M.O.S. and J.-F.D.).

References:

[1]. Gasparini, R, Prota, AE, Bargsten, K et al (2017) Chem 2: 102-113.

[1]. Gérez-Pérez, MJ, Priego, EM, Bueno, O et al (2016). J Med Chem. 59: 8685-8711.

3]. Canela MD, Bueno O, Noppen, S et al (2016) RSC Adv 6:19492-19506

[4]. Cortés-Cabrera, A, Gago, F. Available at http://farmamol.uah.es/index.php/en/

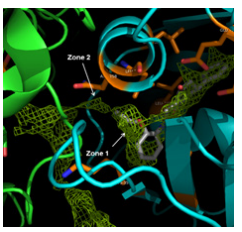

\section{P14 - Synthesis of planar chiral ferrocene sulfonamides}

\section{bearing fenchane and menthane moieties}

Martin Ravutsov ${ }^{\text {a }}$ Georgi Dobrikova ${ }^{\text {a }}$ Miroslav Dangalov ${ }^{\text {a }}$ Boris Shivachev $^{\mathrm{b}}$, Vladimir Dimitrov ${ }^{\mathrm{a}}$

Institute of Organic Chemistry with Centre of Phytochemistry, Bulgarian Academy of Sciences, Acad. G. Bonchev Str. 9, Sofia 1113, Bulgaria

'Institute of Mineralogy and Crystallography "Acad. Ivan Kostov", Bulgarian

Academy of Sciences, Acad. G. Bonchev Str. 107, Sofia 1113, Bulgaria

Ferrocene derived compounds have attracted much attention in a wide range of scientific areas. 1 The stability of the ferrocenyl group in aqueous and aerobic media, and its favorable electrochemical properties, have made ferrocene and its derivatives suitable molecules for biological applications.2 A recent work of our group has revealed promising cytotoxic and cytostatic activities against large set of cancer and normal human cell lines of $(+)$-camphor derivatives bearing ferrocenylmethylidene and sulfonamide moieties. 3 In another study we have shown comparable to ethambutol in vitro activity of fenchane-based sulfonamides against Mycobacterium tuberculosis

in vitro actir

In this regard, herein is reported a diastereoselective ortho-lithiation of chiral ferrocenesulfonamides leading to new planar chiral fenchol- and menthol-derivatives with potential biological activity. The configuration of the isolated planar chira diastereoisomers was determined by NMR experiments and/or X-ray crystallography. References:

[1]. Adams R. D. (2001). J. Organomet. Chem. 637-639: 1-849.

[2]. Ornelas C. (2011). New J. Chem. 35: 1973-1985 and cited therein

[3]. Kamenova-Nacheva M., Schröder M., Pasheva E., Slavchev I., Dimitrov V., [3]. Kamenova-Nacheva M., Schröder M., Pasheva E., Slavchev I., Dimitrov V., J. Chem., in press.

[4] Dobrikov G. M., Valcheva V., Nikolova Y., Ugrinova I., Pasheva E., Dimitrov V. (2014). Eur. J. Med. Chem. 77: 243-247.

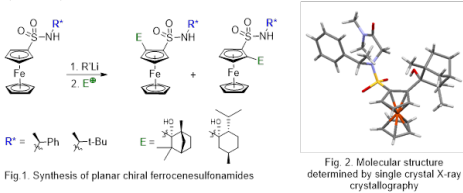

P15 - NDosage and Time Related Efficacy Assessment of Growth Inhibitory Activity of Ankaferd Hemostat on Primary Melanoma Cells and Cell Lines

Mehdi Ghasemia , Seyhan Turk ${ }^{b}$, Umit Malkanc, Duygu Mutlua , Helin Hocaoglua, Ali Gurea ${ }^{a}$ Ibrahim C. Haznedaroglu ${ }^{\mathrm{c}}$

${ }^{a}$ Department of Molecular Biology and Genetics, Bilkent University, Ankara, Turkey ${ }^{b}$ Department of Biochemistry, Faculty of Pharmacy, Hacettepe University, Ankara, Turkey ${ }^{\mathrm{c}}$ Department of Hematology, Faculty of Medicine, Hacettepe University, Ankara, Turkey

Ankaferd Hemostat (ABS) is the first and only patented Turkish drug which is demonstrated in multiple studies to exert anti-cancer effects. ABS is a natural drug consisting of five different plant extracts. The aim of the present study was to determine the effect of Ankaferd Hemostat on viability of melanoma cells. We believe this is of great importance as the rate of malignant melanoma has been increasing recently. For this purpose different melanoma cell lines and primary cells were used in the present study. These cells were treated with different concentrations of ABS to assess the impact of different dosages of the drug. All cells treated with different concentrations were incubated for different time intervals. After the data had been obtained, one tailed T-tes was used to determine whether the Ankaferd Hemostat would have any significan inhibitory impact on cell growth. We demonstrated in the present study that cells treated with Ankaferd Hemostat showed a significant decrease in cell viability compared to control groups. Based on the findings of the present study, we conclude that Ankaferd Hemostat is an effective drug against melanoma cells. Moreover we demonstrated that the cells showed different resistances against ABS which depended on the dosage applied and the time the treated cells had been incubated. We also demonstrated an inverse relationship between the concentration of the drug and the incubation time on one hand and the viability of the cells on the other hand, i.e. increasing the concentration of the drug and the incubation time had a negative impact on cell viability.

References:

[1]. Goker H, Cetinkaya D, Kilic E (2008). Naviga Publications 1: 109.

[2]. Haznedaroglu BZ, Beyazit Y, Walker SL (2012). Crit Rev Oncol Hematol 83(1): $21-34$

[3]. Beyazit Y, Kurt M, Kekilli M (2010). Altern Med Rev 15(4): 329-336.

\section{P16 - Subgroups of Acute Leukemia Based on RAS Gene Family Expression}

Seyhan Turk ${ }^{b}$, Mehdi Ghasemi ${ }^{a}$, Umit Malkanc, Nilgun Sayinalpc, Mufide Okay ${ }^{c}$, Ibrahim C. Haznedarogluc, Ali Gure ${ }^{\mathrm{a}}$

${ }^{a}$ Department of Molecular Biology and Genetics, Bilkent University, Ankara, Turkey ${ }^{b}$ Department of Biochemistry, Faculty of Pharmacy, Hacettepe University, Ankara, Turkey Department of Hematology, Faculty of Medicine, Hacettepe University, Ankara, Turkey

Hematological cancers including Acute myeloblastic leukemia (AML) and Acute lymphoblastic leukemia (ALL) in terms of incidence and mortality, are the second most important cancer type in Turkey. Numerous studies show that cancer patients respond differently to treatment thus supporting the idea of personalized therapy need for individuals.

Renin angiotensin system (RAS) have key roles in AML and ALL progression and it has been shown by many studies suggests that these system's genes might be good biomarkers for AML and ALL personalized therapy.

We aimed to identify RAS gene based homogeneous subgroups of acute leukemia and determine the most effective chemotherapoetic agent for each subgroup. After validation and verification of the results, more effective drugs can be recommended for the use in clinics for chemotherapy of AML and ALL.

Results of our preliminary studies showed that we are able to identify subgroups of AML and ALL as well as correlating each existing subgroup with FDA approved drugs. Considering the long and highly cost process of developing new drugs for cancer treatment makes the present study all the more valuable. In addition, there is a serious need for change in AML and ALL therapy since there is no highly effective chemotherapy protocol available for their treatment. Welcome Trust Sanger (WTS) and Cancer Cell Line Encyclopedia (CCLE) databases will be used to determine subgroups of AML and ALL based on RAS genes or whole genome expression using standard deviation and hierarchical clustering analysis. The most effective drugs for each subgroup will be identified using Pearson's $\mathrm{r}$ correlation analysis with drug sensitivity data (IC50, IC50, Amax, Aare, etc.) available in same databases. Further validation tests will be performed by in vitro validation using AML and ALL cell lines: drug sensitivity profiles will be determined and gene expression will be shown by Q-RTPCR.

References:

[1]. Beyazit Y, Aksu S, Haznedaroglu I (2007). Nat Med 99: 57-63.

[2]. Beyazit Y, Purnak T, Haznedaroglu I (2011). Cardiology Research and Practice $1: 714515$. 


\section{P17 - Ferrocene quinidine - epimers sensitize human cancer cell lines to paclitaxel exerting pro-oxidant activity}

\section{Ana Podolski-Renića , Szilvia Bősze ${ }^{\mathrm{b}}$, Jelena Dinića, László Kocsis ${ }^{\mathrm{c}}$, Ferenc} Hudecz $^{\mathrm{b}, c}$, Antal Csámpai ${ }^{\mathrm{d}}$ and Milica Pešića

aDepartment of Neurobiology, Institute for Biological Research "Siniša Stanković" (IBISS), University of Belgrade, Belgrade, Serbia

bMTA-ELTE Research Group of Peptide Chemistry, Eötvös Loránd University, Budapest, Hungary

'Department of Organic Chemistry, Eötvös Loránd University (ELTE), Budapest, Hungary ${ }^{d}$ Department of Inorganic Chemistry, Eötvös Loránd University (ELTE), Budapest, Hungary

Our study of ferrocene - containing compounds with cinchona moiety revealed their considerable anticancer potential [1]. We investigated the mechanism of action of the most promising isomers: quinidine - epimers in two human multidrug resistant (MDR) cancer cell lines and their sensitive counterparts (colorectal carcinoma DLD1-TxR DLD1 and glioblastoma U87-TxR/U87). MDR cancer cell lines were established by continuous exposure to paclitaxel (PTX) and developed new characteristics such as overexpression of P-glycoprotein, changes in cell cycle and antioxidant capacity $[2,3]$ The presence of MDR phenotype did not diminish the activity of compounds suggesting that ferrocene quinidine - epimers are not substrates for P-glycoprotein. Considering that ferrocene - based anticancer agents, at least in part, could act through the generation of reactive oxygen species (ROS), we investigated the potential of our compounds to induce ROS production. The compounds more readily increased ROS level and induced mitochondrial damage in MDR than in corresponding sensitive cancer cells. Consequently, ferrocene quinidine - epimers induced cell death more efficiently in MDR cancer cells. Our results also suggest that these compounds could act as inhibitors of autophagy. Simultaneous combined treatments with PTX increased the sensitivity of MDR cancer cells. Therefore, our study showed that the ferrocene - quinidine epimers are selective towards MDR cancer cells and possess potential to overcome PTX resistance [4].

References:

[1]. Kocsis L, Szabó I, Bősze S, Jernei T, Hudecz F, Csámpai A (2013). Bioorg Med Chem Lett 26(3):946-949.

[2]. Podolski-Renić A, Andelković T, Banković J, Tanić N, Ruždijić S, Pešić M (2011). Biomed Pharmacother 65:345-353.

[3]. Stanković T, Dankó B, Martins A, Dragoj M, Stojković S, Isaković A, Wang HC, Wu YC, Hunyadi A, Pešić M (2015). Cancer Chemother Pharmacol 76(3):555-565.

[4]. Podolski-Renić A, Bősze S, Dinić J, Kocsis L, Hudecz F, Csámpai A, Pešić M

(2017). Metallomics doi: 10.1039/c7mt00183e.

\section{P18 - Enantioselective Total Synthesis of (+)-Gephyrotoxin 287C}

Miriam Piccichè, Alexandre Pinto, Rosa Griera, Joan Bosch and Mercedes Amat

Laboratory of Organic Chemistry, Faculty of Pharmacy and Food Science, University of Barcelona, 08028-Barcelona

Gephyrotoxin $287 \mathrm{C}$ is a decahydroquinoline (DHQ) alkaloid isolated from the skin extracts of dendrobatid frogs that shows an interesting array of neurological activities. Our approach to the synthesis of this alkaloid involves the use of a phenylglycinolderived tricyclic lactam as the starting enantiomeric scaffold, which can be easily converted to enantiopure $\mathrm{C}-5$ substituted 2 -oxo-cis-DHQ derivatives bearing a trans $\mathrm{H}-4 \mathrm{a} / \mathrm{H}-5$ relative configuration. ${ }^{1}$

Using this methodology, we prepared cis-DHQ 1, which has the correct configuration at three of the five stereocenters of gephyrotoxin $287 \mathrm{C}$. To complete the synthesis of this target, three main transformations had to be addressed: the elaboration of the appropriate C-2 and C-5 chains and the final closure of the pyrrolidine ring.

First, a Stille coupling with the vinyl triflate prepared from 1 was used for the introduction of a 3-propenyl chain. The subsequent stereoselective reduction of the enamide moiety of 2 took place under stereoelectronic control to give 3 , with a $\mathrm{H}-2 / \mathrm{H}-$ 8 a trans relative configuration. A subsequent hydroboration-oxidation of the termina double bond, followed by a Dess-Martin oxidation and a Wittig olefination, generated the unsaturated ester function in 4 .

The elongation of the C-5 lateral chain to introduce the cis-enyne moiety was carried out with total stereoselectivity by a Peterson-Yamamoto reaction from the corresponding aldehyde.

Finally, an intramolecular aza-Michael addition of the secondary amine on the unsaturated ester, followed by reduction of the ester group, provided the tricyclic alkaloid $(+)$-gephyrotoxin $287 \mathrm{C}$.

Acknowledgements:

Acknowledgements:
Financial support from the MINECO/FEDER (CTQ2015-65384-R) and the Generalitat the Catalunya (2014-SGR-155) and the networking contribution from the COST Action CM1407.

References:

[1]. Amat, M.; Griera, R.; Fabregat, R.; Molins, E.; Bosch, J. Angew. Chem. Int. Ed. 2008, 47, 3348.

[2]. Amat, M.; Fabregat, R.; Griera, R.; Bosch, J. J. Org. Chem. 2009, 74, 1794.

[3]. Amat, M.; Fabregat, R.; Griera, R.; Florindo, P.; Molins, E.; Bosch, J. J. Org. Chem. $2010,75,3797$

[4]. Amat, M.; Ghirardi, E.; Navio, L.; Griera, R.; Llor, N.; Molins, E.; Bosch. J. Chem. Eur. J. 2013, 19, 16044 .

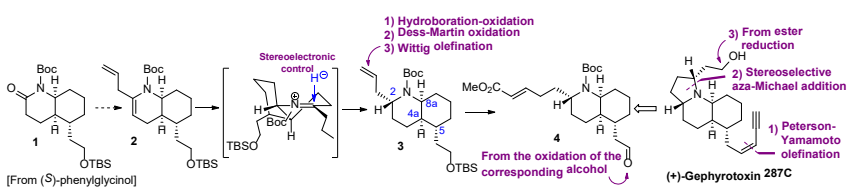

P19 - Chemoenzymatic tactics towards the synthesis of phenylethanoid apioglucosides

Peter Kis, Mária Mastihubová

Institute of Chemistry, Slovak Academy of Sciences, Dúbravská cesta 9, SK-845 38 Bratislava, Slovakia

Naturally occurring glycosides containing $\beta$-D-apiofuranose, from among saponins, flavonoids, or phenylethanoid glycosides play crucial roles in the biochemistry of plants [1]. Most of the isolated compounds from the last mentioned structural group possess interesting biological activities such as antimicrobial, hepatoprotective, antitumor, antiviral, etc. [2]. Synthesis of phenylethanoid apioglucosides is therefore an important step in elucidating the relationship between the structures and biological activities of these natural products.

This work deals with the chemoenzymatic synthesis of four phenylethanoid apioglucosides - Darendoside A (1) isolated from Scutelluria orientalis [3], Osmanthuside H (2) isolated from Osmanthus asiaticus [4], Cuneataside (3) isolated from Sargentodoxa cuneata [5] and the non-natural apioglucoside 4 . The key acceptor intermediates 7-10 were apiosylated with trichloroacetimidate donor 6 prepared from 5 in two steps involving enzymatic deprotection of anomeric hydroxyl of 5 . The use of regioselective enzymatic protecting techniques in the synthesis of the apiosyl donor as well as the suitable glucosyl acceptors 7 and 8 will be discussed.

References:

[1]. Pičmanová M, Møller BL (2016). Glycobiology 26: 430-442.

[2]. Fu G, Pang H, Wong YH (2008). Curr Med Chem 15: 2592-2613.

[3]. Bașaran AA, Calis I, Saracoğlu I, Sticher, O (1993). Phytochemistry 32: 1621-1623.

[4]. Sugiyama M, Kikuchi M (1993). Phytochemistry 32: 1553-1555.

[5]. Case R, Chang J (2005). Phytochemistry 66: 2752-2758.

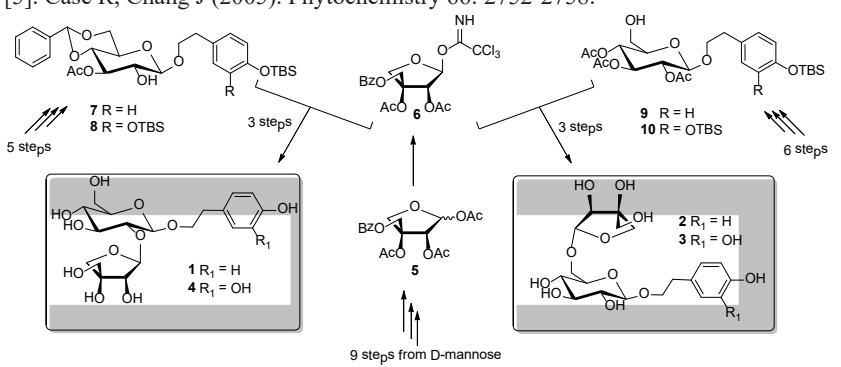

P20 - Synthesis of (-)-sielboldianin A using a squaramide catalyzed enantioselective bromolactonization reaction

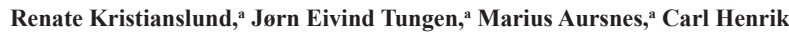
Gørbitz ${ }^{\mathrm{b}}$ and Trond Vidar Hansen

aSchool of Pharmacy, Department of Pharmaceutical Chemistry, Oslo, Norway ${ }^{b}$ Department of Chemistry, University of Oslo, Norway

The bisabol derived sesquiterpene sielboldianin A (1) was isolated from the stem bark of Fraxinus sielboldiana in 2011.1 The relative configuration was determined by a NOE difference experiment, while the absolute configuration was proposed on the basis of biogenetic consideration. This is the first report of a sesquiterpene in the Fraxinus genus. Fraxinus sielboldiana Blume (Oleaceae) is a folk medicine with diuretic, antifebrile, analgesic and anti-rheumatic activities.

One of the key steps in our synthesis towards 1 is the organocatalyzed enantioselective bromolactonization of the unsaturated carboxylic acid 3 using squaramide catalyst 5.2 This method produced bromolactone 4 with the new stereogenic center installed in $90 \%$ enantiomeric excess and $91 \%$ yield. Our synthesis of the suggested structure of is presented, that enabled the establishment of the absolute configuration of naturally occuring 1 to be $(+)$-sielboldianin A.

References:

[1]. Lin S, Zhang Y.-L, Liu M.-T, Zi J.-C, Gan M.-L, Song W.-X, Fan X.-N, Wang S.-J, Yang Y.-C, Shi J.-G (2011). Acta Pharm. Sin. B. 2: 89.

[2]. Aursnes M, Tungen J. E, Hansen T. V (2016). J. Org. Chem.: 81, 8287.
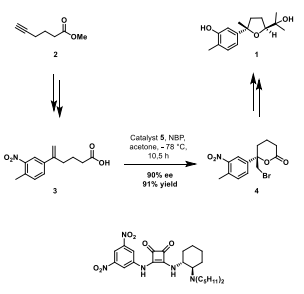


\section{P21 - Identification of novel natural products chemotypes of Hedgehog-dependent tumors inhibitors}

Silvia Corradia,b, Francesca Ghirga ${ }^{a}$, Mattia Moria ${ }^{a}$, Cinzia Ingallina ${ }^{\mathrm{b}}$, Simone Berardozzi $^{\mathrm{a}, \mathrm{b}}$, Elisa De Paolis ${ }^{\mathrm{a}, \mathrm{b}}$, Lucia di Marcotullio ${ }^{\mathrm{c}}$, Romina Alfonsi ${ }^{\mathrm{b}}$, Bruno Botta $^{\text {b }}$, Deborah Quaglio ${ }^{\text {b }}$

a'Center for Life Nano Science@Sapienza, Istituto Italiano di Tecnologia, Rome, Italy ${ }^{b}$ Department of Chemistry and Technology of Drugs, Sapienza University, Rome, Italy 'Department of Molecular Medicine, Sapienza University, Rome, Italy

Hedgehog $(\mathrm{Hh})$ signalling is a morphogenetic pathway that has a crucial role during embryonic development and tissues homeostasis. Aberrant activation of the $\mathrm{Hh}$ pathway occurring either by ligand-dependent or -independent mechanisms is deeply involved in tumorigenesis. In vertebrates, one of the main upstream transducers of involved in tumorigenesis. In vertebrates, one of the main upstream transducers of
the Hh signalling is the transmembrane receptor Smoothened (Smo). For this reason, this receptor is a validated target for the development of anticancer compounds, as underlined by the FDA-approved Smo antagonist Vismodegib (GDC-0449/Erivedge) for the treatment of basal cell carcinoma.[1] However, despite an initial clinica response, a number of drug-resistant Smo mutations have emerged during treatmen with Vismodegib. For this reason, the development of new effective Hh inhibitors represents a major challenge for cancer therapy.

Here, starting from an in house library of natural and synthetic or semi-synthetic compounds, we discovered novel chemotypes of Hh inhibitors (Smo antagonists) by mean of virtual screening against the crystallographic structure of Smo. We identified seventeen potential Smo antagonists, which show a noticeable range of chemical diversity and sources. Hh functional based assay identified the chalcone derivative 12 as the most effective $\mathrm{Hh}$ inhibitor within the test set. The synthetic compound 12 is endowed with a natural scaffold, namely chalcone, and has been synthesized by Claisen-Schmidt reaction[2]. The chalcone 12 binds the Smo receptor and promotes the displacement of Bodipy-Cyclopamine in both Smo WT and drug-resistant Smo mutant. Our molecule stands as a promising Smo antagonist, able to specifically impair the growth of Hh-dependent tumor cells in vitro and in vivo and potentially overcome the associated drug resistance.[3]

References:

[1]. Sekulic A, Migden MR, Oro AE, Dirix L, Lewis KD, Hainsworth JD, Solomon JA, Yoo S, Arron ST, Friedlander PA, Marmur E, Rudin CM, Chang AL, Low JA Mackey HM, Yauch RL, Graham RA, Reddy JC, Hauschild A (2012). N Engl J Med 366: $2171-2179$.

[2]. Sogawa S, Nihro Y, Ueda H., Miki T, Matsumoto H, Satoh T (1994). Biol Pharm Bull 17: 251-256.

[3]. Infante P, Alfonsi R, Ingallina C, Quaglio D, Ghirga F, D'Acquarica I, Di Magno L, Canettieri G, Screpanti I, Gulino A, Botta B, Mori M, Di Marcotullio L (2016). Cell Death \& Disease 7: e2376.

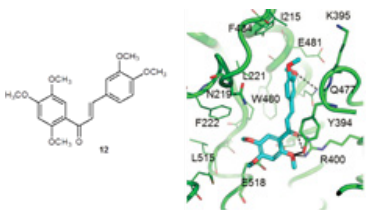

P22 - Synthesis and biological activity of oxidized chalcone derivatives

\section{Tímea Gonda, ${ }^{\mathrm{b}}$ Gabriella Spengler, ${ }^{\mathrm{b}}$ Annamária Kincses, ${ }^{\mathrm{a} A t t i l a ~ C s o r b a, ~}$ ${ }^{a}$ Norbert Kúsz, a Attila Hunyadi}

ansitute of Pharmacognosy, University of Szeged, Eötvös str 6, H-6720-Szeged

bepartment of Medical Microbiology and Immunobiology, University of Szeged, Dóm square 10, H-6720-Szeged

Protoflavones represent a unique and pharmacologically interesting class of naturally occurring molecules: they exert antiviral, anti-angiogenic and cytotoxic activity, and they have lately also been found to interfere with DNA damage response mechanisms [1] Structure-activity relationships revealed that the pharmacophore of these compounds is Structure-activity relationships revealed that the pharmacophore of these compounds is
the unusual non-aromatic p-quinol moiety which can conveniently be synthesized from the corresponding p-phenols by the application of hypervalent iodine reagents[2]. During the current project our aim was to synthesise a potentially bioactive compound library of protoflavone analogs from 4'-hydroxychalcones. The preparation of the key intermedier 4'-hydroxychalcones $(5,6)$ was performed via Claisen-Schmidt condensation. The non-aromatic p-quinol moiety was formed in the presence of hypervalent iodine reagents in various solvent mixtures resulting in compounds 7-13. hypervalent lodine reagents in various solvent mixtures resulting in compounds $7-13$. 14 , followed by oxidative dearomatization in the presence of PIFA resulting in compound 15. Preparation and bioactivity testing of naphtyl analogs of compounds $7-13$ is currently in progress.

In vitro antitumor potential of the compounds was tested against two susceptible/multidrug resistant cancer cell line pairs, including MCF-7 and its doxorubicin-resistant counterpart, and L5178 mouse lymphoma and its sub-cell line transfected to express the human P-glycoprotein (P-gp). Compounds 8-13 and 15 effectively bypassed resistance conferred by P-gp. While compound 14 was inactive, 15 exerted a particularly potent $($ IC $50<200 \mathrm{nM})$ antiproliferative activity on both mouse lymphoma cell lines. Acknowledgements:

This work was supported by the NKFIH, Hungary (K119770). A.H. acknowledges the János Bolyai fellowship of the Hungarian Academy of Sciences and the Kálmán Szász Prize. References:

[1]. Wang H. C, Lee A. Y-L, Chou W-C, Wu C-C, Tseng C-N, Lin K. Y-L, Chang F. R, Chuang D. W, Hunyadi A, Wu Y. C (2012), Mol. Cancer Ther. 11: 1443-1453.

[2]. Hunyadi A, Martins A, Danko B, Chang F. R, Wu Y. C (2014). Phytochem. Rev. 13: $69-77$.

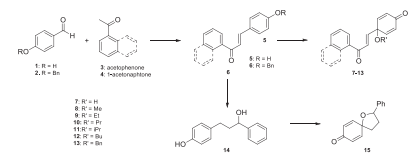

P23 - Optimization of tryptophanol-derived oxazoloisoindolinones: chemical scaffold with interesting anticancer properties

Valentina Barcherini ${ }^{\mathrm{a}}$, Sara Gomes ${ }^{\mathrm{b}}$, Margarida Espadinha ${ }^{\mathrm{a}}$, Joana Loureiro ${ }^{\mathrm{b}}$, Alexandra M.M. Antunes ${ }^{\mathrm{c}}$, Lucília Saraivab ${ }^{\mathrm{b}}$, Maria M.M. Santos

aiMed.Ulisboa, Faculty of Pharmacy, Universidade de Lisboa, Lisboa, Portugal

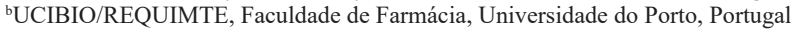
${ }^{\mathrm{C}} \mathrm{CQE}$, Instituto Superior Técnico, Universidade de Lisboa, Portugal

The synthesis of enantiopure drugs is of high importance in the field of pharmaceutical industry as well as, in organic synthesis. One methodology to access enantiomerically pure compounds involves the use of an enantiopure starting material, such as an amino acid/ alcohol, an alkaloid or a carbohydrate, that acts as chiral inductor. Starting from the enantiopure aminoalcohol tryptophanol, we have recently developed several biologically active small molecules. 1 Here, we will present our most recent results on the development of (S) and (R)-tryptophanol-bicyclic lactams with anticance properties. Specifically, the chemical library was obtained through a highly efficient atom economic cyclocondensation reaction of enantiopure tryptophanol with differen commercially available $\gamma$-ketoacids. The target compounds were screened as p53 activators using a yeast model, followed by validation of the molecular mechanism of action in human tumor cell lines and in human xenograft mice models. 2 The stability profile of this chemical family was also assessed in human liver microsomes and plasma.

Acknowledgments:

This work was supported by FCT (Fundação para a Ciência e a Tecnologia) through iMed.Ulisboa (UID/DTP/04138/2013), fellowship SFRH/BD/96189/2013 (S. Gomes), grant IF/00732/2013 (M.M.M. Santos), and also by the European Union and National Funds under the project PTDC/DTP-FTO/1981/2014-POCI-01-0145-FEDER-016581. References:

[1]. a) Espadinha M, Dourado J, Lajarin-Cuesta R, Herrera-Arozamena C, Gonçalves L, Rodrígues-Franco MI, de los Rios C, Santos MMM (2017) ChemMedChem 12 537-545; b) Pereira NAL, Sureda FX, Perez M, Amat M, Bosch J, Santos MMM (2016) Molecules 21: 1027-1039.

[2]. Soares J, Raimundo L, Pereira NAL, Monteiro A, Gomes S, Bessa C, Pereira C, Queiroz G, Bisio A, Fernandes J, Gomes C, Reis F, Gonçalves J, Inga A, Santos MMM (2016) Oncotarget 7: 4326-4343; b) Saraiva L, Santos MMM, Pereira NAL, Pereira C, Moreira S, Leão M, Monteiro A, Soares J (2014) PCT/IB2014/062617, WO2014/207688 A1; c) Soares J, Espadinha M, Raimundo L, Ramos H, Gomes AS Gomes S, Loureiro JB, Inga A, Reis F, Gomes C, Santos MMM, Saraiva L (2017) Molecular Oncology 11: 612-627.

\section{P24 - Synthesis and Biology of Jaspamide, Seragamide and Geodiamolide Hybrids}

Veselin Nasufovic ${ }^{a}$, F. Küllmer ${ }^{\text {a }}$, J. Bößneck ${ }^{\text {a }}$, S. Paceb, L.-M. Semmrau ${ }^{\text {a }}$ O. Werz $^{\text {b }}$ H.-D. Arndt ${ }^{\mathrm{a}}$

${ }^{a}$ Friedrich Schiller Universität, Institut für Organische Chemie und Makromolekulare Chemie, Humboldtstr. 10, D-07743 Jena

bFriedrich Schiller Universität, Institut für Pharmazie, Philosophenweg 14, D-07743 Jena

The family of actin binding cyclodepsipeptides consists of more than 50 natura products.[1] Jaspamides, seragamides, chondramides and geodiamolides feature high structural similarities, like methylated and halogenated amino acids, stereochemistry, and high affinity for binding to the actin.[2] We noticed that not all combinations of features are present in the natural products. Hybrid molecules with alternative combinations could provide useful SAR information in design of actin inhibitors and offer advantages compared to the potentially labile natural scaffolds. Fine tuning of activity, permeability and stability could possibly lead to molecules selective for some certain actin isoforms or cancer cell line.

Starting from our previous total synthesis, $[2,3]$ we established synthetic methodology for the synthesis of hybrids and analogs. [4] A focused library of more than 50 compound was synthesized. Beyond cyclodepsi-peptides the corresponding lactam isosters were investigated. Biological profiling showed that some hybrid molecules have significantly lower activity compared to the parent natural products, indicating evolutionary pressure operating during convergent evolution. Systematic structural variations led to highly potent analogs and - importantly - improve our previous SAR models.[2]

References:

[1] J. R. Stehn, N. K. Haass, T. Bonello, M. Desouza, G. Kottyan, H. Treutlein, J. Zeng, P. R. B. B. Nascimento, et al., Cancer Res. 2013, 73, 5169-5182;

[2] R. Tannert, L. G. Milroy, B. Ellinger, T. S. Hu, H. D. Arndt, H. Waldmann, J. Am Chem. Soc. 2010, 132, 3063-3077;

[3] H.-D. Arndt, S. Rizzo, C. Nöcker, V. N. Wakchaure, L.-G. Milroy, V. Bieker, A. Calderon et al., Chem. - A Eur. J. 2015, 21, 5311-5316.

[4] V. Nasufovic, F. Küllmer, J. Bößneck, L.-M. Semmrau, O. Werz, H.-D. Arndt manuscript in preparation.

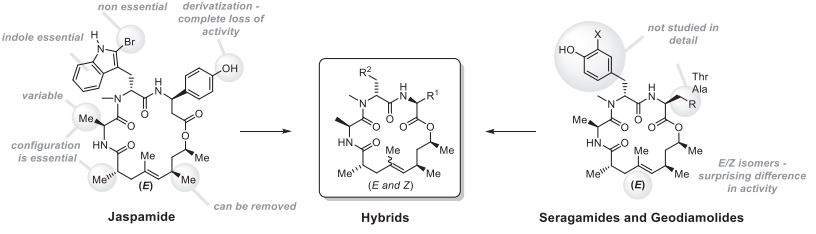




\section{P25 - Marine alkaloid oroidin analogues as novel human Topoisomerase II inhibitors}

\section{Žiga Skok, Nace Zidar, Martina Durcik,Janez Ilaš}

Department of Pharmaceutical Chemistry, Faculty of Pharmacy, University of Ljubljana, Aškerčeva 7, SI-1000 Ljubljana, Slovenia

DNA topoisomerases comprise an important family of enzymes that catalyze the induction of topological changes in the DNA molecule which makes them play vital roles in processes like replication, transcription, chromosome separation and segregation, and thus represent an important collection of design targets for novel anticancer drugs.1 Because of the similarity of ATPase domain with DNA Gyrase, Hsp90, histidine kinase and MutL proteins, human DNA topoisomerase II belongs to the GHKL protein superfamily.2 Based on that fact we predicted that known ATP-competitive DNA-gyrase inhibitors could be used as a starting point in design of new human DNA topoisomerase II inhibitors. Faculty of Pharmacy in Ljubljana possesses a library of about 800 ATP-competitive DNA-gyrase based on the structure of marine alkaloid oroidin, isolated from Agelas sponges, which shows antibacterial activity. 3 We selected 132 compounds from that library and screened them for their human DNA topoisomerase II inhibitory activity using Inspiralis human DNA topoisomerase relaxation assay. We identified 13 hits in micromolar affinity range and predicted their binding poses using molecular docking (Maestro by Schrödinger). One of the hit compounds also shows antiproliferative activity on MCF-7 breast cancer cell line. The goal of future research is to optimize the structure of hit compounds into a promising lead compound. Our optimization strategy includes synthesis of lower molecular mass analogues of our original hits in order to find new inhibitors with a better ligand efficiency which would potentially provide us with more optimizable leads.

References:

[1]. Pogorelčnik B, Perdih A, Šolmajer T (2013). Curr Med Chem 20: 694-709.

[2]. Dutta, R.; Inouye, M. (2000). Trends Biochem Sci 25: 24-28.

[3]. Tomašič T, Katsamakas S,2, Hodnik Ž, Ilaš J, Brvar M, Solmajer T, Montalvão S, Tammela P, Banjanac M, Ergović G, Anderluh M, Peterlin Mašič L, Kikelj D (2015). J Med Chem 58: 5501-5521. 